\title{
WestVirginiaUniversity
}

THE RESEARCH REPOSITORY @ WVU

Graduate Theses, Dissertations, and Problem Reports

2006

\section{Use of data mining for investigation of crime patterns}

\author{
Manoday D. Padhye
}

West Virginia University

Follow this and additional works at: https://researchrepository.wvu.edu/etd

\section{Recommended Citation}

Padhye, Manoday D., "Use of data mining for investigation of crime patterns" (2006). Graduate Theses, Dissertations, and Problem Reports. 1781.

https://researchrepository.wvu.edu/etd/1781

This Thesis is protected by copyright and/or related rights. It has been brought to you by the The Research Repository @ WVU with permission from the rights-holder(s). You are free to use this Thesis in any way that is permitted by the copyright and related rights legislation that applies to your use. For other uses you must obtain permission from the rights-holder(s) directly, unless additional rights are indicated by a Creative Commons license in the record and/ or on the work itself. This Thesis has been accepted for inclusion in WVU Graduate Theses, Dissertations, and Problem Reports collection by an authorized administrator of The Research Repository @ WVU. For more information, please contact researchrepository@mail.wvu.edu. 


\title{
Use of Data Mining for Investigation of Crime Patterns
}

$$
\text { by }
$$

\author{
Manoday D. Padhye
}

Thesis submitted to The College of Engineering and Mineral Resources at West Virginia University in partial fulfillment of the requirements for the degree of

\author{
Master of Science \\ in \\ Industrial Engineering
}

Dr. Rashpal Singh Ahluwalia, Ph.D. (Chair)

Dr. Wafik Iskander, Ph.D.

Dr. Arun Ross, Ph.D.

Department of Industrial and Management Systems Engineering Morgantown, West Virginia 2006

Keywords: Crime Database, Data Querying, Data Mining, Association Rules, Decision Rules, WEKA 


\section{ABSTRACT \\ Use of Data Mining for Investigation of Crime Patterns}

\section{Manoday Dhananjay Padhye}

Lot of research is being done to improve the utilization of crime data. This thesis deals with the design and implementation of a crime database and associated search methods to identify crime patterns from the database. The database was created in Microsoft SQL Server (back end). The user interface (front end) and the crime pattern identification software (middle tier) were implemented in ASP.NET. Such a web based approach enables the user to utilize the database from anywhere and at anytime. A general ARFF file can also be generated, for the user in Windows based format to use other Data Mining software such as WEKA for detailed analysis. Further, an effective navigation was provided to make use of the software in a user friendly way. 


\section{ACKNOWLEDGEMENT}

I thank my advisor Dr. Rashpal Singh Ahluwalia for his continued support, guidance and encouragement during the course of this research work. I also wish to thank my committee members that include Dr. Wafik Iskander and Dr. Arun Ross for their valuable advice and support.

Above all, I wish to thank my colleagues at the research laboratory, friends and specially, my parents for their constant support and blessings for enabling my success and happiness in all my pursuits and endeavors in life. 


\section{TABLE OF CONTENTS}

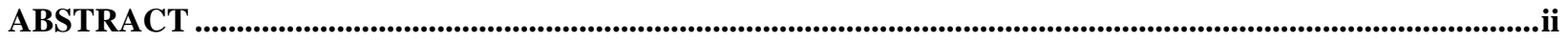

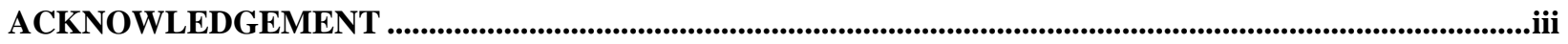

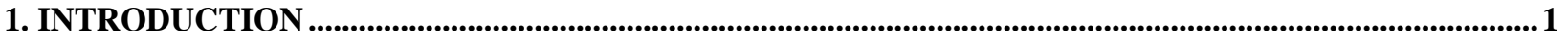

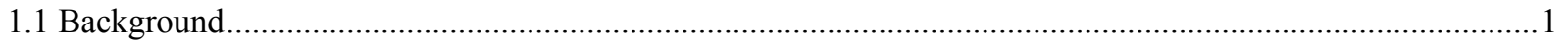

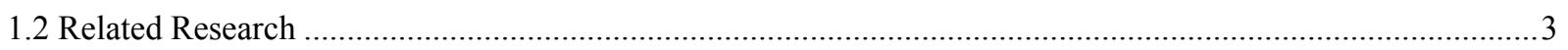

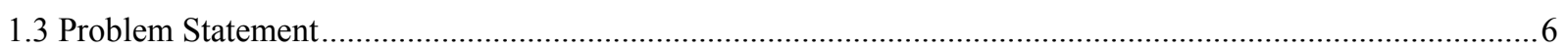

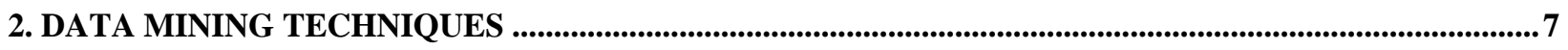

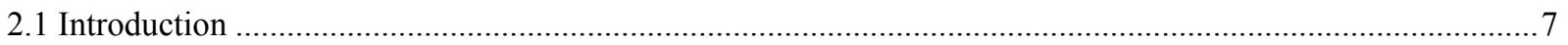

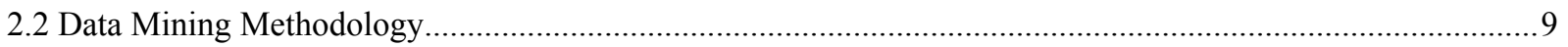

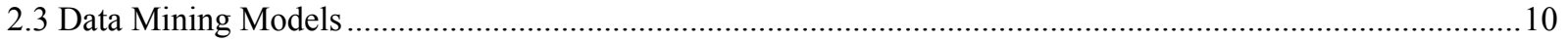

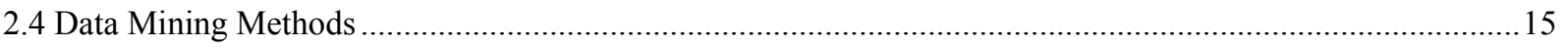

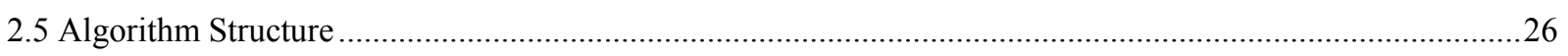

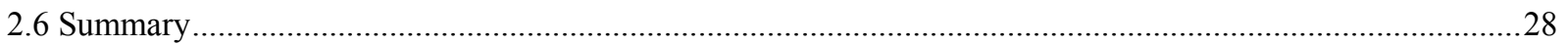

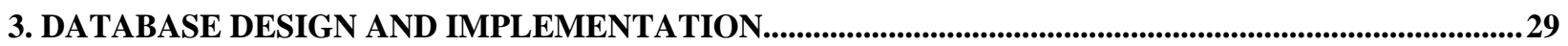

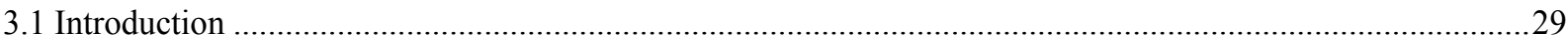

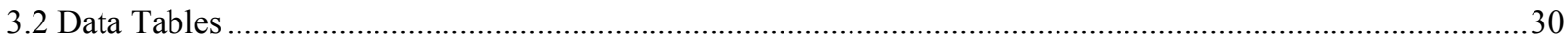

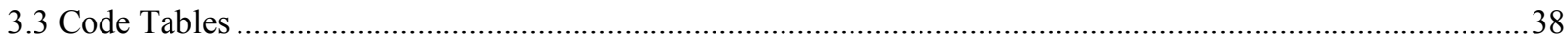

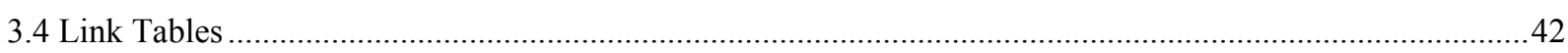

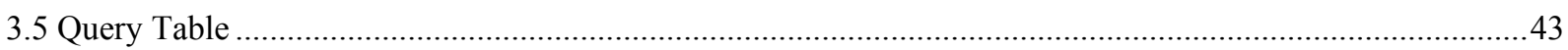

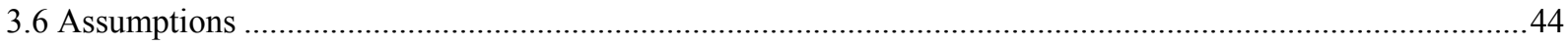

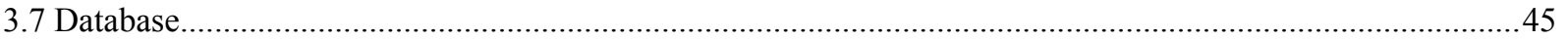

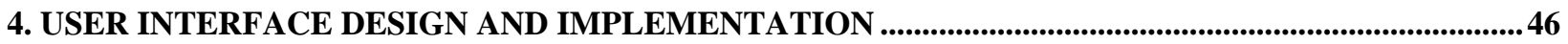

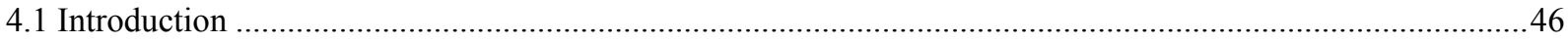

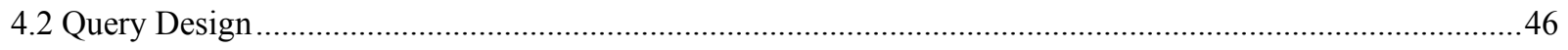

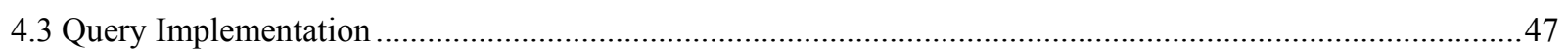

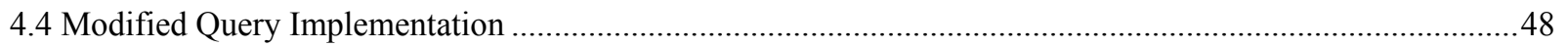

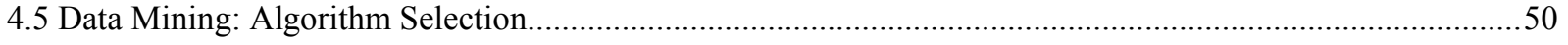

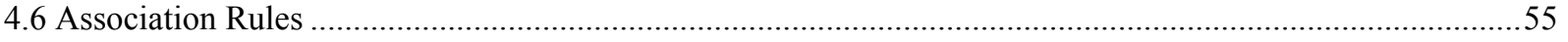

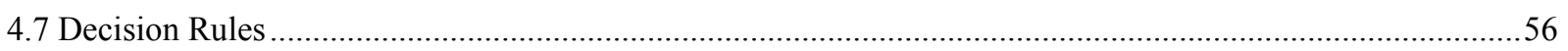

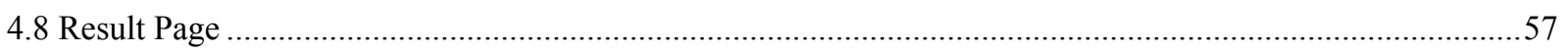

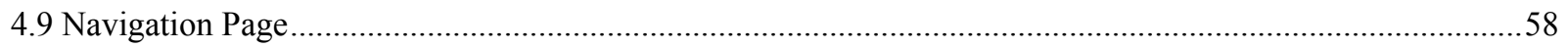

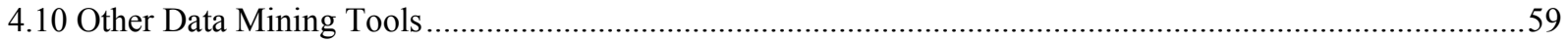




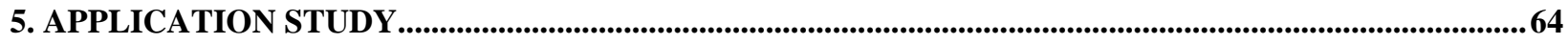

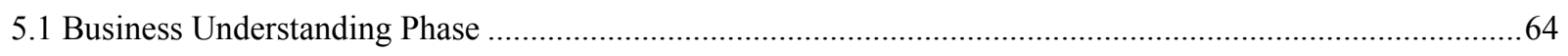

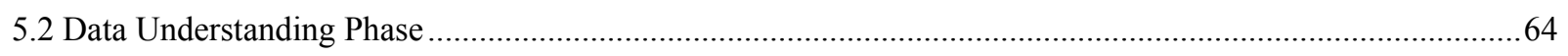

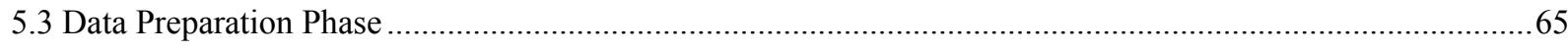

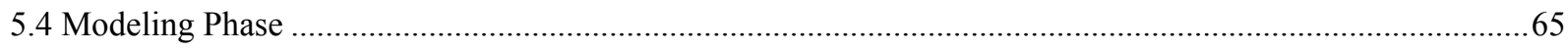

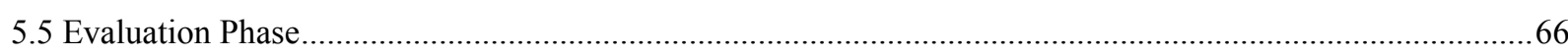

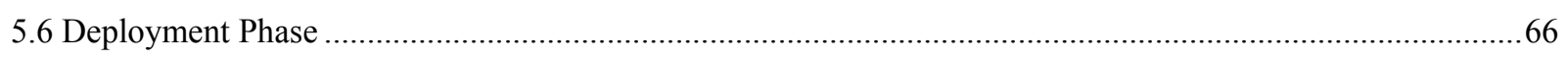

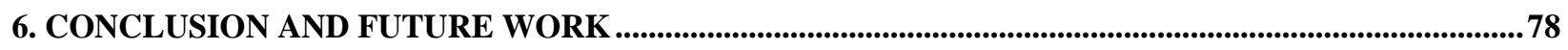

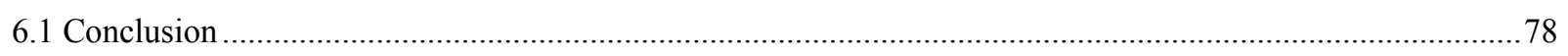

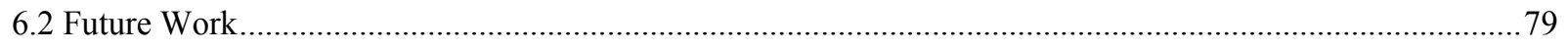

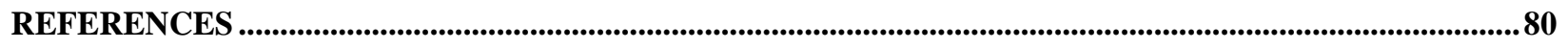

APPENDIX A: Test Data from Query Table “tblQuery” ................................................................................................82

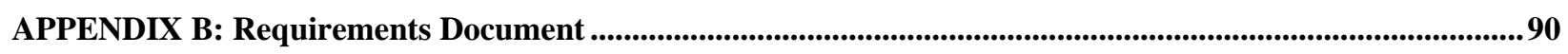

APPENDIX C: Association Rules Output ..............................................................................................................92

APPENDIX D: Decision Rule Output..................................................................................................................................94

APPENDIX E: WEKA Output ....................................................................................................................................... 103 


\section{LIST OF FIGURES}

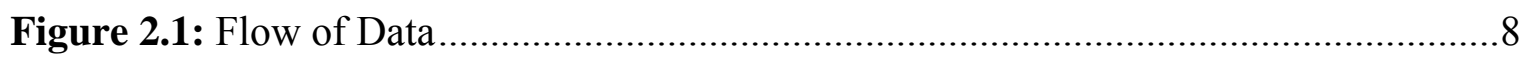

Figure 2.2: Cross-Industry Standard Process for Data Mining [1] ...................................10

Figure 2.3: Data Mining Approach................................................................................11

Figure 3.1: Database Diagram .................................................................................45

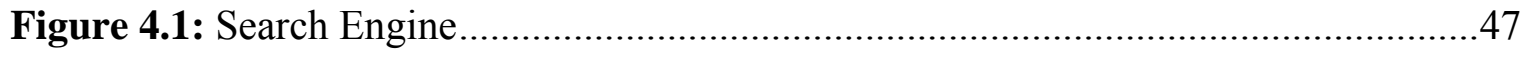

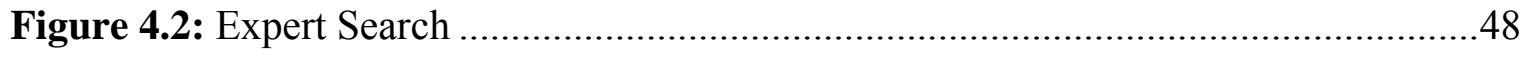

Figure 4.3: Result page of "Expert Search" ...............................................................49

Figure 4.4: Good Credit Score Tree.............................................................................54

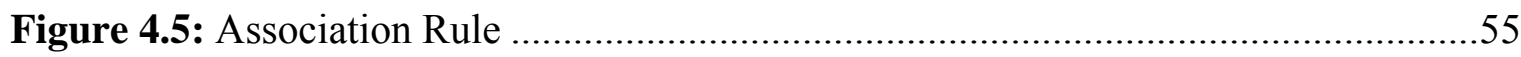

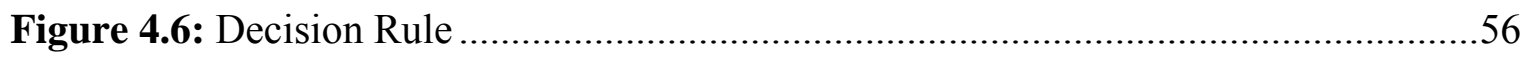

Figure 4.7: Result Page

Figure 4.8: Navigation Page - "PageOne". ....................................................................58

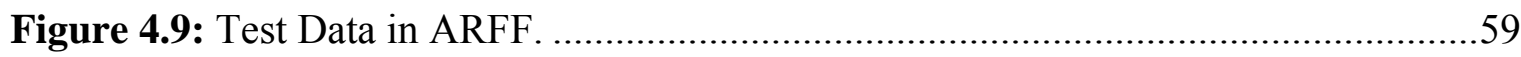

Figure 4.10: WEKA - Front Page ……………………..........................................60

Figure 4.11: WEKA - Explorer Page ......................................................................61

Figure 4.12: WEKA - Visualize (Confusion Matrix).......................................................62

Figure 4.13: WEKA - Plot from confusion matrix …………………………………....63

Figure 5.1: Tree for Deployment Phase.....................................................................67

Figure 5.2: Association Rules with selected fields ...........................................................69

Figure 5.3: Association Rules outcome …………………............................................69

Figure 5.4: Decision Rules for OffType = "Accident" ................................................71

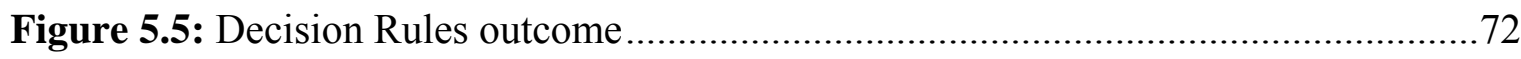

Figure 5.6: Tertius classifier with 6 attributes using Discretize filter ................................76 


\section{LIST OF TABLES}

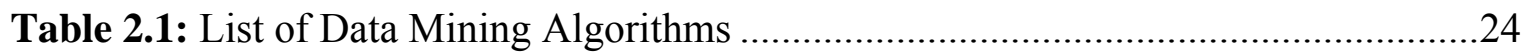

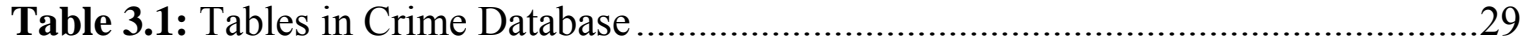

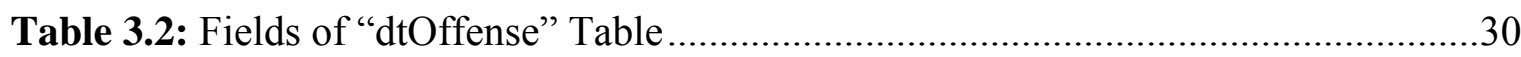

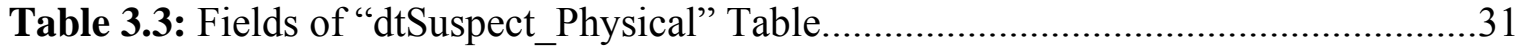

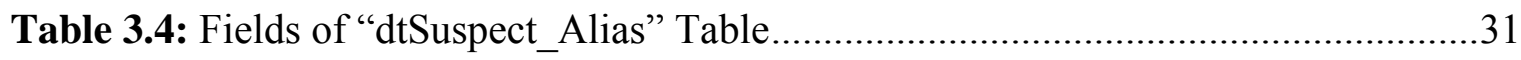

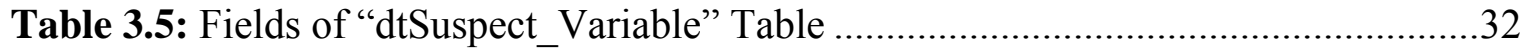

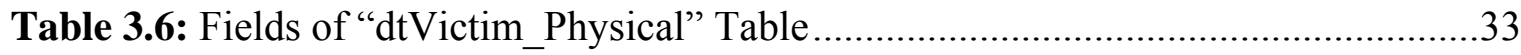

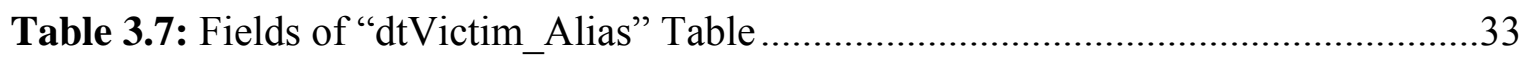

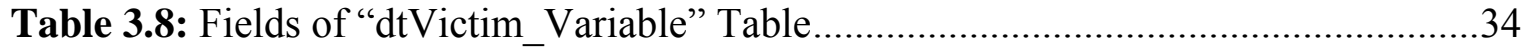

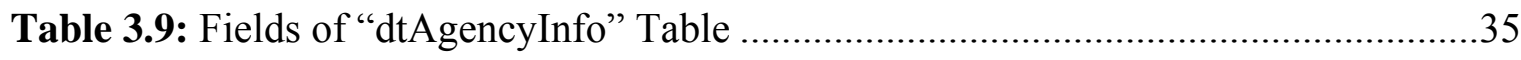

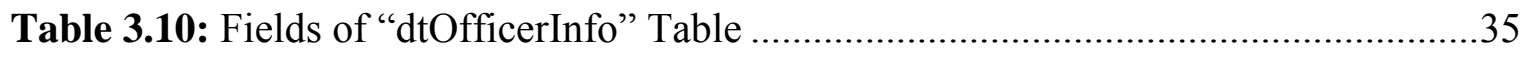

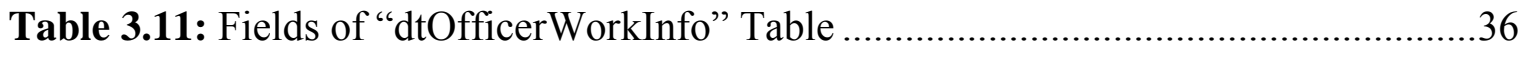

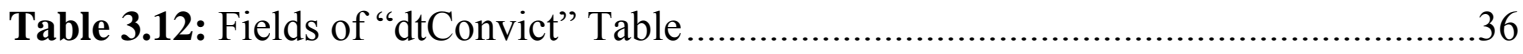

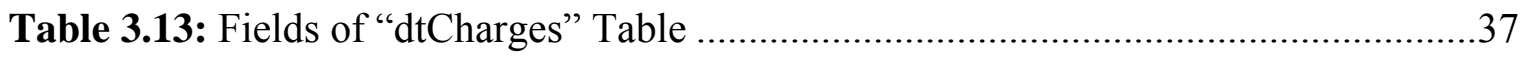

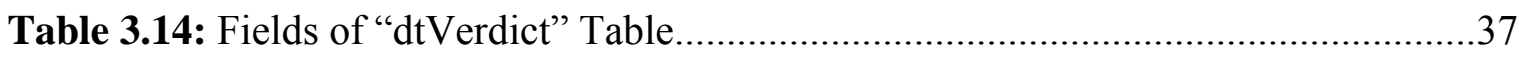

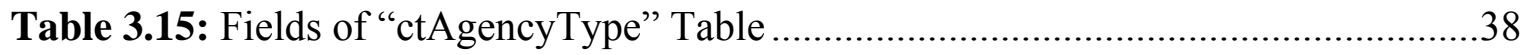

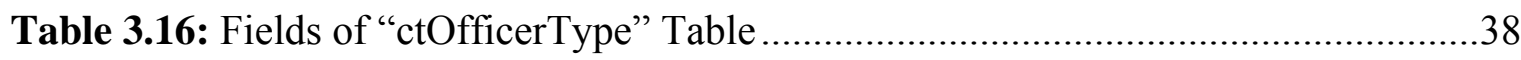

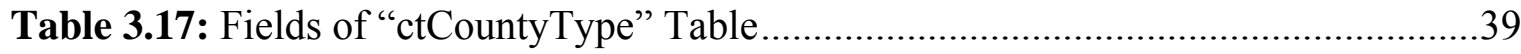

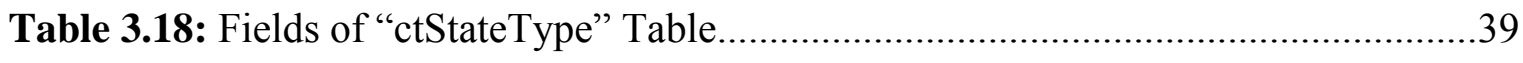

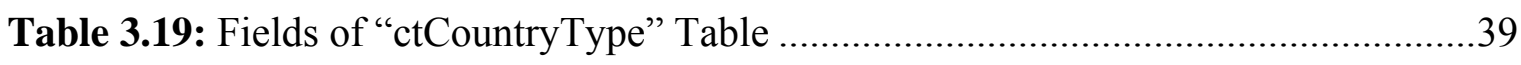

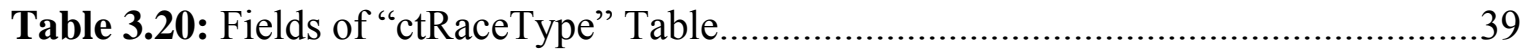

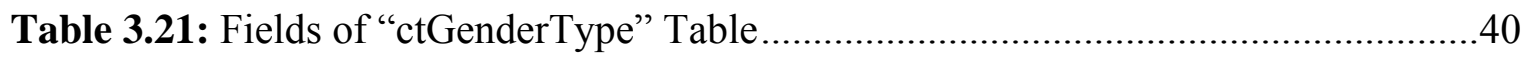




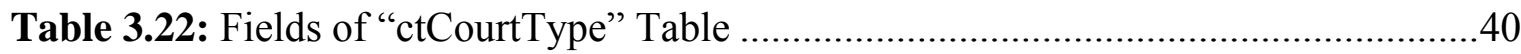

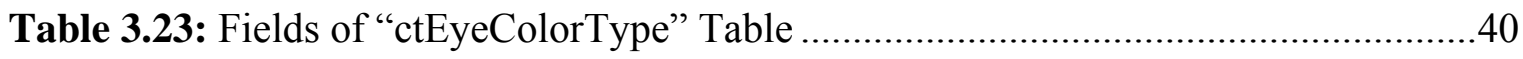

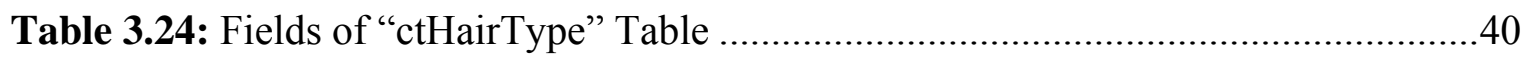

Table 3.25: Fields of "ctFinCondtnType" Table ......................................................41

Table 3.26: Fields of "ctBehvAspectType" Table ........................................................41

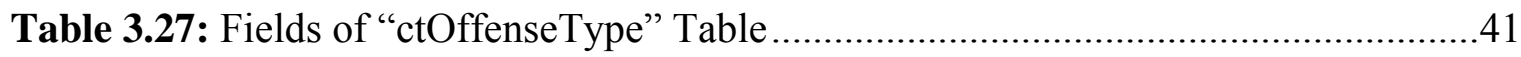

Table 3.28: Fields of "ltLnkOffSus" Table ..............................................................42

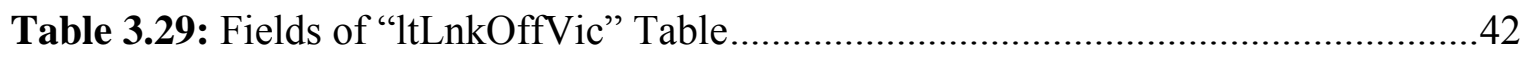

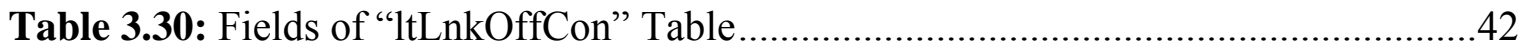

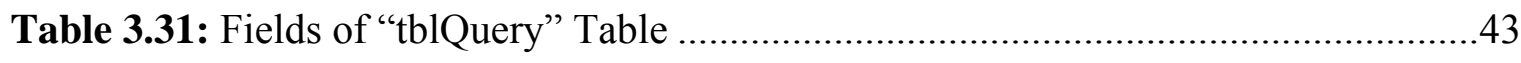

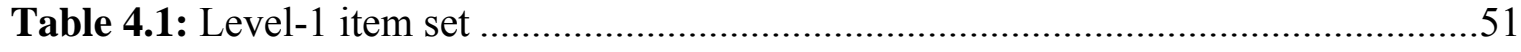

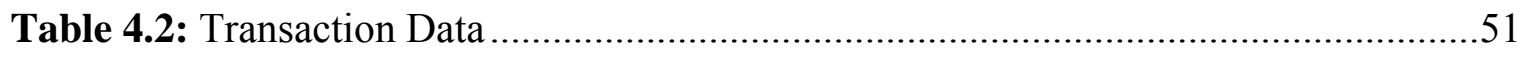

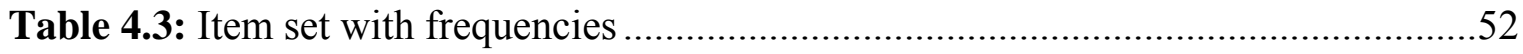

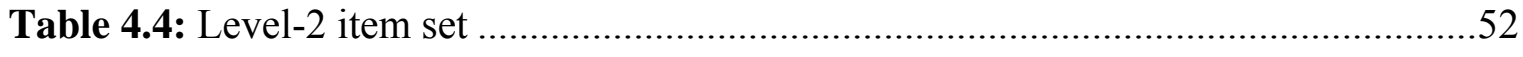

Table 4.5: Factors for determining credit score - Stage I ......................................53

Table 4.6: Factors for determining credit score - Stage II......................................54

Table 5.1: Tabulated Outcome of Association Rule .................................................. 70

Table 5.2: Tabulated Outcome of Decision Rule...................................................73

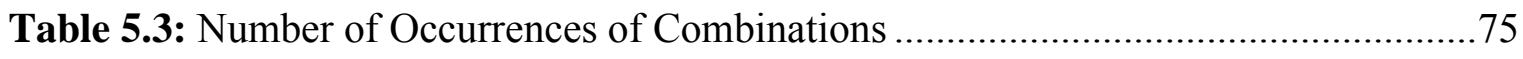

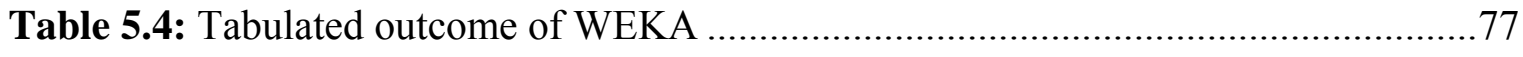




\section{INTRODUCTION}

\subsection{Background}

In recent years, there has been an exponential growth in the amount of data being generated. Unseen to all, such data may seem irrelevant, but to some it is a gold mine that needs to be fathomed for precious information pertaining to the cause. Thus, one is introduced to the terminologies of data generation, data collection, data processing, retention and security. Activities such as purchasing groceries, watching television, traveling, health care, opinion polls, elections, drug purchase, and crime, generate stupendous amounts of data. For example, WalMart captures point-of-sale transactions from over 2,900 stores in 6 countries and continuously transmits these data to its massive 7.5 terabyte data storage facility, referred to as the "data warehouse" [1,2]. Previously, such data were lost due to lack of tools. Recent advancements in data collection, storage and manipulation tools, such as phenomenal storage and computational capacity, use of the Internet, advanced surveillance equipments etc., have broadened the scope and limits for the same. Moreover, the increasing dependence on high technology equipment has also eased the process of data collection. For example, each and every credit card that is swiped at the WalMart store generates data that can be valuable not only to WalMart, but to credit card companies, manufacturers, advertisement agencies, financial institutions, etc [3]. Another aspect worth mentioning is the security of the database which has to do with protection not just from losing the data, but also from the data falling into undesirable hands. Also, often the privacy of citizens is breached due to lack of established protocols over the use of data, because the data that look harmless are not necessarily so. For example, with the name and social security number stripped from files, still $87 \%$ of Americans can be identified simply by their date of birth, gender, and five-digit zip code,

as established from a review at Carnegie Mellon University [4]. Much to one's relief, several companies are becoming increasingly conscious of this fact.

The data may or may not be in a directly usable form and may need some interpretation based on previous knowledge, experience and most importantly the purpose 
of data analysis. This problem is further augmented by sheer volume, texture of the data, and lack of human capability to infer it in different ways. For this reason, many computational tools are used and are broadly termed as "Data Mining Tools." The tools are comprised of basic Statistics and Regression methods, ANOVA, Decision Trees, Rule Based Techniques, and, more importantly, advanced algorithms that use Artificial Intelligence, Neural Networks, etc. Such tools are used to query the database either individually or in a combined form, also called "Hybrid Algorithms" [2]. The result of such data processing is that many important non-obvious relationships can be identified. The applications of Data Mining tools are boundless and basically driven by cost, time constraints, and requirements of the community, business, and the government. The application of Data Mining can be broadly classified in the following fields:
a. Medical and scientific research
b. Commercial and financial institutions
c. Security agencies
d. Sports and entertainment

Applications in medicine can be best exemplified by the fact that there are around 3000 cases of brain tumors each year in United States and almost half of them are fatal. The Children's Memorial Hospital in Chicago is mining the gene expression database for pediatric brain tumors [1]. With this effort, the researchers not only wish to understand the tumors in a better way but also to provide more effective treatment to children. Further, Data Mining has extensive application in space research such as studying stars and their movements, studying weather patterns all over the world, and in understanding electromagnetic bursts. In the commercial field, Data Mining is used by credit card companies primarily to look for patterns of suspicious activities in order to prevent fraud. Stores such as WalMart do Data Mining to determine customer buying patterns and trends.

In an ABC News Broadcast of 15 February 2006, it was reported that the U.S. government is developing a massive computer system called Analysis, Dissemination, Visualization, Insight, and Semantic Enhancement System (ADVISE) that can collect 
large amounts of data. It will then search for patterns of terrorist activities by crossreferencing them against U.S. intelligence and law-enforcement records. Moreover, the idea is to identify critical patterns in data that illuminate their motives and intentions. The storage requirements alone are huge -- enough to retain about 1 quadrillion entries. While, privacy concerns have put many hurdles in the way of this program and place some restriction on government use of private data, they do not prevent intelligence agencies from buying information from commercial data collectors [4].

The National Basketball Association (NBA) offers a Data Mining application that can be used in conjunction with video recordings of basketball games to analyze the movements of players which helps coaches orchestrate plays and strategies against their opponents.

There are quite a few Data Mining tools that are available commercially or opensource. Some of these tools are: SAS - Enterprise Miner, JMP, R, TeraData, Clementine, and WEKA. Data Analysis tools such as Microsoft Excel, MiniTab and Statistica can indirectly do Data Mining by searching for vital trends in the data. The primary issue with such software is that they are generalized tools and require significant data preparation and/or coding on the part of the user. Moreover, the data are often not in the form to be interpreted directly. Currently, these tools are being upgraded to reduce user input, to improve cross functionality and to get better results. The main thrust of research is in commercial and health care sector followed by science and technology. It is only recently that Data Mining has gained recognition in the national security field.

\subsection{Related Research}

Searching databases to extract vital information has been practiced for several years. Pre-9/11 it was driven by commercial needs. Post-9/11 has seen increased use of database search techniques for regional and national security needs. By drawing correlations, Data Mining can lead to identification of crime patterns which will help in crime investigation, and, most importantly, to crime prediction. 
The Tucson Police Department was able to trace a narcotics network comprised of approximately 60 criminals using Data Mining tools [5]. It was difficult to detect subgroups, interaction patterns, and the overall structure of the network manually. They utilized clustering and block-modeling methods to identify a chain structure. Various techniques were applied as per their applicability and depending on the investigation. The developed system aided investigators in a better and faster understanding of the network and operations of criminals. Most importantly, it suggested investigative leads to the investigators that otherwise might have been overlooked [6].

Based on past experience, it has been observed that clustering techniques group data items into classes based on characteristics so as to maximize in-class similarity. For example, they can identify suspects those conduct crimes in similar fashion or distinguish among groups belonging to different gangs. While, association rules mine frequent data patterns by treating them as rules, so any discrepancy can be identified as an intrusion. Classification is often used to predict crime trends. It can reduce the time required to identify criminal entities. However, it requires a complete training and testing database. It is also limited by a high degree of missing data values that seem to limit the prediction accuracy.

As per the Regional Crime Analysis Program (RECAP) at Richmond B\&E, if one decides to use only one year of crime data for detailed analysis then an analyst must spend 1.5 million minutes, and will be able to perform only $15 \%$ of queries and spend approximately 20 minutes of time on each case [7]. Thus, the infeasibility of querying the database for analysis is stressed. Also, it was noted that, to effectively relate crimes, the analyst needs to consider combinations of spatial, demographic, personnel and other data attributes.

In intrusion and fraud detection [8], it was observed that besides scalability and efficiency, the fraud detection task had other problems such as skewed distributions of the training data and non-uniform cost per error, which had not been considered by the Knowledge-Discovery and Data Mining research. Moreover, post pruning succeeded in computing with similar or better fraud detection capabilities, while reducing their size and improving efficiency. Finally, the results of the study clearly demonstrated that 
distributed Data Mining techniques that combine multiple models produce more effective fraud and intrusion detectors.

To explore associations among a large number of objects of different types, Link Analysis concepts have been implemented [9]. Used in the case of money laundering, these objects include people, bank accounts, businesses, wire transfers, and cash deposits. Exploring relationships among different objects help indicate networks of activity, both legal and illegal. The technique ensured productive use of records, but proved to be computationally intensive and required great skill and judgment on the part of the analyst during link construction and interpretation of whether the networks represented a legitimate pattern or that of a criminal organization.

The use of statistical methods, predominantly Logistic Regression and Bayesian Networks, has also been suggested [10]. However, these methods are in a primitive stage. There is no clear consensus on how to control groups from the population as a datum for a given type of crime. There is also lack of consensus regarding the selection of a particular method based on crime. Lastly, the interpretation of the results depends on the viewpoint of the statisticians and the crime investigators.

All of the above cases stress the fact that there are many means to the end, and more research is required to efficiently and effectively get the desirable outcomes. In other words, there are many tools at our disposal but not an all-encompassing model or approach [2]. Examples of the current research field reaffirm the fact that, human intervention is absolute. Also, better software and hardware are keys to analyzing the data that are routinely being generated these days. 


\subsection{Problem Statement}

The objective of this thesis is to design and implement a crime database and to provide the user with a capability to detect crime patterns in the data. The data fields will be identified from the crime information in the available literature. Basic and advanced search algorithms will be implemented. Moreover, Association Rules and Decision Rules algorithms will be implemented and validated with the WEKA software.

The database will be created in Microsoft SQL Server (back end). The user interface (front end) and the crime pattern identification software (middle tier) will be implemented in ASP.NET. This will enable the user to utilize the database from anywhere and at anytime. A code to generate ARFF file that is compatible with WEKA will be provided to the user to graphically view the data. Further, an effective navigation will be provided to make use of the software in user friendly way.

It is expected that the Data Mining Tool will be able to identify hidden patterns from the test data that one cannot identify with routine database queries. 


\section{DATA MINING TECHNIQUES}

\subsection{Introduction}

Data Mining (also called Knowledge Discovery) is the process of analyzing data from different perspectives and summarizing it into useful information or relationships. It is also characterized as the process of finding correlations or patterns among dozens of fields in large relational databases. Data Mining as defined by Larose [1] is an interdisciplinary field bringing together techniques from machine learning, pattern recognition, statistics, databases and visualization to address the issue of information extraction from large data bases.

Such extracted information is deemed both understandable and useful to the data owner. Organizations accumulate vast amounts of data in different formats and different databases, which are often located at more than one physical location. For Data Mining applications, only the elements that can be interpreted and converted into a computer usable form are treated as data. Data are defined as, any facts, numbers, or text that can be processed by a computer, to generate information. This may include:

a. Operational or transactional data such as, sales, cost, inventory, payroll, and accounting

b. Non-operational data, such as industry sales, forecast data, and macro economic data

c. Meta data--data about the data itself, such as logical database design or data dictionary definitions

Further, the databases are combined, either by actual transfer of data or just logically with the use of database servers. From these, the data can be accessed on a realtime basis in ever increasing amounts and frequencies. Almost all of the medium to large organizations have built their own data banks (warehouses). The term data warehousing is defined in [1], as a process of centralized data management and retrieval. It represents an ideal vision of maintaining a central repository of all organizational data. 
The organizations often rely on external agencies for proper use of the data. Thus, the data warehouses are subjected to use by various Data Warehousing agencies with the aim of retrieving useful bits of information. This information may not have any mathematical logical, or, for that matter, any sense at all, but may help the database researcher close in on the objective. Thus, information is defined by [1]; are the patterns, associations, or relationships among all this data. Information can be converted into knowledge about historical patterns and future trends.

Figure 2.1 shows the flow of data while being generated, stored and processed to get information which in turn becomes knowledge when interpreted.

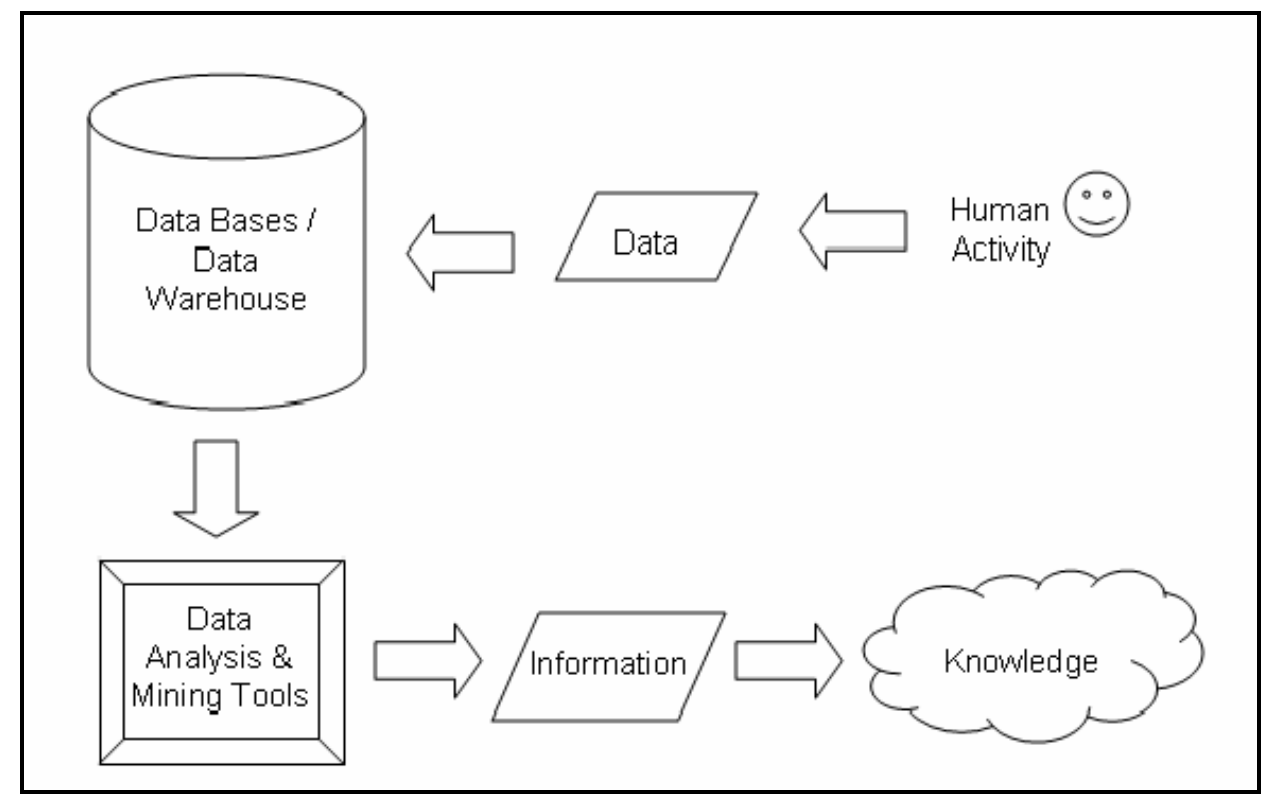

Figure 2.1: Flow of Data 


\subsection{Data Mining Methodology}

Data Mining is typically carried out in six phases referred to as CRISP - DM (Cross-Industry Standard Process for Data Mining) [1].

1. Business Understanding: This is the initial phase of CRISP-DM. In this, one strives to understand the main objective of the Data Mining endeavor. A problem definition is established clearly stating its goals, restrictions and strategy.

2. Data Understanding: The primary focus during this phase is to evaluate data in terms of quality and quantity. Finally, an initial level classification is done on the database to get actionable data patterns.

3. Data Preparation: During this phase, these data are transformed into a suitable form. This often involves modifying/transforming the database as well as normalizing if needed.

4. Modeling: An appropriate model for the database is selected from the pool of options and optimized to suite the requirements. Often, more than one model is applied to meet the goals of the Data Mining project.

5. Evaluation: In this phase, the model is evaluated to check whether it meets all the required parameters, objectives, and constraints, and to monitor if any aspect is left unattended with respect to the pre-established goals.

6. Deployment: The model is implemented and detailed reports are generated based on the outcome. After brief analyses of the reports by the end user, possible ways of making more complex models are explored and to apply the model at more facilities. 
Typical life cycle diagram of the CRISP_DM process is shown in the Figure 2.2 below.

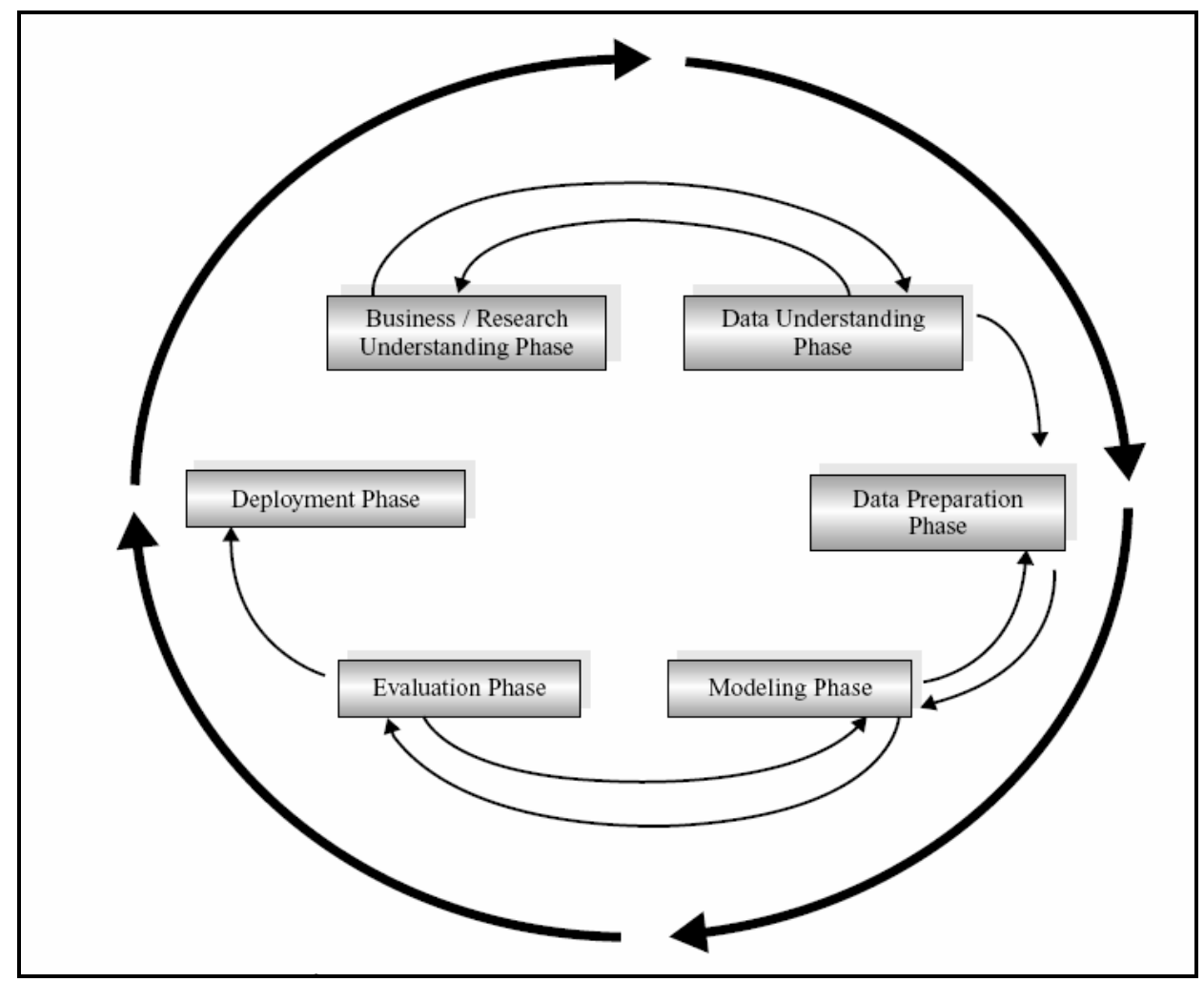

Figure 2.2: Cross-Industry Standard Process for Data Mining [1].

\subsection{Data Mining Models}

Selection of a Data Mining Technique is the most important aspect of any Data Mining endeavor. Based on the objective, one decides what data should be used from the pool of data, and how they should be processed. This is followed by analysis of that data in a predefined way, which paves the way for the selection of a particular algorithm or a set of algorithms. In many of the emerging applications, it is clear that no single approach is optimal and that multiple methods and approaches need to be used. Consequently, combining several modalities and classifiers or techniques is now a common practice [10].

The Data Mining models are categorized into different leaves. Further, each leaf signifies the relationship, if any, that is highlighted from the database. The techniques that 
are actually applied may be a part of one or more leaves, and, based on which the categorization may vary. This sometimes is a cause of discord amongst the researchers. For most applications the Data Mining Models can be put into one of the six main categories: 1) Association, 2) Classification, 3) Clustering, 4) Prediction, 5) Sequence Discovery, and 6) Generalization. Figure 2.3 shows the Data Mining Models along with associated methods. The models are briefly discussed below:

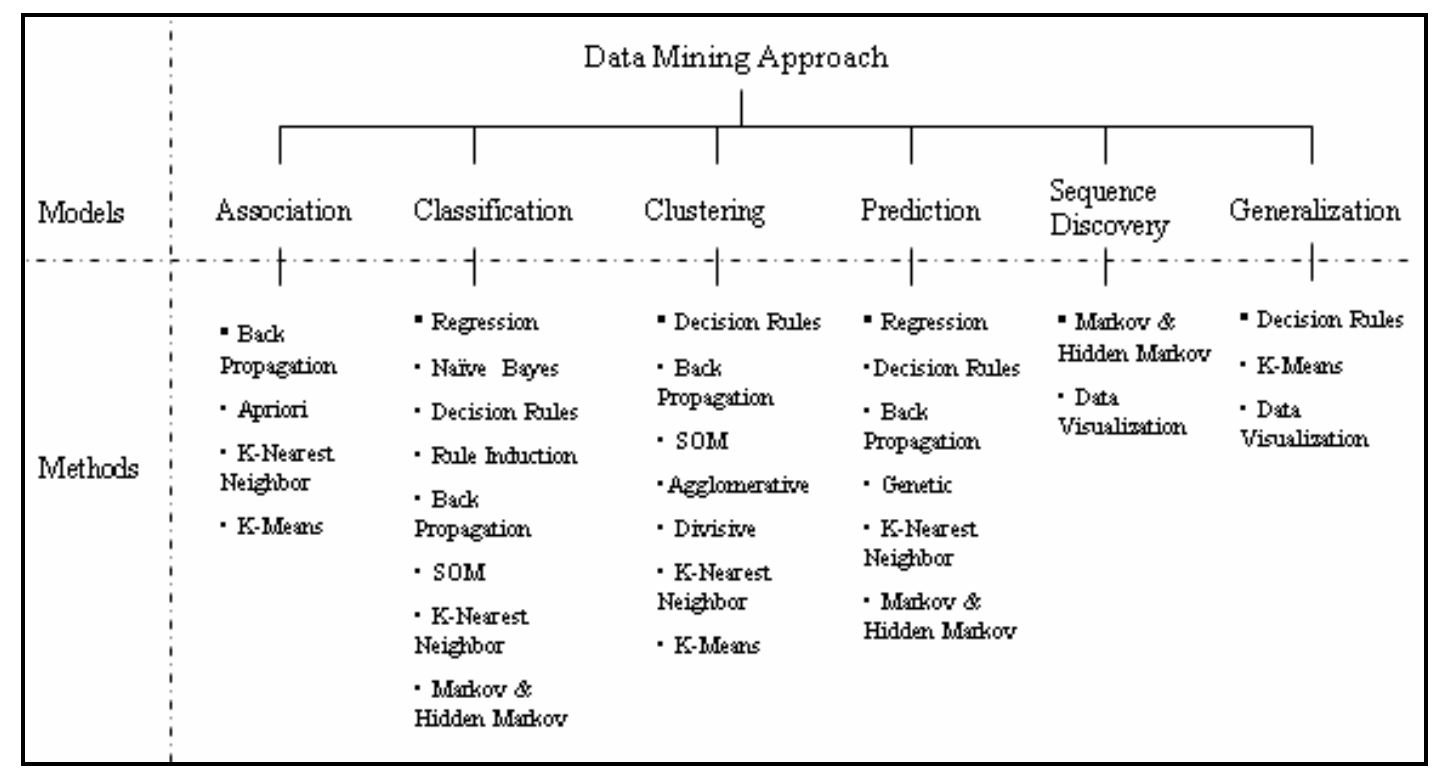

Figure 2.3: Data Mining Approach

\section{Association:}

Association rules depict the inter-relationship between the data items. These relationships often do not have any coherence with functional dependencies or correlation (Statistical Relationships). Interpretation of the outcome by this technique may be best achieved by behavioral-based reasoning rather than use of any engineering technique. The data are paired or transactional, often present in a date-time-based sequence. Partitioning of the data into training and validation sets purely depends on the type of algorithm being used for this technique. The sole aim is to come up with maximum number of item pairs with most number of transactions. The typical examples of association are the transaction data from a retail store, collected over the year. The interest is to find hidden relationships, if any, between any two items that are sold. For 
example, the items can be formal trousers and a shoe polish, that otherwise do not have any statistical and/or functional relation, but makes sense if one follows the thinking of a person who might be buying the trousers for an interview and remembers to buy the shoe polish as well.

\section{Classification:}

Classification, as the name suggests, is the process of placing or assigning the categorical variables into predefined classes. An algorithm needs to be selected to place these data in categories. The decision rules are based on training data and then used to locate these data in pre-determined groups. The rules are further validated by the validation dataset. Classification falls under supervised or directed Data Mining technique. Most of the Data Mining techniques end up classifying these data in some way or other. The classification techniques can be best explained by an example. Let's say a restaurant chain could mine customer purchase data to determine when they visit and what they typically order. This information could be used to increase customer traffic by having daily specials. Also, the menu could be arranged to suit customer needs. Some of the issues in classification are:

a. Missing Data: Missing values in the database can have a significant impact on the decision rules. The missing data are filled by the mean value of the database or based on the business logic. This may lead to improper decision rules because they have tendency to pull the regression line towards themselves.

b. Measuring Accuracy: Accuracy is measured as the percentage of tupules that are placed into correct classes. This is often based on user intellect, the algorithms that are chosen and the quantity and quality of data. Data that overlap (belong to more than one class) can bear significant effect on the accuracy of the model.

c. Being a highly supervised technique user input is required to determine the number of levels, leaves, etc. 
d. Finally, the size of training, validation, and, test data affect the outcome of the relationship significantly.

\section{Clustering:}

In clustering, the data items are grouped according to their logical relationships or natural groupings and a structure as a whole is generated. No clustering technique is universally applicable in uncovering the variety of structures present in multidimensional datasets; usually the 'best' applicable technique is selected [10]. There are no pre-defined groups, thus, clustering comes in the group of undirected Data Mining techniques. Each cluster is collection of homogeneous elements, which may be exclusive to that group, but are similar to each other. The presence of an element in a particular cluster may be definite or probabilistic. They might even have a hierarchical structure, having a crude division of elements at the highest level of the hierarchy, which is then refined to subclusters at lower levels. Moreover, each cluster may be different from other clusters. Clustering prior to application of other Data Mining techniques might reduce the complexity by dividing the space of elements [12]. These space partitions might exhibit improved results when mined separately. Clustering has found extensive application in the fields of marketing, Web mining, insurance, disaster planning, etc. Clustering techniques identify clusters, whereas the classification methods place data in pre-defined clusters. The main requirements of any clustering model are [3]:

a. It should be robust to deal with multiple attributes of data, have high dimensionality and scalability

b. It must successfully discover clusters even with arbitrary shape, but avoid reaching local minimum for a local function/decision

c. For some algorithms, the number of clusters or distance needs to be chosen scientifically

d. It should deal with noise and insensitivity better when compared to other models

e. For a given model, the user is responsible to check whether the clusters are real and interesting from an application point of view 


\section{Prediction:}

In prediction, data are mined to anticipate behavior, patterns, and trends. This is often the outcome of the previous three basic models. The idea is that once the decision rules are generated through classification or clustering, those rules form the basis of the prediction model. Thus, all the techniques discussed earlier are capable of prediction to some extent. The error or the probability factor is considered while choosing any particular algorithm over another. A good example of prediction would be an outdoor equipment retailer predicting the likelihood of a backpack being purchased based on a consumer's purchase of sleeping bags and hiking shoes.

\section{Sequence Discovery:}

Sequence discovery is used to determine sequential patterns in the data. These sequences are more often associations between various data fields, but they are essentially based on time and often follow a particular queue. This technique encompasses association rules as well as Markov concepts; hence not much can be elaborated on regarding this. For instance, if a person buys a $\mathrm{CD}$ player then he is bound to buy CDs for it sooner than later [2].

\section{Generalization:}

Generalization, also called Description or Summarization, pulls the data into subsets with their respective descriptions. Sometimes actual portions of the mined data are retrieved and based on that the subsets described above are created. Generalization is not a Data Mining method; it is the outcome of Data Mining technique.

Often algorithms are called by the name of the model they fit into or by the name

of the algorithm. For example, an algorithm for finding clusters in the database is called a “Clustering Algorithm," whereas an algorithm used to establish association rules is called an "Apriori Algorithm." 


\subsection{Data Mining Methods}

The common Data Mining methods are 1) Regression Analysis, 2) Naïve Bayes Classification, 3) Decision Rules, 4) Rule Induction, 5) Neural Networks, 6) Genetic Algorithm, 7) Association Rules, 8) Hierarchical Clustering, 9) Partitional Clustering, 10) Markov Model, and 11) Data Visualization. A brief description of each method is provided below:

\section{Regression Analysis}

Regression Analysis is used by the classification and prediction models. Statistical regression models are implemented that best fit the training data. The objective is to minimize the Sum of Squared Error (SSE). Once a model is developed, it is then validated with the validation dataset. The model is run on a new set of data (independent variables). Regression algorithms consider effects of interaction and correlation in data; they also measure trend in the data that many other Data Mining methods cannot. Even so, Logistic Regression has found more practical applications in many real-life scenarios [14]. It is a non-linear regression model where the response variables are discrete in nature, often qualitative for Data Mining, with a sigmoidal response function. Different response functions are used, namely, Probit, Logit, Log-Log, MLE, give the probability for the event. These functions often generate the odds or probability of the event under study.

\section{Naïve Bayes Algorithm}

The Naïve Bayes algorithm is based on the Bayesian theorem and is particularly well suited when the dimensionality of the inputs is high. Essentially it classifies a new record based on probabilities estimated from the training data. Despite its simplicity, Naïve Bayes can often outperform many sophisticated classification methods.

For example, a task could be to classify new cases as they arrive based on the existing types of objects with their respective probability of occurrence i.e. prior 
probability. Then, for a new point in space, one can calculate the likelihood as, the number of objects in vicinity, divided by total objects of the same type. The final classification would then be produced by combining both sources of information, i.e., the prior and the likelihood, to form a probability of classification into a particular class (posterior probability) using the Bayes' rule. This algorithm has accuracy problems, based on the complexity of data, for continuous data.

\section{Decision Rules}

Decision Rules or decision trees are based on an inductive approach. Decision rules take an if/then approach and Decision trees develop a graph similar to a tree diagram. Decision trees are constructed in order to help in decisions that in turn generate rules for the classification of a new unclassified dataset. They also act as a tool for selection of variables for Neural Networks and Regression. Some of the methods are Iterative Dichotomizer 3 (ID3), Classification and Regression Trees (CART), and Chi Square Automatic Interaction Detection (CHAID). ID3 and CART segment the dataset by binary splits and CHAID does multi-way splits. Also, decision rule algorithms have difficulty with missing values (now imputed, i.e., removed or replaced), continuous data (now pruned), and most ignore correlations and interactions in data [2].

\section{Rule Induction}

Rule Induction algorithms work complementarily to the Decision Tree algorithm, concerning, extraction of useful rules from data. Each class is considered separately and then an attempt is made to cover all elements in that class. The Rule Induction is called the "Covering Approach," because at each stage, rules would be determined that cover a set of the elements. Further, these algorithms test the rule being constructed, thus maximizing accuracy. 


\section{Neural Networks}

Neural Networks algorithms originated from the research aimed at understanding biological information processing systems. Thus, the concept of Artificial Neural Networks (ANN) was born in an attempt to simulate the brain's processing system. Even though there is lack of understanding about how the brain works, the models that were built produced reasonably good results. Instead of using the central processor to analyze a number of instructions, the neural net software analyzes the data by passing them through several simulated processes that are interconnected.

A simple neural network consists of input, hidden, and output layers:

1. The Input Layer is comprised of the input nodes. The input data are scaled and then a model is built to calculate the scaled output values.

2. The Hidden Layer receives the data from the input nodes and transmits their combined value to the output node.

3. The Output Layer gets the inputs from the hidden layer and these inputs are used to calculate the output of the whole system. These outputs are scaled back to their original values.

The Neural Networks can be used for Data Mining applications [15]. Some of the popular Neural Network algorithms for Data Mining are: a) Back Propagation Algorithm that is effectively able to do all six main tasks of Data Mining, but primarily, used for prediction purposes, b) Kohonen, Self Organizing Maps is essentially a clustering method only, and has been extensively used for that.

Historically, Neural Networks are found to generate outcomes that are best amongst the group, but often by a small margin especially in case of Regression Algorithms and Decision Trees. At the same time, they use many more parameters as compared to any other method. Therefore, in practice there is a trade off with the use of Neural Networks and other Data Mining Algorithms. All Neural Networks are prone to 
over-fitting the data; they require data in numerical or converted to numerical form. Moreover, their training is slow and, being "Black Box," relatively harder to interpret and use.

\section{Genetic Algorithm}

This optimization search technique is based on the concepts of natural evolution, sometimes considered as an automatically evolving special case of the Rule Induction algorithm [16]. Unlike other algorithms, the output is general yet specific to the case under study and is understandable mainly by the domain experts. Hence, it cannot be used to build generic applications for Data Mining. During each run, a large population of random chromosomes is created. When decoded, each one represents a different solution to the problem at hand. The following steps are repeated until a solution is found:

a. Test each chromosome with fitness function to see how good it is at solving the problem at hand and assign a fitness score accordingly

b. Select two members from the current population based on fitness. The Roulette wheel selection is a commonly used method where size of a section is proportional to fitness

c. Dependent on the crossover rate the bits from each chosen chromosome swap at a randomly chosen point

d. Step through the chosen chromosomes bits and flip depending on the mutation rates

e. Repeat step b, c, d until a new population of $\mathrm{N}$ members has been created

Thus a generalized solution to problem is reached. Genetic Algorithm is preferred for applications pertaining to relatively smaller databases. 


\section{Association Algorithm}

Association algorithms generate candidate item sets from complete item sets; of those, the ones with infrequent sub-patterns are pruned. Thus, the generated candidate sets contain item sets that scan the whole transaction database to determine frequent item sets among the candidates. For determining frequent items in a fast manner, the algorithm stores candidate item sets. Unlike other algorithms, Association algorithms are designed to operate on databases containing transactions. The algorithms are generally simple to implement and reasonably efficient.

For example, the owner of a store that sells DVDs, VCD, books, and games may want to discover which of these items customers are likely to buy together. Customers in this particular store may like buying a DVD and a game in 10 out of every 100 transactions, or the sale of VCD may hardly ever be associated with a sale of a DVD. With the information above, the store could strive for more optimum placement of DVDs and games, as the sale of one of them may improve the chances of the sale of the other frequently associated item.

Some of the association methods are: Apriori, Partitioning Algorithm, Count Distribution Algorithm (CDA), and Data Distribution Algorithm (DDA) [2]. Of these, the Partitioning algorithms generate a large number of candidates for non-uniform data, thus increasing the computational complexity and resource consumption, but they are able to utilize the memory. The CDA and DDA often need parallel processing or even multiprocessing for computation as they have large message traffic.

\section{Advantages and Drawbacks}

\section{Advantages:}

a. Decision Rule models are simple to understand and interpret (White Box).

b. They can handle both nominal and categorical data, once discrete before use in the model.

c. They do not need normalization and or removal of missing values.

d. They are robust and work well with large data. 
Drawbacks:

a. Difficult to predict the value of the continuous attributes.

b. Reduced accuracy of classification for high dimensional data.

c. They are computationally expensive. Moreover, pruning algorithms add to the complexity as many candidate sub-trees are formed and compared.

d. Decision rules often lead to rectangular classification boxes that might not correspond well with the actual distribution of records.

\section{Hierarchical Clustering}

The two primary algorithms of this type are a) Agglomerative Algorithm and b) Divisive Algorithm [2].

\section{Agglomerative Clustering}

Agglomerative Clustering algorithms start with each individual item as its own cluster and then iteratively merge clusters until all items merge into one cluster as per the threshold distance criteria. The three sub-types of these algorithms are Single Link, Complete Link and Average Link algorithms.

\section{Divisive Clustering}

These algorithms behave in the way that is exactly opposite to the Agglomerative Clustering. Here, all the items are considered to be part of a single cluster and then split. All hierarchical clustering algorithms face excessive space and time constraints. Thus, they are difficult to use on large databases. Moreover, these algorithms cannot handle trends in data, whenever new data are added or old data removed, it has to be re-run. 


\section{Partitional Clustering}

The two primary algorithms of this type of clustering are: a) K- Means Clustering, and b) Nearest Neighbor.

\section{K - means Clustering}

K-means Clustering are the most common unsupervised learning algorithms that are used for classification or partition of the data into clusters that are fixed a priori. The main idea is to pre-define centroids, one for each cluster, the artificial points in the spaces which represent a mean location of all the items of that particular cluster. These centroids should be placed in an intelligent way, as the algorithm is sensitive to initial selection, because their different location gives different results. So, the better choice is to place them as far as possible from each other. Centroid is defined as the representative element of a cluster; it is the point whose parameter values are the average of the parameter values of every point in the current cluster. The steps of the K-means algorithm are:

a. Randomly select some points to be the seeds for the centroids of the clusters.

b. Assign data items to the centroid closest to them, thus forming clusters of items.

c. Find new centroids for the items belonging to the same cluster.

d. If the centroids have changed their "coordinates," then start again from step b. Else, cluster detection is finished with all cluster memberships defined.

The K-means algorithm might not find the most optimal configuration, corresponding to the global objective function minimum. A simple approach is to compare the results of multiple runs with different seed selection and choose the best one as per given criterion, while taking care of overfitting. Also, the values in the dataset must all be numeric; categorical data must be transformed into numeric ones, and should be normalized in order to allow fair computation of the overall distances in a multi-attribute space. Median values are often used to tackle outliers. Also, individual significance of the items in the group, towards the centroid, remains unknown. 


\section{Nearest Neighbor}

These are memory-based algorithms, typically used for classification and prediction scenario. Each dataset consists of a set of independent values labeled by a set of dependent outcomes. They would be either continuous or categorical based on which regression or classification is done. For a new dependent value called query point, the outcome is estimated based on the $\mathrm{KNN}$ datasets. For regression, the predictions are based on averaging the outcomes of the k nearest neighbors and for classification; voting is used. Choice of " $\mathrm{k}$ " could be the most important factor of the algorithm which also acts as a smoothing parameter. A higher value for " $\mathrm{k}$ " increases the bias and reduces variance and vice versa also holds true.

The value of " $k$ " is estimated by Cross-validation when model parameters are unknown. The data are divided into numbers of randomly drawn samples. For a fixed value of " $\mathrm{k}$," the KNN model is used to make predictions and evaluate the error (SSE for regression or Accuracy for prediction). This is then successively applied to all possible sample choices. At the end, the errors are averaged to yield a measure of the stability of the model. The above steps are repeated for various " $k$ " and the value with lowest error or highest classification accuracy is selected. It would be worth the effort, however only for fast queries and large numbers of items. Moreover, nearest neighbor search gets progressively harder as the dimensionality increases.

For prediction i.e. regression the typical score functions would be Euclidean, or other Weighted Distance measures. While for classification, a voting scheme is used. The KNN is often found to be vulnerable in case of equal instances and weights of variables.

\section{Markov and Hidden Markov}

Markov and Hidden Markov Algorithms are widely used to model sequential processes, and have achieved practical successes in many areas such as Web log mining, computational biology, speech recognition, robotics, fault diagnosis, and survival analysis [17]. A first-order Markov model contains a single variable, the state, and specifies the probability of each state and of transiting from one state to another. Hidden Markov 
Models (HMMs) contain two variables: the hidden state and the observation. In addition to the transition probabilities, HMMs specify the probability of making each observation in each state. Because the number of parameters of a first-order Markov model is quadratic in the number of states (and higher for higher-order models), learning Markov models is feasible only in relatively small state spaces. This requirement makes them unsuitable for many Data Mining applications, which are concerned with very large state spaces. Still, their advantage is that they can be estimated statistically and adapted quickly. For example, they could be used to predict the probability of seeing a link on a Web page given a history of accessed links and also help generate a sequence of links that could be accessed by the user in the future.

\section{Data Visualization}

The visual interpretations of complex relationships in the multidimensional data are often termed as Data Visualization. Many new and innovative graphics tools are used to illustrate the data in space and, more importantly the data relationships. Data Visualization is mostly used in combination with other algorithms to make the results more presentable, readable, and understandable. Thus, it is an important part of Data Mining group, even though it does not analyze the data.

\section{DMQL}

With increased use of RDBMS (Relational Database Models) and recent advancements in SQL based querying tools, such as Oracle 9i and MS SQL Server 2005, more complicated tasks such as OLAP (Online Analytical Processing) and Data Mining Applications are being developed. A Data Mining Query Language (DMQL) has been proposed. This works only with RDBMS [2].

Table 2.1 classifies the various Data Mining algorithms according to problem type, namely, Association, Classification, Clustering, Prediction, Discovery, and Summarization. 


\begin{tabular}{|c|c|c|c|c|c|c|c|c|c|}
\hline \multicolumn{10}{|c|}{ Table 2.1: List of Data Mining Algorithms } \\
\hline \multirow[b]{2}{*}{$\begin{array}{l}\text { S. } \\
\text { No. }\end{array}$} & \multirow[b]{2}{*}{ Methods } & \multicolumn{6}{|c|}{ Problem Types } & \multirow[b]{2}{*}{ Input } & \multirow[b]{2}{*}{ Output } \\
\hline & & Association & Classification & Clustering & Prediction & $\begin{array}{l}\text { Sequence } \\
\text { Discovery }\end{array}$ & $\begin{array}{l}\text { Description/ } \\
\text { Summarization }\end{array}$ & & \\
\hline 1 & Regression Analysis & & $\mathbf{Y}$ & & $\mathbf{Y}$ & & & Numerical Values & $\begin{array}{l}\text { Multivariate } \\
\text { Equation }\end{array}$ \\
\hline 3.1 & $\begin{array}{l}\text { Decision Rules or } \\
\text { Trees (DT): ID3 }\end{array}$ & & $\mathbf{Y}$ & $\mathbf{Y}$ & $\mathbf{Y}$ & & $\mathbf{Y}$ & $\begin{array}{c}\text { Sample } \\
\text { Computational } \\
\text { Data, Numeric. }\end{array}$ & Decision Rules/Tree \\
\hline 3.2 & DT: C4.5 & & $\mathbf{Y}$ & & $\mathbf{Y}$ & & & $\begin{array}{c}\text { Sample } \\
\text { Computational } \\
\text { Data, }\end{array}$ & Decision Rules/Tree \\
\hline 3.4 & $\begin{array}{c}\text { DT: Chi Squared } \\
\text { Automatic Interaction } \\
\text { Detection (CHAID) }\end{array}$ & & $\mathbf{Y}$ & & $\mathbf{Y}$ & & & $\begin{array}{c}\text { Sample } \\
\text { Computational } \\
\text { Data, Numeric. }\end{array}$ & Decision Rules/Tree \\
\hline 3.5 & $\begin{array}{l}\text { DT: Quick Unbiased } \\
\text { Efficient Statistical } \\
\text { Tree (QUEST) }\end{array}$ & & $\mathbf{Y}$ & & $\mathbf{Y}$ & & & $\begin{array}{c}\text { Sample } \\
\text { Computational } \\
\text { Data, Numeric. }\end{array}$ & Decision Rules/Tree \\
\hline 4 & Rule Induction & & $\mathbf{Y}$ & & $\mathbf{Y}$ & & & $\begin{array}{c}\text { Sample } \\
\text { Computational } \\
\text { Data, Numeric. }\end{array}$ & Decision Rules/Tree \\
\hline 5.1 & $\begin{array}{c}\text { NN: Back Propagation } \\
\text { Algorithm }\end{array}$ & $\mathbf{Y}$ & $\mathbf{Y}$ & $\mathbf{Y}$ & $\mathbf{Y}$ & & & Feature of pattern. & $\begin{array}{l}\text { Classification, } \\
\text { Prediction, } \\
\text { Clustering and } \\
\text { Association results. }\end{array}$ \\
\hline
\end{tabular}




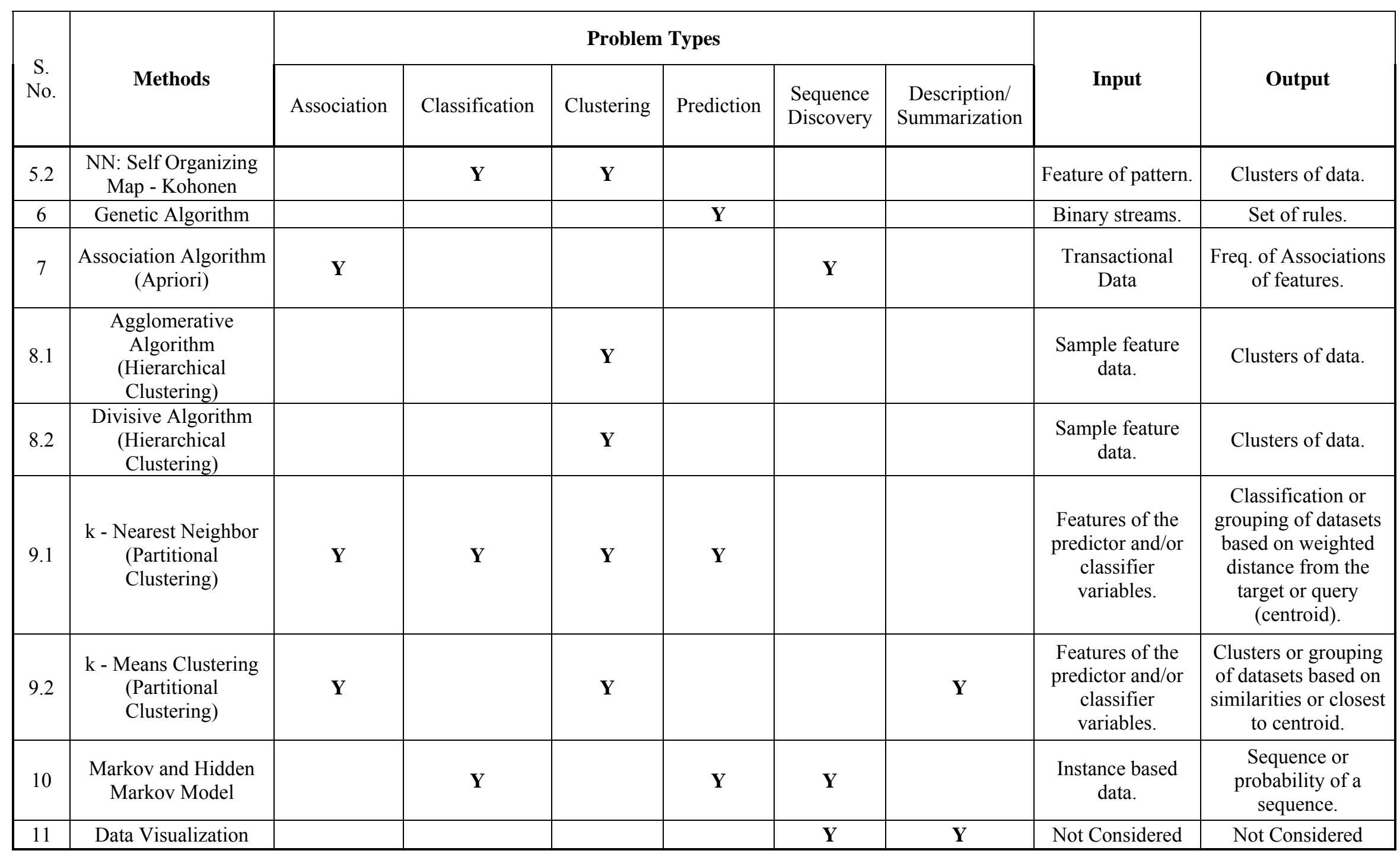




\subsection{Algorithm Structure}

Section 2.3 described how the Data Mining models are categorized. This section describes the different components of Data Mining algorithms. The four components of a typical Data Mining algorithm are [13]:

\section{Pattern Structure:}

Pattern structure is the underlying structure or functional form that is part of the algorithm. Based on the score or selection criterion, data similar to the pattern structures are sought from the data. They are often called the relevant condition, constraint or parameter that will be computed by the algorithm. The name "pattern structure" is sometimes replaced by the term "model structure."

\section{Score Function:}

This quantifies how well a given pattern or parameter fits the given dataset. Thus, based on the error that is generated, modifications are made to the algorithm. Further, the range of the input values to the model, in the form of constraints of the function, can be determined. They often serve the purpose of comparing the utility or efficiency of one method over the other, thus helping to choose one model over another. Finally, it is desirable that the score function should be robust and not be sensitive to the input values. There are many types of score functions, including Squared Error, Gini Coefficient, Euclidean Distance, and Entropy.

\section{Optimization and Search Function:}

The task of the optimization function is to determine the "best" set of values from the given data depending on the objective. The best set essentially means the values that minimize or maximize the score function as desired by the Data Mining logic. The task of finding an interesting pattern is essentially the task of a search function. The search function may make use of searching techniques such as binary search, index search and more importantly using different heuristic search techniques. 


\section{Data Management Strategy}

This concerns efficient handling of data during the optimization and search operation. Until recently, this had little bearing on the Data Mining model, but now significant emphasis is put on the data that are being managed in order to improve the overall efficiency of the Data Mining algorithm. Moreover, the way (format, order, etc.) in which data are to be arranged from the user or algorithm viewpoint is also important. This is supported by fact that with increase in the size of data, it takes more and more time to train, validate and actually mine them. 


\subsection{Summary}

The significance of the Data Mining field can be attributed to:

a. Explosive growth in data.

b. Advancement in data gathering mechanisms. Superior Internet and intranet facilities.

c. Proportionate increase in data storage and computation capability.

d. Competitive pressure to maintain market share in this era of globalization.

e. Advancement in health care facilities.

f. Security needs of the community, country and the world.

Some issues concerning Data Mining are:

a. It is an open-ended search which does not guaranty a solution to the problem.

b. Most algorithms require significantly skilled human input.

c. The outcome of the Data Mining procedure is highly dependent on the data quality and quantity for the given objective.

d. The significance of the outcome has to be gauged by the end user, while keeping the objective in mind.

e. The returns of Data Mining in terms of cost, time, and effort are a matter of dispute. 


\section{DATABASE DESIGN AND IMPLEMENTATION}

\subsection{Introduction}

For the crime database, various data fields were identified to cover real world scenarios. The inputs were taken from the Forensic Information Management System (FIMS) that is being developed for West Virginia State Police Department [21] and Web sources of various crime investigation agencies [22]. The entities that were identified are, 1) Offense, 2) Suspect, 3) Victim, 4) Convict, 5) Investigating Agency, 6) Officer Incharge, 7) Charges (against convict), and 8) Verdict. Four groups of tables as shown in Table 3.1 were created (Data Tables, Code Tables, Link Tables, and Query Tables). The various tables under each group are shown below.

\begin{tabular}{|c|c|c|c|c|c|c|c|}
\hline \multicolumn{8}{|c|}{ Table 3.1: Tables in Crime Database } \\
\hline $\begin{array}{l}\text { S. } \\
\text { No. }\end{array}$ & Data Tables & \begin{tabular}{|l|} 
S. \\
No.
\end{tabular} & Code Tables & $\begin{array}{l}\text { S. } \\
\text { No. }\end{array}$ & Link Tables & \begin{tabular}{|c} 
S. \\
No
\end{tabular} & Query Tables \\
\hline 1 & dtOffense & 1 & ctOffenseType & 1 & 1tLnkOffSus & 1 & tblQuery \\
\hline 2 & dtSuspect Physical & 2 & ctDrugListType & 2 & 1tLnkOffVic & & \\
\hline 3 & dtSuspect Alias & 3 & ctAgencyType & 3 & ltLnkCon & & \\
\hline 4 & dtSuspect Variable & 4 & ctOfficerTitle & & & & \\
\hline 5 & dtVictim_Physical & 5 & ctCountyType & & & & \\
\hline 6 & dtVictim Alias & 6 & ctStateType & & & & \\
\hline 7 & dtVictim Variable & 7 & ctCountryType & & & & \\
\hline 8 & dtAgencyInfo & 8 & ctRaceType & & & & \\
\hline 9 & dtOfficerInfo & 9 & ctGenderType & & & & \\
\hline 10 & dtOfficerWorkInfo & 10 & ctEyeColorType & & & & \\
\hline 11 & dtConvict & 11 & ctHairColorType & & & & \\
\hline 12 & dtCharges & 12 & ctFinCondtnType & & & & \\
\hline 13 & dtVerdict & 13 & ctBehvAspctType & & & & \\
\hline
\end{tabular}




\subsection{Data Tables}

The fields of the data tables were built from various sources as stated earlier. The tables are populated as the cases are registered by the crime investigating agency. The various fields of the "dtOffense" table are shown in Table 3.2. This table has details related to offense such as registration, time, type and address of offense as well as brief description of offense.

\begin{tabular}{|l|l|l|l|}
\hline \multicolumn{4}{|c|}{ Table 3.2: Fields of “dtOffense" Table } \\
\hline Field Name & Data Type & Length & Description \\
\hline ACN & nvarchar & 50 & Agency Case Number \\
\hline AgencyID & nvarchar & 50 & Agency Identification Number \\
\hline OfficerID & nvarchar & 50 & Officer's Identification Number \\
\hline EntryDate & datetime & 8 & Entry date of case \\
\hline ModifDate & datetime & 8 & Modification date \\
\hline OffenseDate & datetime & 8 & Offense date \\
\hline OffenseTime & datetime & 8 & Offense time \\
\hline OffenseDay & nvarchar & 50 & Offense day \\
\hline OffenseType & nvarchar & 50 & Offense type \\
\hline Street & nvarchar & 50 & Address of offense \\
\hline City & nvarchar & 50 & City of Offense \\
\hline County & nvarchar & 50 & County of Offense \\
\hline State & nvarchar & 50 & State of Offense \\
\hline Country & nvarchar & 50 & Country of Offense \\
\hline ZipCode & nvarchar & 50 & Zip Code of Offense \\
\hline OffenseDescp & nvarchar & 500 & Brief description of offense \\
\hline CaseStatus & nvarchar & 50 & Status of the case \\
\hline
\end{tabular}


The fields of the "dtSuspect_Physical" table are shown in Table 3.3. This table stores the physical attributes (non-changeable) of a suspect in the database and a suspect identification number is generated.

\begin{tabular}{|l|l|l|l|}
\hline \multicolumn{5}{|c|}{ Table 3.3: Fields of "dtSuspect_Physical" Table } \\
\hline Field Name & Data Type & Length & Description \\
\hline SuspectID & nvarchar & 50 & Identification Number of suspect \\
\hline EntryDate & datetime & 8 & Entry date of record \\
\hline ModifDate & datetime & 8 & Modification date of record \\
\hline SSN & nvarchar & 50 & Social security of the suspect \\
\hline LName & nvarchar & 50 & Last Name of the suspect \\
\hline FName & nvarchar & 50 & First Name of the suspect \\
\hline MName & nvarchar & 50 & Middle Name of the suspect \\
\hline Suffix & nvarchar & 50 & Suffix of the suspect \\
\hline DOB & nvarchar & 8 & Date of birth \\
\hline POB & nvarchar & 50 & Place of birth \\
\hline Age & nvarchar & 50 & Age of the suspect \\
\hline Height & nvarchar & 50 & Height of the suspect \\
\hline Weight & nvarchar & 50 & Weight of the suspect \\
\hline Dexterity & nvarchar & 50 & Right/Left handedness of the suspect \\
\hline EyeColor & nvarchar & 50 & Eye Color of the suspect \\
\hline HairColor & nvarchar & 50 & Hair Color of the suspect \\
\hline SkinColor & nvarchar & 50 & Skin Color of the suspect \\
\hline FingerClass & nvarchar & 50 & Finger Print Classification of the suspect \\
\hline FingerPatt & nvarchar & 50 & Finger Print Pattern of the suspect \\
\hline IndvMarks & nvarchar & 500 & Marks on individual's body of the suspect \\
\hline Race & nvarchar & 50 & Race of the suspect \\
\hline Gender & nvarchar & 50 & Gender of the suspect \\
\hline
\end{tabular}

The fields of the table "dtSuspect_Alias" are shown in Table 3.4. This table stores various aliases of the suspect in the database for the same suspect identification number.

\begin{tabular}{|l|l|l|l|}
\hline \multicolumn{4}{|c|}{ Table 3.4: Fields of "dtSuspect_Alias" Table } \\
\hline Field Name & Data Type & Length & Description \\
\hline SuspectID & nvarchar & 50 & Identification Number of suspect. \\
\hline AliasNum & nvarchar & 50 & Alias Number of suspect \\
\hline LastName & nvarchar & 50 & Last Name of the suspect \\
\hline FirstName & nvarchar & 50 & First Name of the suspect \\
\hline MiddleName & nvarchar & 50 & Middle Name of the suspect \\
\hline Suffix & nvarchar & 50 & Suffix of the suspect \\
\hline
\end{tabular}


The fields of the "dtSuspect_Variable" table are shown in Table 3.5. This table stores variable characteristics (changeable) of a suspect in the database based on suspect identification number and alias number.

\begin{tabular}{|l|l|l|l|}
\hline \multicolumn{5}{|c|}{ Table 3.5: Fields of “dtSuspect_Variable" Table } \\
\hline Field Name & Data Type & Length & Description \\
\hline SuspectID & nvarchar & 50 & Identification Number of Suspect \\
\hline AliasNum & nvarchar & 50 & Alias Number of Suspect \\
\hline EntryLevel & nvarchar & 50 & Level of record entry for given alias \\
\hline EntryDate & datetime & 8 & Date of record entry \\
\hline PassportNo & nvarchar & 50 & Passport No of suspect \\
\hline Citizenship & nvarchar & 50 & Citizenship of suspect \\
\hline LiscenceNo & nvarchar & 50 & License No of suspect \\
\hline Religion & nvarchar & 50 & Religion of suspect \\
\hline Occupation & nvarchar & 50 & Occupation of suspect \\
\hline Street & nvarchar & 50 & Street of suspect \\
\hline City & nvarchar & 50 & City of suspect \\
\hline County & nvarchar & 50 & County of suspect \\
\hline State & nvarchar & 50 & State of suspect \\
\hline Country & nvarchar & 50 & Country of suspect \\
\hline ZipCode & nvarchar & 50 & Zip Code of suspect \\
\hline Phone & nvarchar & 50 & Phone No of suspect \\
\hline EmerContact & nvarchar & 50 & Emergency contact of suspect \\
\hline FinCondtn & nvarchar & 50 & Financial condition of suspect \\
\hline FinDescp & nvarchar & 50 & Financial description of suspect \\
\hline BehvAspect & nvarchar & 50 & Behavioral aspect of suspect \\
\hline BehvDescp & nvarchar & 50 & Behavioral description of suspect \\
\hline DefnTrain & nvarchar & 50 & Defense training if any \\
\hline WeapTrain & nvarchar & 50 & Weapons training if any \\
\hline DrugHist & nvarchar & 50 & Drug history if any \\
\hline DrugType & nvarchar & 50 & Drug type associated with if any \\
\hline Charge1 & nvarchar & 50 & Charge1 if any \\
\hline Charge2 & nvarchar & 50 & Charge2 if any \\
\hline Charge3 & nvarchar & 50 & Charge3 if any \\
\hline Status & nvarchar & 50 & Status as in prior conviction etc \\
\hline
\end{tabular}


The fields of the "dtVictim_Physical" table are shown in Table 3.6. This table stores the physical attributes (non-changeable) of a victim in the database and a victim identification number is generated.

\begin{tabular}{|l|l|l|l|}
\hline \multicolumn{4}{|c|}{ Table 3.6: Fields of “dtVictim_Physical” Table } \\
\hline Field Name & Data Type & Length & Description \\
\hline VictimID & nvarchar & 50 & Identification Number of victim \\
\hline EntryDate & datetime & 8 & Entry date of record \\
\hline ModifDate & datetime & 8 & Modification date of record \\
\hline SSN & nvarchar & 50 & Social security of the victim \\
\hline LName & nvarchar & 50 & Last Name of the victim \\
\hline FName & nvarchar & 50 & First Name of the victim \\
\hline MName & nvarchar & 50 & Middle Name of the victim \\
\hline Suffix & nvarchar & 50 & Suffix of the victim \\
\hline DOB & nvarchar & 8 & Date of birth \\
\hline POB & nvarchar & 50 & Place of birth \\
\hline Age & nvarchar & 50 & Age of the victim \\
\hline Height & nvarchar & 50 & Height of the victim \\
\hline Weight & nvarchar & 50 & Weight of the victim \\
\hline Dexterity & nvarchar & 50 & Right/Left handedness of the victim \\
\hline EyeColor & nvarchar & 50 & Eye Color of the victim \\
\hline HairColor & nvarchar & 50 & Hair Color of the victim \\
\hline SkinColor & nvarchar & 50 & Skin Color of the victim \\
\hline FingerClass & nvarchar & 50 & Finger Print Classification of the victim \\
\hline FingerPatt & nvarchar & 50 & Finger Print Pattern of the victim \\
\hline IndvMarks & nvarchar & 500 & Marks on individual's body of the victim \\
\hline Race & nvarchar & 50 & Race of the victim \\
\hline Gender & nvarchar & 50 & Gender of the victim \\
\hline
\end{tabular}

The fields of the "dtVictim_Alias" table are shown in Table 3.7. This table stores the aliases of the victim in the database for the same victim identification number.

\begin{tabular}{|l|l|l|l|}
\hline \multicolumn{4}{|c|}{ Table 3.7: Fields of “dtVictim_Alias" Table } \\
\hline Field Name & Data Type & Length & Description \\
\hline VictimID & nvarchar & 50 & Identification Number of victim \\
\hline AliasNum & nvarchar & 50 & Alias Number of victim \\
\hline LastName & nvarchar & 50 & Last Name of the victim \\
\hline FirstName & nvarchar & 50 & First Name of the victim \\
\hline MiddleName & nvarchar & 50 & Middle Name of the victim \\
\hline Suffix & nvarchar & 50 & Suffix of the victim \\
\hline
\end{tabular}


The fields of the "dtVictim_Variable" table are shown in Table 3.8. This table stores variable characteristics (changeable) of a victim in the database based on identification number and alias number.

\begin{tabular}{|l|l|l|l|}
\hline \multicolumn{4}{|c|}{ Table 3.8: Fields of "dtVictim_Variable” Table } \\
\hline Field Name & Data Type & Length & Description \\
\hline Victim ID & nvarchar & 50 & Identification Number of victim \\
\hline AliasNum & nvarchar & 50 & Alias Number of victim \\
\hline EntryLevel & nvarchar & 50 & Level of record entry for given alias \\
\hline EntryDate & datetime & 8 & Date of record entry \\
\hline PassportNo & nvarchar & 50 & Passport No of victim \\
\hline Citizenship & nvarchar & 50 & Citizenship of victim \\
\hline LiscenceNo & nvarchar & 50 & License No of victim \\
\hline Religion & nvarchar & 50 & Religion of victim \\
\hline Occupation & nvarchar & 50 & Occupation of victim \\
\hline Street & nvarchar & 50 & Street of victim \\
\hline City & nvarchar & 50 & City of victim \\
\hline County & nvarchar & 50 & County of victim \\
\hline State & nvarchar & 50 & State of victim \\
\hline Country & nvarchar & 50 & Country of victim \\
\hline ZipCode & nvarchar & 50 & Zip Code of victim \\
\hline Phone & nvarchar & 50 & Phone No of victim \\
\hline EmerContact & nvarchar & 50 & Emergency contact of victim \\
\hline FinCondtn & nvarchar & 50 & Financial condition of victim \\
\hline FinDescp & nvarchar & 50 & Financial description of victim \\
\hline BehvAspect & nvarchar & 50 & Behavioral aspect of victim \\
\hline BehvDescp & nvarchar & 50 & Behavioral description of victim \\
\hline DefnTrain & nvarchar & 50 & Defense training if any \\
\hline WeapTrain & nvarchar & 50 & Weapons training if any \\
\hline DrugHist & nvarchar & 50 & Drug history if any \\
\hline DrugType & nvarchar & 50 & Drug type associated with if any \\
\hline Charge1 & nvarchar & 50 & Charge1 if any \\
\hline Charge2 & nvarchar & 50 & Charge2 if any \\
\hline Charge3 & nvarchar & 50 & Charge3 if any \\
\hline Status & nvarchar & 50 & Status as in prior conviction etc \\
\hline
\end{tabular}


The fields of the "dtAgencyInfo" table are shown in Table 3.9. This table stores information pertaining to the different agencies involved in solving the crime.

\begin{tabular}{|l|l|l|l|}
\hline \multicolumn{4}{|c|}{ Table 3.9: Fields of "dtAgencyInfo" Table } \\
\hline Field Name & Data Type & Length & Description \\
\hline AgencyID & nvarchar & 50 & Agency Identification Number \\
\hline AgencyName & nvarchar & 50 & Agency Name \\
\hline AgencyType & nvarchar & 50 & Type of agency Ex. Forensic, Investigation etc. \\
\hline Street & nvarchar & 50 & Street of the agency \\
\hline City & nvarchar & 50 & City of the agency \\
\hline County & nvarchar & 50 & County of the agency \\
\hline State & nvarchar & 50 & State of the agency \\
\hline Country & nvarchar & 50 & Country of the agency \\
\hline ZipCode & nvarchar & 50 & Zip Code of the agency \\
\hline Phone & nvarchar & 50 & Phone number of the agency \\
\hline Contact & nvarchar & 50 & Contact person at the agency \\
\hline Notes & nvarchar & 500 & Important notes if any \\
\hline
\end{tabular}

The fields of the "dtOfficerInfo" table are shown in Table 3.10. This table stores the personal information about the crime investigating and other security officers.

\begin{tabular}{|l|l|l|l|}
\hline \multicolumn{4}{|c|}{ Table 3.10: Fields of "dtOfficerInfo" Table } \\
\hline Field Name & Data Type & Length & Description \\
\hline OfficerID & nvarchar & 50 & Identification Number of the officer \\
\hline LName & nvarchar & 50 & Last Name of the officer \\
\hline FName & nvarchar & 50 & First Name of the officer \\
\hline MName & nvarchar & 50 & Middle Name of the officer \\
\hline Suffix & nvarchar & 50 & Suffix of the officer \\
\hline SSN & nvarchar & 50 & Social security number of the officer \\
\hline DOB & datetime & 8 & Date of birth of the officer \\
\hline Gender & nvarchar & 50 & Gender of the officer \\
\hline Race & nvarchar & 50 & Race of the officer \\
\hline Street & nvarchar & 50 & Street of the officer \\
\hline City & nvarchar & 50 & City of the officer \\
\hline County & nvarchar & 50 & County of the officer \\
\hline State & nvarchar & 50 & State of the officer \\
\hline Country & nvarchar & 50 & Country of the officer \\
\hline ZipCode & nvarchar & 50 & Zip Code of the officer \\
\hline Phone & nvarchar & 50 & Phone number of the officer \\
\hline Notes & nvarchar & 500 & Important notes if any \\
\hline
\end{tabular}


The fields of the "dtOfficerWorkInfo" table are shown in Table 3.11. This table stores the professional information about the crime investigating and other security officers.

\begin{tabular}{|l|l|l|l|}
\hline \multicolumn{4}{|c|}{ Table 3.11: Fields of "dtOfficerWorkInfo" Table } \\
\hline Field Name & Data Type & Length & Description \\
\hline OfficerID & nvarchar & 50 & Identification Number of the officer \\
\hline EntryDate & datetime & 8 & Date of record entry \\
\hline ModifDate & datetime & 8 & Date of record modification \\
\hline JobTitle & nvarchar & 50 & Title of the officer \\
\hline Dept & nvarchar & 50 & Department of the officer \\
\hline HireDate & datetime & 8 & Date of hire of the officer \\
\hline TitleDate & datetime & 8 & Date of current title \\
\hline Status & nvarchar & 50 & Status of the officer \\
\hline Specialization & nvarchar & 500 & Specialization of the Officer \\
\hline Performance & nvarchar & 500 & Performance of the Officer \\
\hline
\end{tabular}

The fields of the "dtConvict" table are shown in Table 3.12. This table stores the official information about the individuals convicted of crime.

\begin{tabular}{|l|l|l|l|}
\hline \multicolumn{4}{|c|}{ Table 3.12: Fields of "dtConvict" Table } \\
\hline Field Name & Data Type & Length & Description \\
\hline ConvictID & nvarchar & 50 & Identification Number of the convict \\
\hline ArrestDate & datetime & 8 & Arrest date of the convict \\
\hline CourtAssigned & nvarchar & 50 & Court assigned for trial \\
\hline Trial & nvarchar & 50 & Type of trial \\
\hline Counsel & nvarchar & 50 & Counsel status, type and name \\
\hline PurposeCode & nvarchar & 50 & Purpose Code of the convict \\
\hline OBTS & nvarchar & 50 & OBTS of the convict \\
\hline SuspectID & nvarchar & 50 & Suspect Identification if matches \\
\hline VictimID & nvarchar & 50 & Victim Identification if matches \\
\hline
\end{tabular}


The fields of the "dtConvict" table are shown in Table 3.13. This table stores the charges and related information of the individual convicted of crime.

\begin{tabular}{|l|l|l|l|}
\hline \multicolumn{4}{|c|}{ Table 3.13: Fields of “dtCharges" Table } \\
\hline Field Name & Data Type & Length & Description \\
\hline ConvictID & nvarchar & 50 & Convict's Identification Number \\
\hline ChargeNum & nvarchar & 50 & Charge Number \\
\hline Charge & nvarchar & 50 & Type of charge \\
\hline Motivation & nvarchar & 50 & Motivation for crime \\
\hline ProsecData & nvarchar & 50 & Data available with prosecution \\
\hline CourtData & nvarchar & 50 & Data available with court \\
\hline ConvictPlea & nvarchar & 50 & Convict's plea \\
\hline Status & nvarchar & 50 & Guilty / Not Guilty \\
\hline
\end{tabular}

The fields of the "dtVerdict" table are shown in Table 3.14. This table stores the verdict against individual charge of the individual convicted of crime.

\begin{tabular}{|l|l|l|l|}
\hline \multicolumn{5}{|c|}{ Table 3.14: Fields of "dtVerdict" Table } \\
\hline Field Name & Data Type & Length & Description \\
\hline ConvictID & nvarchar & 50 & Convict Identification Number \\
\hline ChargeNum & nvarchar & 50 & Charge Number \\
\hline Statute & nvarchar & 50 & Statute \\
\hline StatueDate & datetime & 8 & Date of statute \\
\hline StatuteLevel & nvarchar & 50 & Level or Degree of statute \\
\hline StatuteDescp & nvarchar & 50 & Description of Statute \\
\hline Sentence & nvarchar & 50 & Type of sentence \\
\hline SentenceDate & datetime & 8 & Date of sentence \\
\hline SentencePlace & nvarchar & 50 & Place of sentence \\
\hline FinalDispo & nvarchar & 50 & Final Disposition \\
\hline DispoDate & datetime & 8 & Date of disposition \\
\hline MdtRelDate & datetime & 8 & Mandatory release date \\
\hline MdtExpDate & datetime & 8 & Mandatory expiry date \\
\hline SupRelDate & datetime & 8 & Supplementary release date \\
\hline SupExpDate & datetime & 8 & Supplementary expiry date \\
\hline SupRelTerms & nvarchar & 50 & Supplementary release terms \\
\hline SupStatus & nvarchar & 50 & Supplementary status \\
\hline ParoleDate & datetime & 8 & Parole date \\
\hline ParoleExpDate & datetime & 8 & Parole expiration date \\
\hline ProbDate & datetime & 8 & Probation date \\
\hline
\end{tabular}




\begin{tabular}{|l|l|l|l|}
\hline ProbExpDate & datetime & 8 & Probation expiration date \\
\hline SPTDate & datetime & 8 & SPT date \\
\hline SPTExpDate & datetime & 8 & SPT expiration date \\
\hline PTDDate & datetime & 8 & PTD date \\
\hline PTDExpDate & datetime & 8 & PTD expiration date \\
\hline StatusWanted & nvarchar & 50 & Convict status \\
\hline
\end{tabular}

\subsection{Code Tables}

These tables are used to populate the fields of the data tables. They are also termed as "Filler Tables" as they do not serve any direct purpose other than the aforesaid task. The fields of the "ctAgencyType" table are shown in Table 3.15. This table stores different agency types.

\begin{tabular}{|l|l|l|l|}
\hline \multicolumn{4}{|c|}{ Table 3.15: Fields of "ctAgencyType" Table } \\
\hline Field Name & Data Type & Length & Description \\
\hline ID & nvarchar & 50 & Serial Number \\
\hline AgencyType & nvarchar & 50 & Types of Agency \\
\hline
\end{tabular}

The fields of the "ctOfficerType" table are shown in Table 3.16. This table stores different officer designations.

\begin{tabular}{|l|l|l|l|}
\hline \multicolumn{4}{|c|}{ Table 3.16: Fields of "ctOfficerType" Table } \\
\hline Field Name & Data Type & Length & Description \\
\hline ID & nvarchar & 50 & Serial Number \\
\hline OfficerTitle & nvarchar & 50 & Types of Officer Title \\
\hline
\end{tabular}


The fields of the "ctCountyType" table are shown in Table 3.16. This table stores all names of the counties in West Virginia.

\begin{tabular}{|l|l|l|l|}
\hline \multicolumn{4}{|c|}{ Table 3.17: Fields of "ctCountyType" Table } \\
\hline Field Name & Data Type & Length & Description \\
\hline ID & nvarchar & 50 & Serial Number \\
\hline CountyType & nvarchar & 50 & Type of Counties \\
\hline
\end{tabular}

The fields of the "ctStateType" table are shown in Table 3.18. This table stores names of all states in US. For now, this has only single id for the State of West Virginia.

\begin{tabular}{|l|l|l|l|}
\hline \multicolumn{4}{|c|}{ Table 3.18: Fields of "ctStateType" Table } \\
\hline Field Name & Data Type & Length & Description \\
\hline ID & nvarchar & 50 & Serial Number \\
\hline StateName & nvarchar & 50 & Type of States \\
\hline
\end{tabular}

The fields of the "ctCountryType" table are shown in Table 3.19. This table stores names of all the countries in the world. For now, this has only single id for the US.

\begin{tabular}{|l|l|l|l|}
\hline \multicolumn{4}{|c|}{ Table 3.19: Fields of "ctCountryType" Table } \\
\hline Field Name & Data Type & Length & Description \\
\hline ID & nvarchar & 50 & Serial Number \\
\hline CountryName & nvarchar & 50 & Type of Countries \\
\hline
\end{tabular}

The fields of the "ctRaceType" table are shown in Table 3.20. This table stores different races as identified by the FBI.

\begin{tabular}{|l|l|l|l|}
\hline \multicolumn{4}{|c|}{ Table 3.20: Fields of "ctRaceType" Table } \\
\hline Field Name & Data Type & Length & Description \\
\hline ID & nvarchar & 50 & Serial Number \\
\hline RaceType & nvarchar & 50 & Type of Race \\
\hline
\end{tabular}


The fields of the "ctGenderType" table are shown in Table 3.21. This table stores different genders as identified by the FBI.

\begin{tabular}{|l|l|l|l|}
\hline \multicolumn{4}{|c|}{ Table 3.21: Fields of "ctGenderType" Table } \\
\hline Field Name & Data Type & Length & Description \\
\hline ID & nvarchar & 50 & Serial Number \\
\hline GenderType & nvarchar & 50 & Type of Gender \\
\hline
\end{tabular}

The fields of the "ctCourtType" table are shown in Table 3.22. This table stores names of different courts in US.

\begin{tabular}{|l|l|l|l|}
\hline \multicolumn{4}{|c|}{ Table 3.22: Fields of "ctCourtType" Table } \\
\hline Field Name & Data Type & Length & Description \\
\hline ID & nvarchar & 50 & Serial Number \\
\hline CourtType & nvarchar & 50 & Type of Court \\
\hline
\end{tabular}

The fields of the "ctEyeColorType" table are shown in Table 3.23. This table stores eye colors as identified by the FBI.

\begin{tabular}{|l|l|l|l|}
\hline \multicolumn{4}{|c|}{ Table 3.23: Fields of "ctEyeColorType" Table } \\
\hline Field Name & Data Type & Length & Description \\
\hline ID & nvarchar & 50 & Serial Number \\
\hline EyeType & nvarchar & 50 & Eye Color Type \\
\hline
\end{tabular}

The fields of the "ctHairType" table are shown in Table 3.24. This table stores hair colors as identified by the FBI.

\begin{tabular}{|l|l|l|l|}
\hline \multicolumn{4}{|c|}{ Table 3.24: Fields of "ctHairType" Table } \\
\hline Field Name & Data Type & Length & Description \\
\hline ID & nvarchar & 50 & Serial Number \\
\hline HairType & nvarchar & 50 & Hair Color Type \\
\hline
\end{tabular}


The fields of the "ctFinCondtnType" table are shown in Table 3.25. This table stores attributes related to the financial condition of the individual.

\begin{tabular}{|l|l|l|l|}
\hline \multicolumn{4}{|c|}{ Table 3.25: Fields of "ctFinCondtnType" Table } \\
\hline Field Name & Data Type & Length & Description \\
\hline ID & nvarchar & 50 & Serial Number \\
\hline FinCondtnType & nvarchar & 50 & Types of Financial Condition \\
\hline
\end{tabular}

The fields of the "ctBehvAspectType" table are shown in Table 3.26. This table stores attributes related to the behavioral aspects of the individual.

\begin{tabular}{|l|l|l|l|}
\hline \multicolumn{4}{|c|}{ Table 3.26: Fields of "ctBehvAspectType" Table } \\
\hline Field Name & Data Type & Length & Description \\
\hline ID & nvarchar & 50 & Serial Number \\
\hline BehvAspectType & nvarchar & 50 & Types of Behavioral Aspect \\
\hline
\end{tabular}

The fields of the "ctOffenseType" table are shown in Table 3.27. This table stores all the offense types as identified by different investigation agencies.

\begin{tabular}{|l|l|l|l|}
\hline \multicolumn{4}{|c|}{ Table 3.27: Fields of "ctOffenseType" Table } \\
\hline Field Name & Data Type & Length & Description \\
\hline ID & nvarchar & 50 & Serial Number \\
\hline OffenseType & nvarchar & 50 & Types of Offense \\
\hline
\end{tabular}




\subsection{Link Tables}

The link or linker tables are used to establish many-to-many (logical) relationship between the data tables. The individual tables make one-to-many relation with these tables, and while doing so maintain a many-to-many relation with one another. The linker tables are described below. The fields of the "ltLnkOffSus" table are shown in Table 3.28. This table acts as a link between the table "dtOffense" and "dtSuspect_Physical" table.

\begin{tabular}{|l|l|l|l|}
\hline \multicolumn{4}{|c|}{ Table 3.28: Fields of "ltLnkOffSus" Table } \\
\hline Field Name & Data Type & Length & Description \\
\hline ACN & nvarchar & 50 & Agency Case Number \\
\hline SuspectID & nvarchar & 50 & Suspect Identification Number \\
\hline
\end{tabular}

The fields of the "ltLnkOffVic" table are shown in Table 3.29. This table acts as a link between the table "dtOffense" and "dtVictim_Physical" table.

\begin{tabular}{|l|l|l|l|}
\hline \multicolumn{4}{|c|}{ Table 3.29: Fields of "ltLnkOffVic" Table } \\
\hline Field Name & Data Type & Length & Description \\
\hline ACN & nvarchar & 50 & Agency Case Number \\
\hline VictimID & nvarchar & 50 & Victim Identification Number \\
\hline
\end{tabular}

The fields of the "ltLnkOffVic" table are shown in Table 3.30. This table acts as a link between the table "dtOffense" and "dtConvict" table.

\begin{tabular}{|l|l|l|l|}
\hline \multicolumn{4}{|c|}{ Table 3.30: Fields of "ltLnkOffCon" Table } \\
\hline Field Name & Data Type & Length & Description \\
\hline ACN & nvarchar & 50 & Agency Case Number \\
\hline ConvictID & nvarchar & 50 & Convict Identification Number \\
\hline
\end{tabular}




\subsection{Query Table}

Form the above tables, additional table can be created for the "Knowledge Discovery" purpose, called "tblQuery". This table will be built by extracting important fields from various tables of the database. Initially, the table will be populated with the data specifically prepared for it. In a production system this table would be populated simultaneously with the actual tables of the database. The focus of the initial table is to find typical crime patterns that were carried out within the state boundaries. The fields of the "tblQuery" table are shown in Table 3.31.

\begin{tabular}{|l|l|l|l|}
\hline \multicolumn{4}{|c|}{ Table 3.31: Fields of “tblQuery” Table } \\
\hline Field Name & $\begin{array}{l}\text { Data } \\
\text { Type }\end{array}$ & Length & Description \\
\hline ACN & nvarchar & 50 & Agency Case Number \\
\hline OffYear & datetime & 8 & Offense Year \\
\hline OffMonth & nvarchar & 50 & Offense Month \\
\hline OffDate & nvarchar & 50 & Offense Date \\
\hline OffHour & nvarchar & 50 & Offense Hour \\
\hline OffMinutes & nvarchar & 50 & Offense Minutes \\
\hline OffDay & nvarchar & 50 & Offense Day \\
\hline County & nvarchar & 50 & Offense County \\
\hline OffType & nvarchar & 50 & Offense Type \\
\hline Gender & nvarchar & 50 & Convict's Gender \\
\hline Race & nvarchar & 50 & Convict's Race \\
\hline Age & nvarchar & 50 & Convict's Age \\
\hline CriminalBkgd & nvarchar & 50 & Convict's Previous Crime Status (Yes / No) \\
\hline
\end{tabular}

The salient features of the Query Table are:

a. Important fields, based on domain knowledge and inputs from security agencies, were duplicated from the database into the "Query Table".

b. These fields were essentially put into single table to ensure the integrity and normalization constraints. 
c. While doing so, the privacy and security of the victim, suspect and the convicts are ensured.

d. All fields of the table are of type "nominal" and "non-ordinal"; also most were "Null" able. Moreover, there are no "Dependent - Independent" variable relationship in the data.

e. The data entries are sequential in terms of date of registration and not as per actual event.

f. Based on the conditions Query table would be populated first to have random data in space. Then a pattern would be fed to it. Finally, all the tools would be used to find that pattern and the outcome would be reported.

\subsection{Assumptions}

The data tables had predefined relations between them, and to express them, certain database constraints are required [18]. These constraints provide data stability and at the same time cover security issues. The various assumptions were:

a. One criminal offense can be registered in many agencies.

b. One criminal offense is assigned to one investigating officer only. However, one investigating officer can handle multiple criminal offenses.

c. One criminal offense can include multiple suspects, victims and convicts. They may have multiple aliases having additional set of information.

d. One convict can face multiple criminal charges and each criminal charge will have a single verdict. 


\subsection{Database}

The crime database was created from various tables described below. The relation between different data entities can be "one-to-one" or "one-to-many". The "key" symbol represents primary key relationship and the " $\infty$ " symbol represents one-to-many relationship. The relationships between various tables of the database are shown in the Figure 3.1 as below.

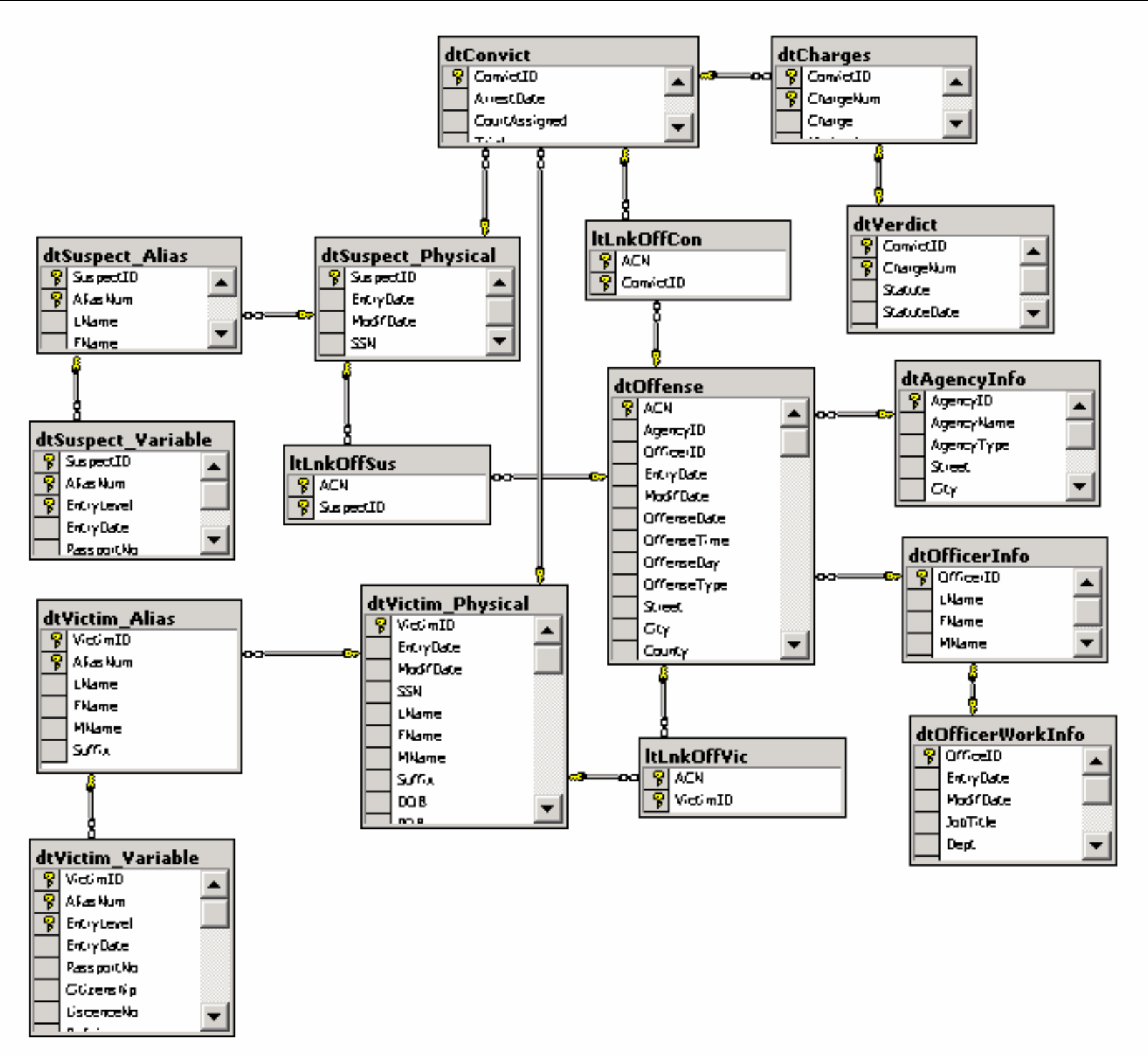

Figure 3.1: Database Diagram 


\section{USER INTERFACE DESIGN AND IMPLEMENTATION}

\subsection{Introduction}

This chapter describes the design and implementation of the user interface. The task was to create Data Mining techniques on the query table that was extracted from the crime database. The table can be searched with tools such as the Search Engine, Expert Search or with the Data Mining techniques. The forms (front end) were designed in ASP.NET, thus giving the user Web-based applicability. Moreover, a Server (Windows) based application were implemented that enabled user to use WEKA for visualization of data.

\subsection{Query Design}

Querying application was designed in "Structured Query Language" and was primarily of "Select" type. The outcome of query was displayed with the help of "Data Grid". The user had a choice of selecting:

a. One or all fields along with their specific value.

b. User could assign conditions such as AND, OR, NOT and its combinations to each of the fields.

Based on user input a run time query is generated and that will be sent through the "Data Adapter" to the database and the outcome of the query displayed. 


\subsection{Query Implementation}

The user can choose different fields, with condition and value selection. Figure 4.1 shows the user selected "Year" as 2005 and on pressing the "Search" button, the generated SQL query as well as the outcome are displayed.

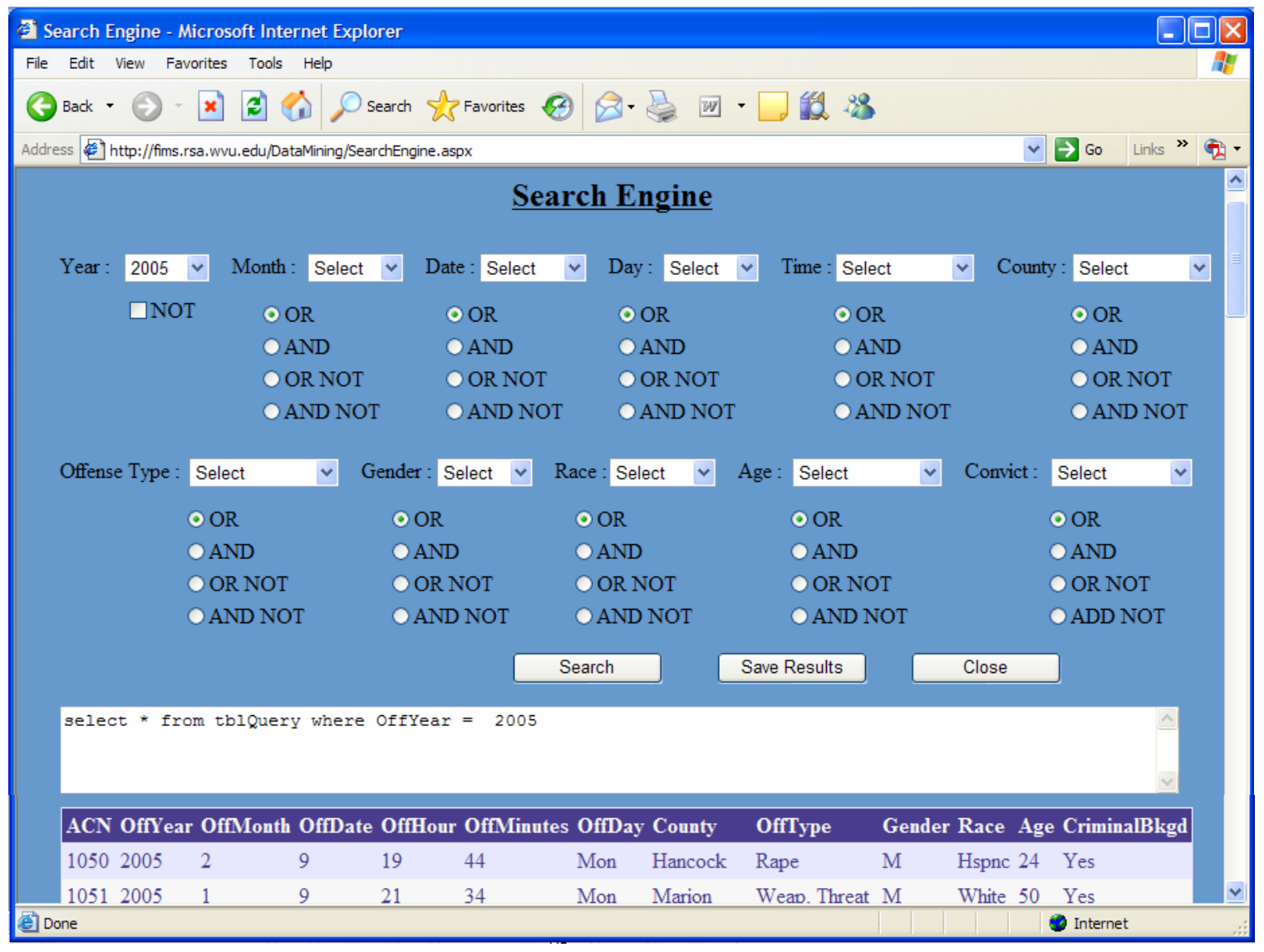

Figure 4.1: Search Engine

The Search Engine was able to generate basic / general queries and displayed the results that were queried by the user. But, it was unable to search multiple and simultaneous "If" statements (queries). Also, it was unable to offer multiple selections on one (same) field. These issues were primarily due to the user interface and data display constraints. 
For that, a better user interface was designed and implemented. With this, the user had the flexibility to query the database with complex queries and also view only the desired information.

\subsection{Modified Query Implementation}

The modified query scheme, "Expert Search" is shown in Figure 4.2.

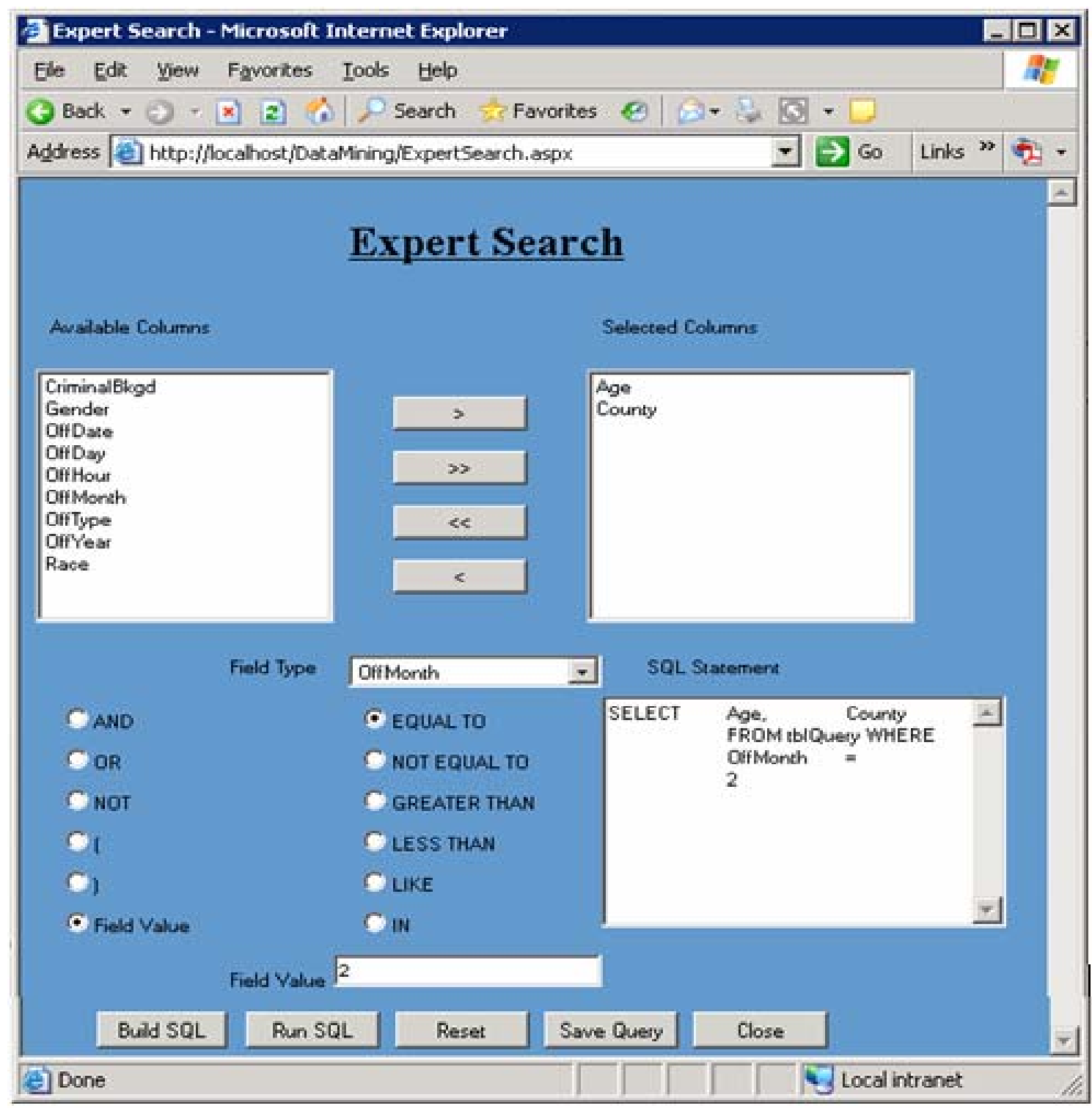

Figure 4.2: Expert Search 
The query was built based on the choice made by the user with the "Build SQL" button and later run once the user clicks on "Run SQL" button. The outcome of the query put forth by the user, with only the selected fields, is show in Figure 4.3. Expert Search requires significant knowledge of SQL on the part of the user.

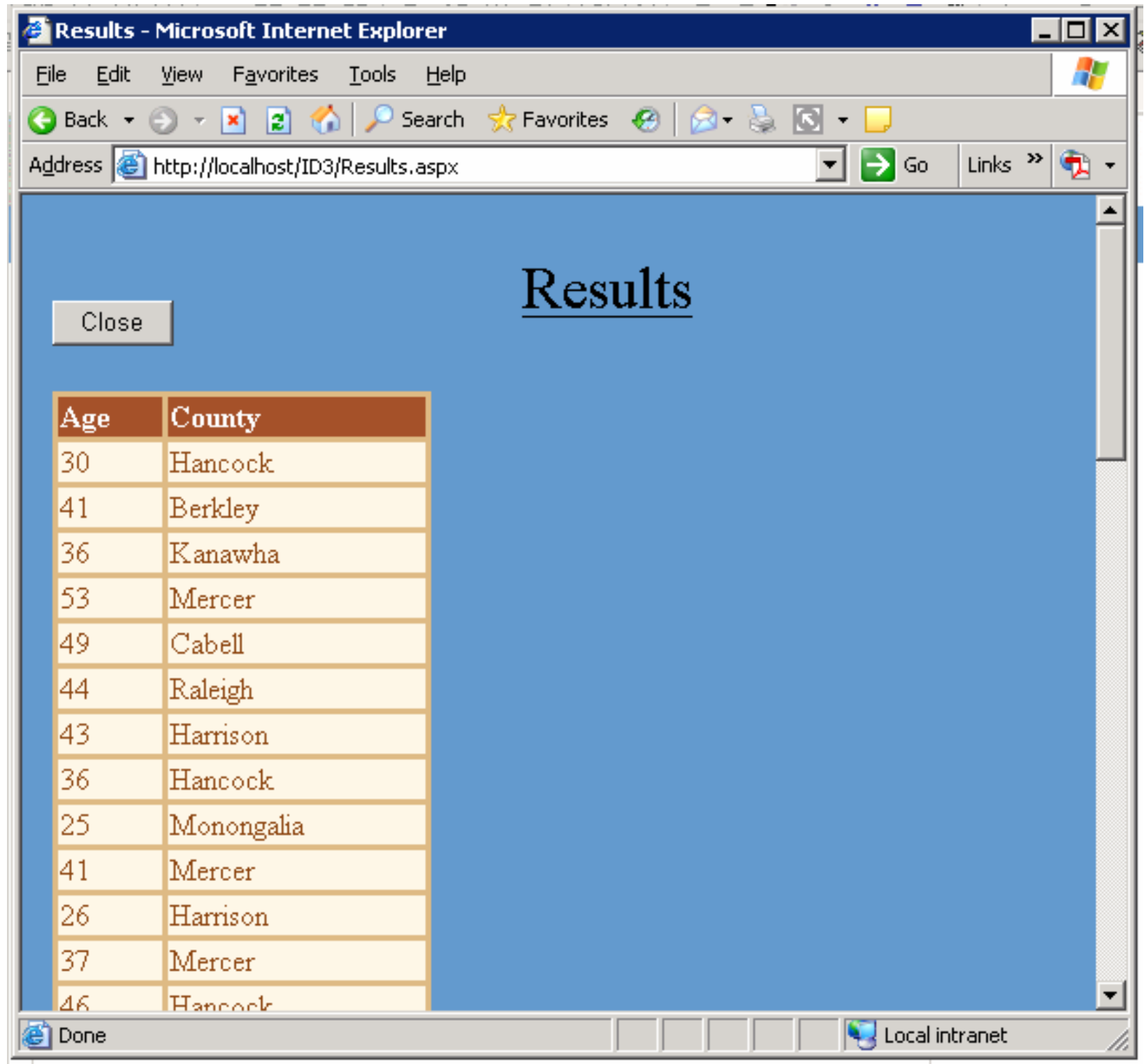

Figure 4.3: Result page of "Expert Search" 
Still, few issues pertaining to querying the database remain unresolved. For nominal values, the user has $\left(2^{n-1}-1\right)$ choices, where ' $n$ ' are the number of fields. That is, for 11 fields, the user would have 1023 choices to select from, without considering the "drop down" selections within each field or the conditions for each field. It is therefore overwhelming for the user without some initial leads. Moreover, the outcome was essentially a static picture and does not present the boundary conditions and / or over all picture to the user.

The above two issues are inherent to the searching method and there was no better method of querying the database. So, one has to look for other means of extracting information / knowledge from the data.

\subsection{Data Mining: Algorithm Selection}

The next level for information extraction is, moving from querying the data to mining it. One might recollect that, quite a few algorithms could be applied to mine the Query Table; as a matter of fact, most of the algorithms can mine the data. Thus, one must select appropriate algorithm, from the pool that was described earlier. However, the selection will depend on the type of data, the final objective and most importantly the kind of application of data, planned by the analyst.

From the Query Table (Section 3.7) it is known that the data are collection of nominal fields with no dependent variables or predefined groups. This rules out the Statistical and Neural Network based algorithms as they primarily work on training dataset with some sort of "dependent-independent" relationship to build the model. The Distance Based algorithms (Clustering) were difficult to apply and would further require significant changes to the existing data table to be applied effectively. This renders them practically infeasible.

Association Rules and Decision Rules / Trees show promise for our Data Mining application. These algorithms address the constraints put forth by the Query Table. Moreover, the outcome is directly seen by the end user and would not need further processing or interpretation. 


\section{Association Rules}

The Association algorithm consists of three main functions, 1) Search Engine, 2) Item Set Generator, and 3) Pruning Algorithm. The Item Set Generator generates a combination of items from the given set. This is then used with help of Search Engine to search for similar patterns through the database. The combinations that have frequency below the desired level are pruned by the Pruning Algorithm. Moreover, the Item Set Generator and Pruning Algorithm work together such that all future instances of the combinations already pruned are automatically pruned. Thus, the solution contains a set of association rules derived from the dataset. One serious drawback of the Association technique is that they work only with nominal data, though this drawback can be overcome by using coding techniques.

For example, shown in Table 4.1 is a Level -1 set of items that are available in a store. These five items are being considered to find an association relation, if any, between them.

\begin{tabular}{|l|l|l|l|l|}
\hline \multicolumn{4}{|c|}{ Table 4.1: Level-1 item set } \\
\hline Beer & Bread & Jelly & Milk & PeanutButter \\
\hline
\end{tabular}

The data available for the analysis are a transactional dataset as observed in Figure 4.2 , where $\mathrm{t} 1$ to $\mathrm{t} 5$ and so on are the transactions. For each transaction there is set of items purchased from the store.

\begin{tabular}{|c|l|}
\hline \multicolumn{2}{|c|}{ Table 4.2: Transaction Data } \\
\hline Transaction & \multicolumn{1}{c|}{ Item } \\
\hline t1 & Bread, Jelly, PeanutButter \\
\hline t2 & Bread, PeanutButter \\
\hline t3 & Bread, Milk, PeanutButter \\
\hline t4 & Beer, Bread \\
\hline t5 & Beer, Milk \\
\hline$:$ & $:$ \\
\hline
\end{tabular}

In essence, the Association algorithm creates various combinations of the item set and runs a frequency check through the entire database. One has to specify a lower bound for the frequency below which the items sets would be pruned. The lower bound is 
usually is terms of Minimum Support and Minimum Confidence. Based on this different combinations of items are pruned. Thus, one is left with the high frequency item combinations.

The Table 4.3 shows different combinations of the item or item sets that are being studied as well as the frequency of each combination. As explained one can select high frequency item combinations that will form the basis for Association Rules.

\begin{tabular}{|l|c|l|c|}
\hline \multicolumn{5}{|c|}{ Table 4.3: Item set with frequencies } \\
\hline Set & Frequency & Set & Frequency \\
\hline Beer & 40 & Beer, Bread, Jelly & 0 \\
\hline Bread & 80 & Beer, Bread, Milk & 0 \\
\hline Jelly & 20 & Beer, Bread, PeanutButter & 0 \\
\hline Milk & 40 & Beer, Jelly, Milk & 0 \\
\hline PeanutButter & 60 & Beer, Jelly, PeanutButter & 0 \\
\hline Beer, Bread & 20 & Beer, Milk, PeanutButter & 0 \\
\hline Beer, Jelly & 0 & Bread, Jelly, Milk & 0 \\
\hline Beer, Milk & 20 & Bread, Jelly, PeanutButter & 20 \\
\hline Beer, PeanutButter & 0 & Bread, Milk, PeanutButter & 20 \\
\hline Bread, Jelly & 20 & Jelly, Milk, PeanutButter & 0 \\
\hline Bread, Milk & 20 & Beer, Bread, Jelly, Milk & 0 \\
\hline Bread, PeanutButter & 60 & Beer, Bread, Jelly, PeanutButter & 0 \\
\hline Jelly, Milk & 0 & Beer, Bread, Milk, PeanutButter & 0 \\
\hline Jelly, PeanutButter & 20 & Beer, Jelly, Milk, PeanutButter & 0 \\
\hline Milk, PeanutButter & 20 & Bread, Jelly, Milk, PeanutButter & 0 \\
\hline & & Beer, Bread, Jelly, Milk, PeanutButter & 0 \\
\hline
\end{tabular}

Small item sets can be managed by simple logic or code. But the ones with large item sets require use of advance algorithms such as Apriori, CDA etc. Just as we saw a Level-1 item set, Table 4.4 shows a Level-2 item set where one can have combinations based on both field and field value.

\begin{tabular}{|l|l|l|l|l|}
\hline \multicolumn{5}{|c|}{ Table 4.4: Level-2 item set } \\
\hline Type & American & Italian & Mexican & Beverages \\
\hline ForHere & Burger & Pasta & Burrito & Soda \\
\hline ToGo & Sandwich & Pizza & Quesadilla & Shakes \\
\hline & Fries & & & Coffee \\
\hline
\end{tabular}


This table represents an actual scenario where Data Mining is useful for finding association rules. A logic similar to this was developed that can find association between different items but in paired form. Moreover, the complexity of algorithm was reduced by selecting only the first three field values having high frequency of occurrence.

\section{Decision Rules}

Decision rules, also called as Decision Trees, help with decisions that enable classification of a new unclassified dataset in an easily interpretable way. They are very easy and efficient way of mining the databases and work irrespective of the database size. They used to suffer from missing values and continuous data; which are now pruned and imputed. Also, most algorithms ignore correlations and interactions in data [2]. The leaves represent classifications, while branches represent conjunction sets of attributes that lead to classifications.

Attributes that have been incorporated higher in the tree are excluded, so that any given attribute can appear at most once along any path through the tree. This process continues for each new leaf node until either every attribute has already been included along this path through the tree, or all elements associated with this leaf node have their score function (entropy) as zero.

For example, Table 4.5 shows set of factors that determine the Credit Score of an individual.

\begin{tabular}{|l|l|l|l|l|l|}
\hline \multicolumn{7}{|c|}{ Table 4.5: Factors for determining credit score - Stage I } \\
\hline Credit Score & Bank Balance & Age & Sex & Job Title & Race \\
\hline Average & $>\$ 10,000$ & $>35$ & Female & Entrepreneur & Asian \\
\hline Bad & $\$ 10,000>\&>\$ 5,000$ & $35>\&>24$ & Male & Manager & Black \\
\hline Good & $\$ 5,000>$ & $24>$ & & Worker & Caucasian \\
\hline
\end{tabular}

Now, the Decision Rules algorithm finds out a Field and Filed Value combinations that maximizes the score function, which in our case can be Entropy or Gain, and that is the point of first split. Let's say from the dataset of 1000 entries, attribute Job Title $=$ "Manager" has maximum gain of 700 entries, so is the point of first split; this will 
generate two branches from the root which is the dataset based on condition of split. The new set of factors is shown in Table 4.6.

\begin{tabular}{|l|l|l|l|l|}
\hline \multicolumn{5}{|c|}{ Table 4.6: Factors for determining credit score - Stage II } \\
\hline Credit Score & Bank Balance & Age & Sex & Race \\
\hline Average & $>\$ 10,000$ & $>35$ & Female & Asian \\
\hline Bad & $\$ 10,000>\&>\$ 5,000$ & $35>\&>24$ & Male & Black \\
\hline Good & $\$ 5,000>$ & $24>$ & & Caucasian \\
\hline
\end{tabular}

Let's say the next two splits are for Age $=">35$ " and "Bank Balance $=">$ $\$ 10,000$ ", with gain of 400 and 250 entries respectively, and, for Sex and Race the gain in zero. Thus, a tree with following conditions is generated.

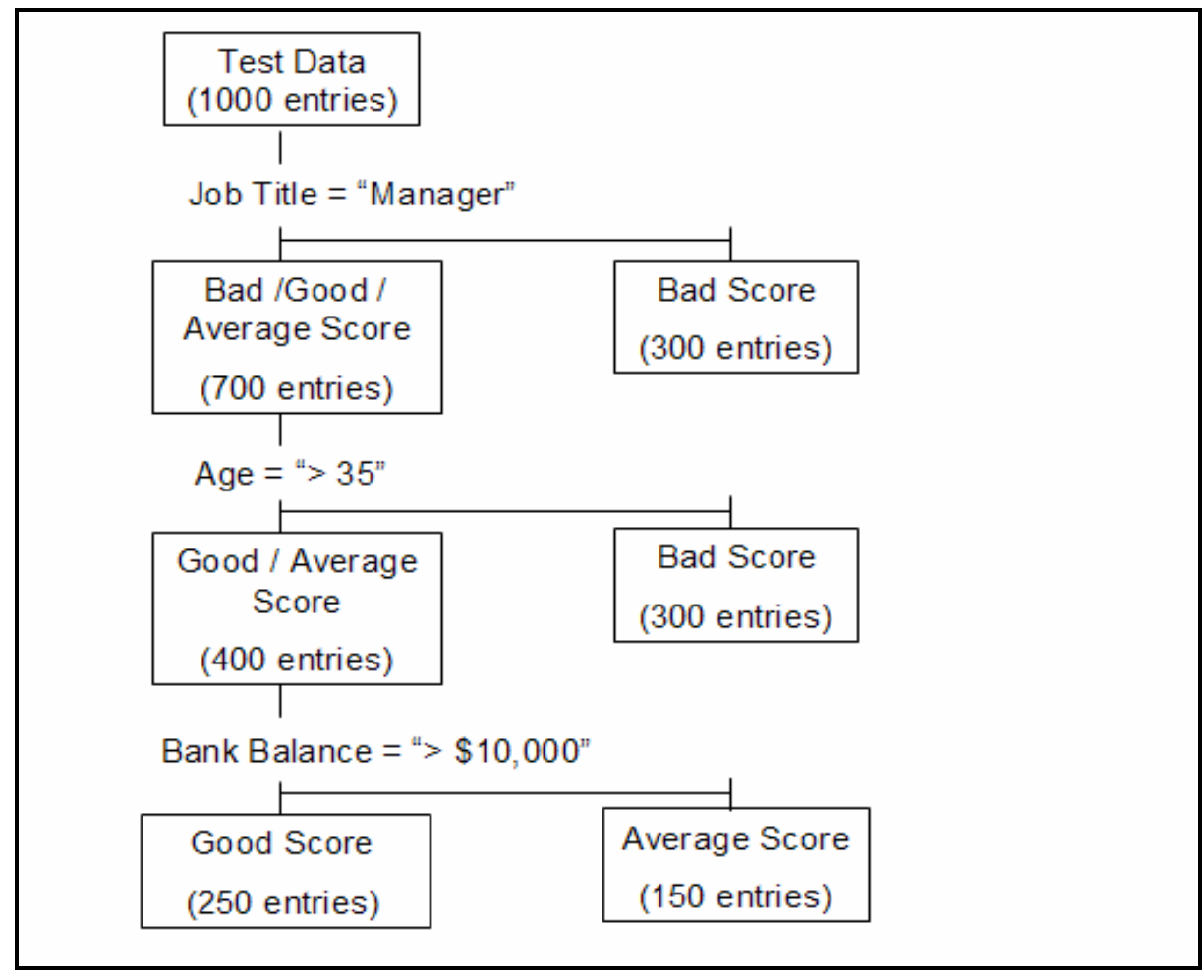

Figure 4.4: Good Credit Score Tree

This, tree is itself the conditions or decision rules for Good Credit Score. Decision rules similar to the example above were generated by implementing a parallel logic, the criteria for decisions being frequency of occurrence of a particular "Field-Value" combination. 
It should be noted that one would use the algorithms in essence / logic along with DMQL concept (Section 2.7 - Page 30). All advanced or commercially available software use better algorithms and make use of Data Visualization to display the results.

\subsection{Association Rules}

In Association Rules, the user will have to select the fields from the database on which he wishes to mine the Query Table. For example, in Figure 4.5, the user selected "OffDay" (Offense Day) and "OffType" (Offense Type) to find associations. After pressing "Run" button, the generated output shows association between different days and offense along with frequency of occurrence.

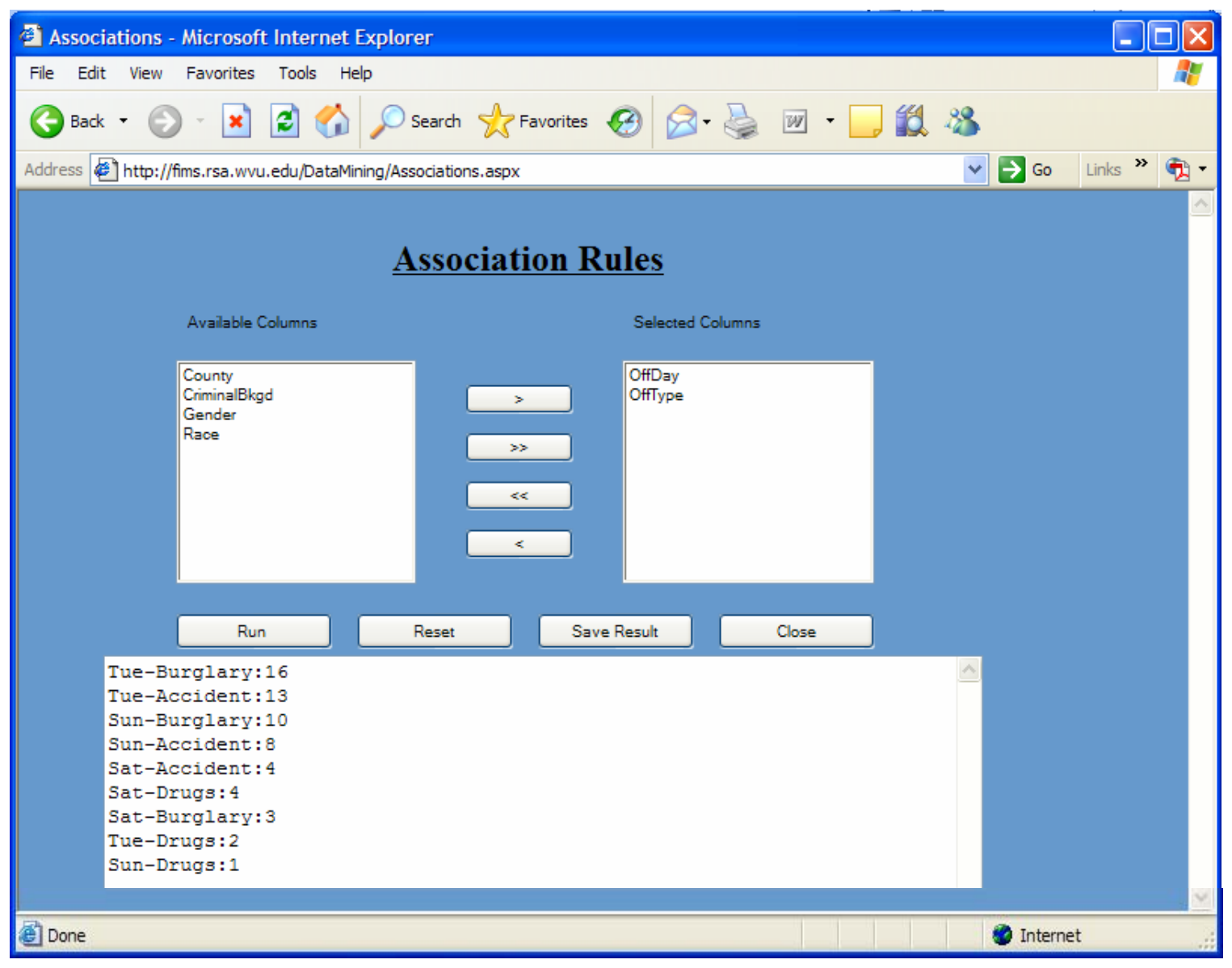

Figure 4.5: Association Rule 


\subsection{Decision Rules}

The Decision Rules algorithm implementation is displayed in Figure 4.6, where, the user selected the Field and Field-value combination as "OffDay" and "Sat". Also, he selected fields "OffType" and "Gender" to find out the Decision Rules. After pressing "Run" button, the generated output points out the frequency of occurrence particular offense and involvement of specific gender on Saturday. This kind of analysis can help in decision making in many real world scenario.

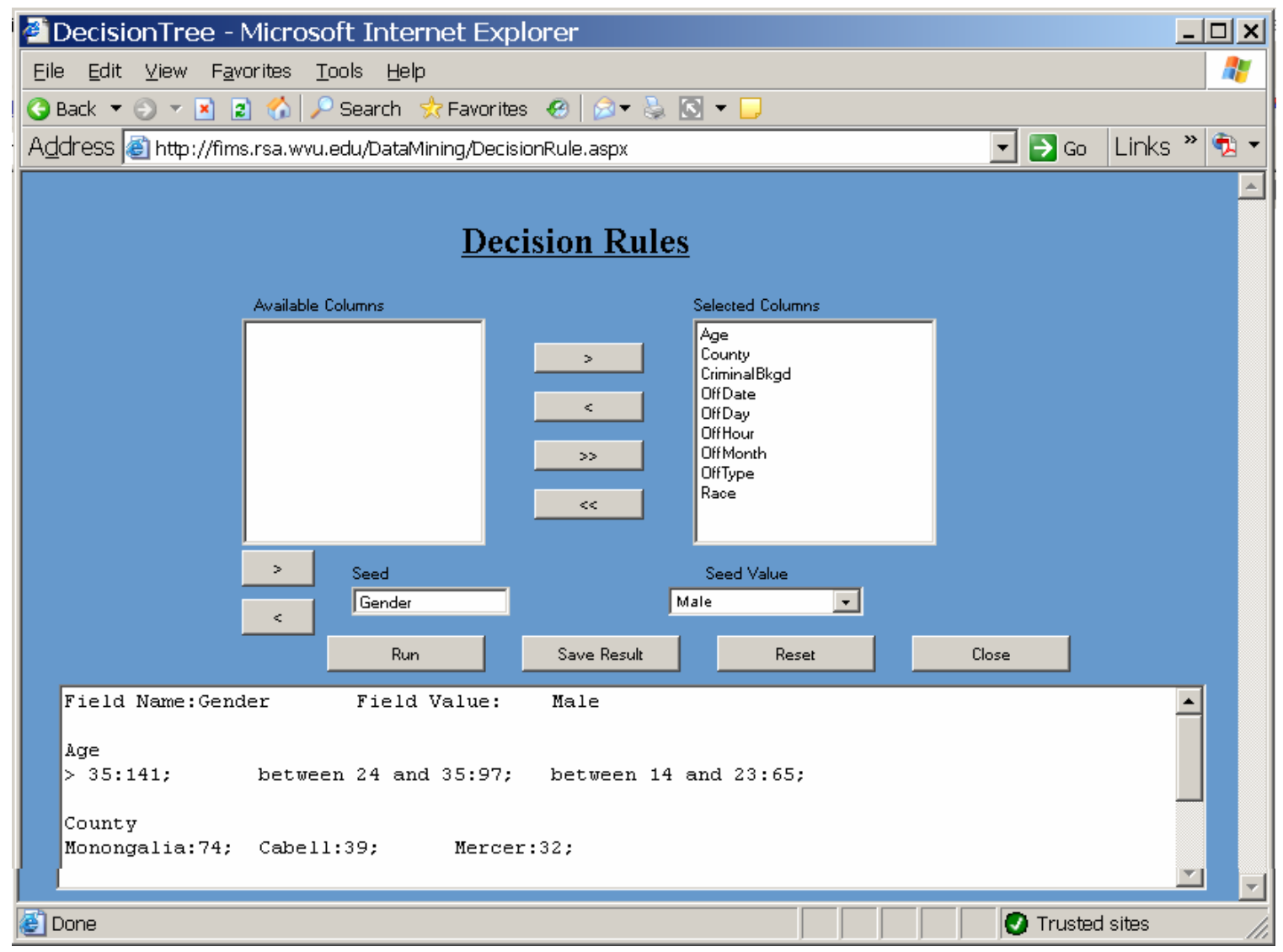

Figure 4.6: Decision Rule 


\subsection{Result Page}

The results of all the techniques are summarized in the "Result Page", as displayed in Figure 4.7 below. This included storing the queries for the Searching procedures and the results for the Data Mining procedures respectively. This can be stored in the database by the user as per the requirement.

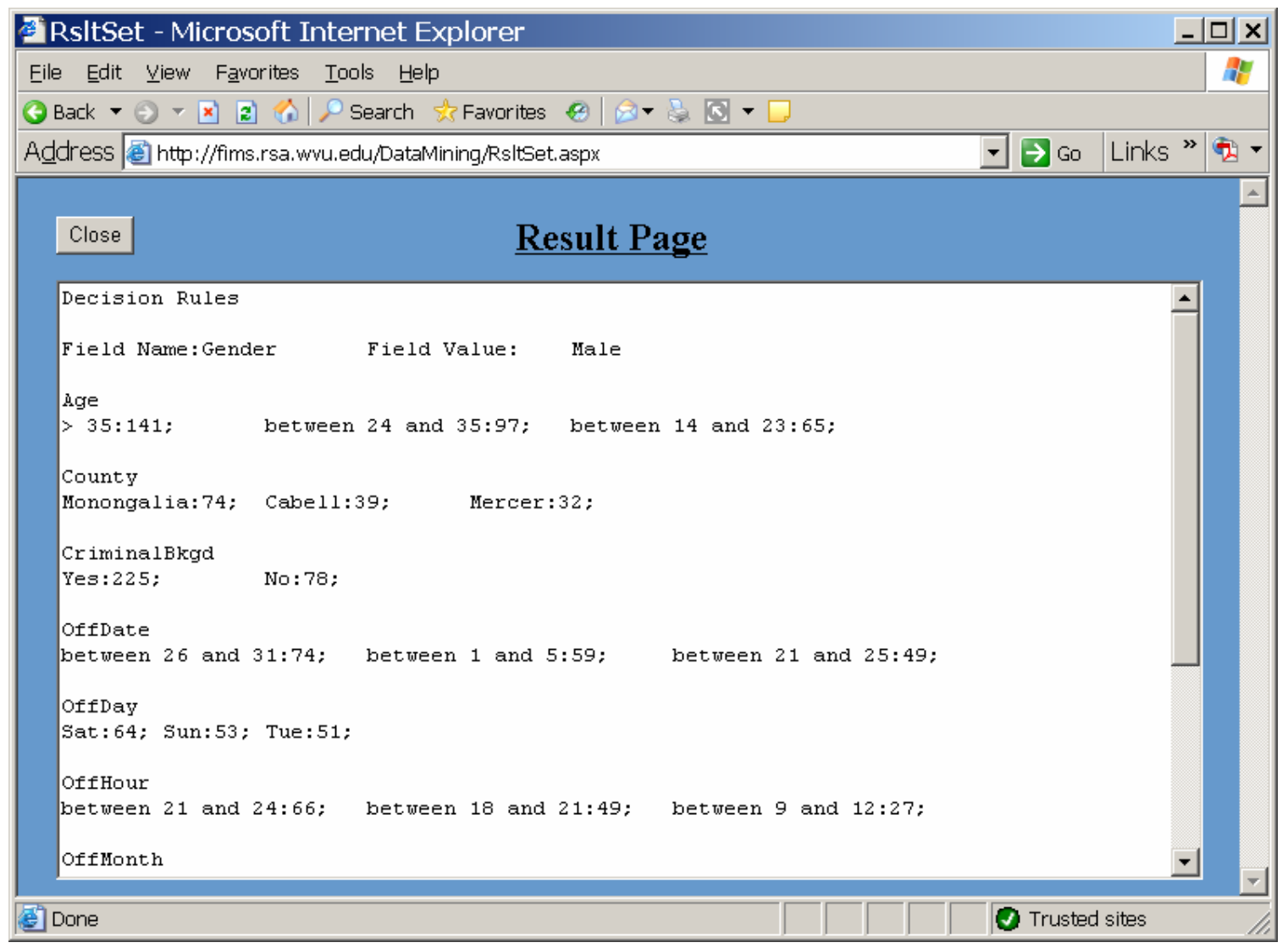

Figure 4.7: Result Page 


\subsection{Navigation Page}

For the user to toggle between the various data search / mine operations navigation page, called "Data Mining Tools" was created. The user can click on a button and the user interface as discussed earlier is presented. Also, "Generate ARFF File" button is provided. This generates an ARFF file that will allow the user to use other Data Mining tools. The user interface for the same is shown in the Figure 4.8.

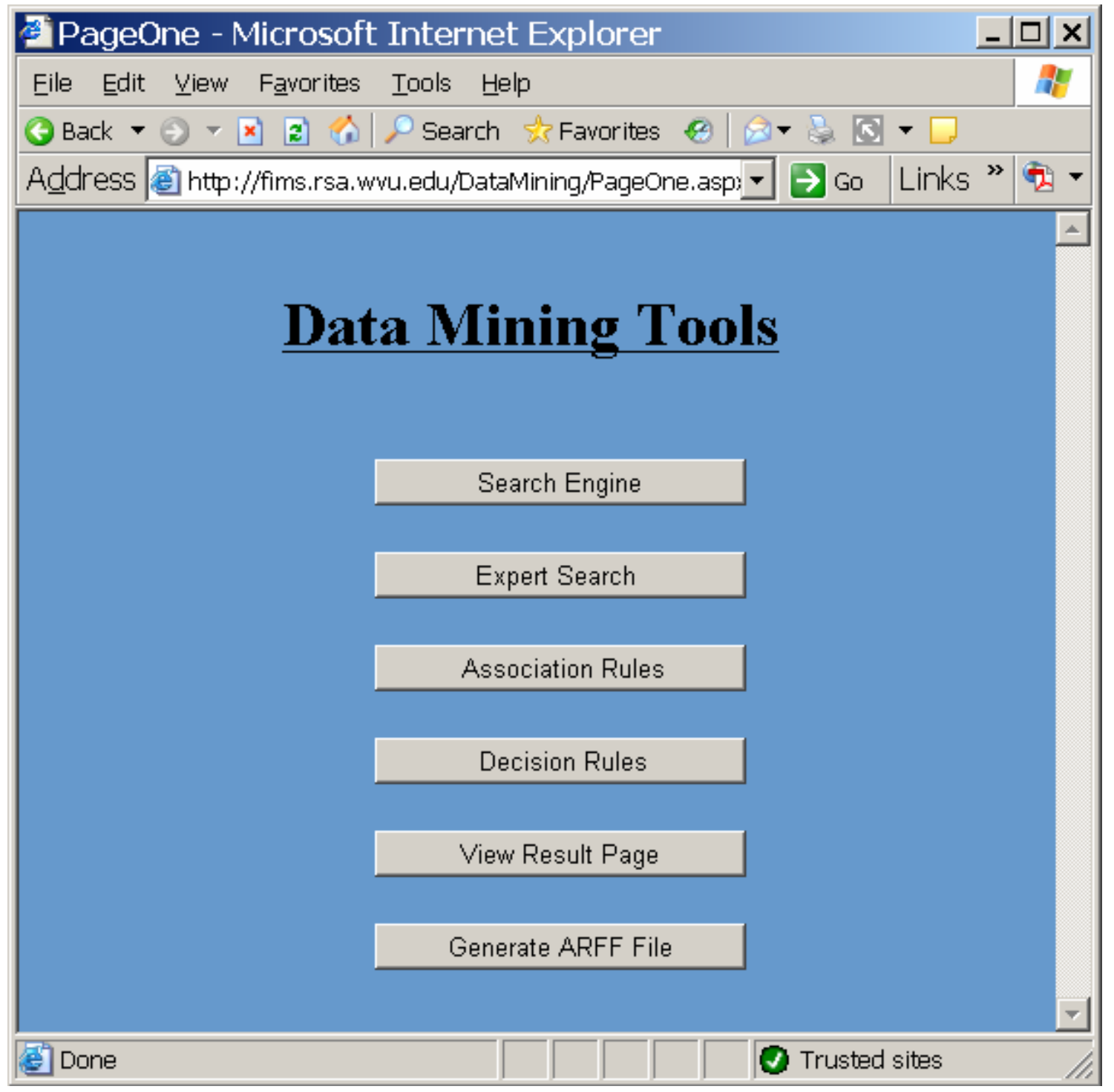

Figure 4.8: Navigation Page - "PageOne". 


\subsection{Other Data Mining Tools}

WEKA is another prototype Data Mining tool available over the Internet. This is being developed by The University of Waikato, New Zealand [20]. Though it is implemented primarily in Java, recently many more computer languages have been added to it. WEKA is a shell command based program. Therefore it cannot be directly executed on the Web. The user has to create a file in Attribute Related File Format (ARFF) file as shown in Figure 4.9. The ARFF file can then be input to the WEKA program.

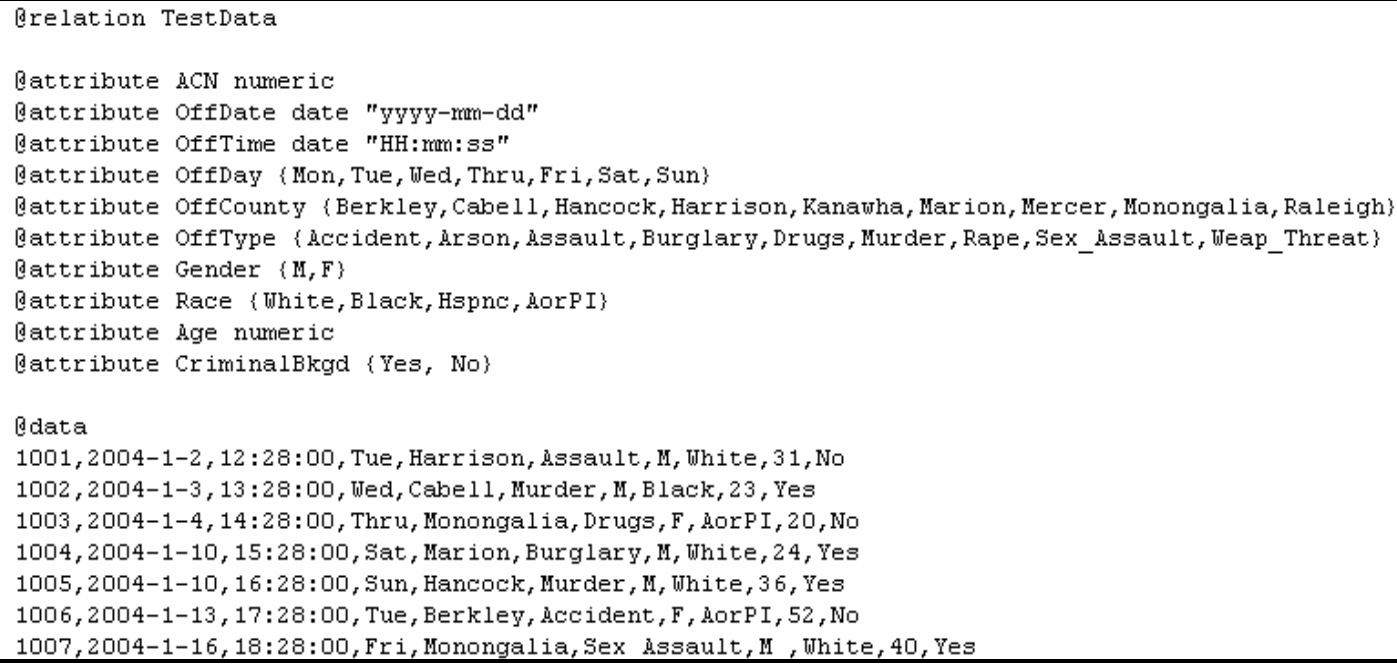

Figure 4.9: Test Data in ARFF.

The above approach provides a generalized way to study the database using variety of algorithms. 
The server based model has button "WEKA" that generates an ARFF file, called "TestData.arff", dynamically from the query table "tblQuery". This will also open the WEKA front page as in Figure 4.10.

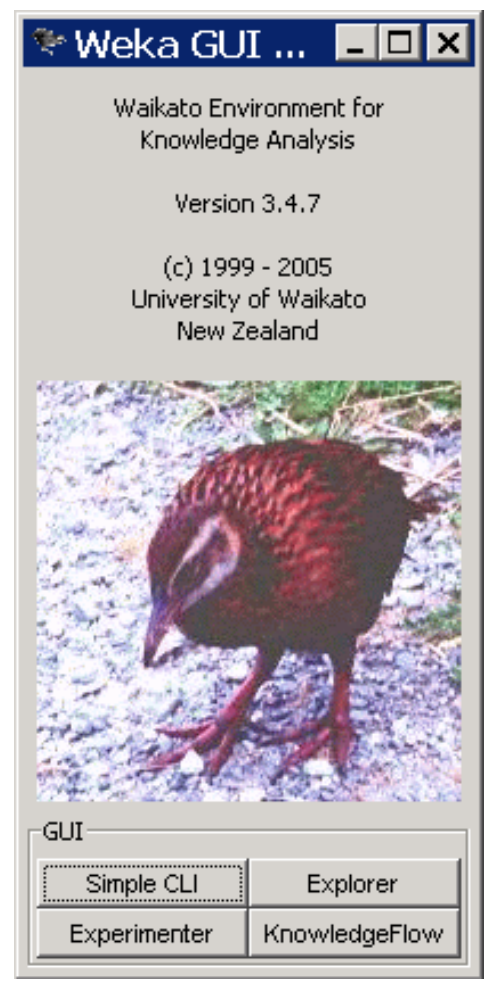

Figure 4.10: WEKA - Front Page 
The user has to click the button named "Explorer" and then open the file by just clicking the "Open File" button, as in Figure 4.11 and select the "TestData.arff" file.

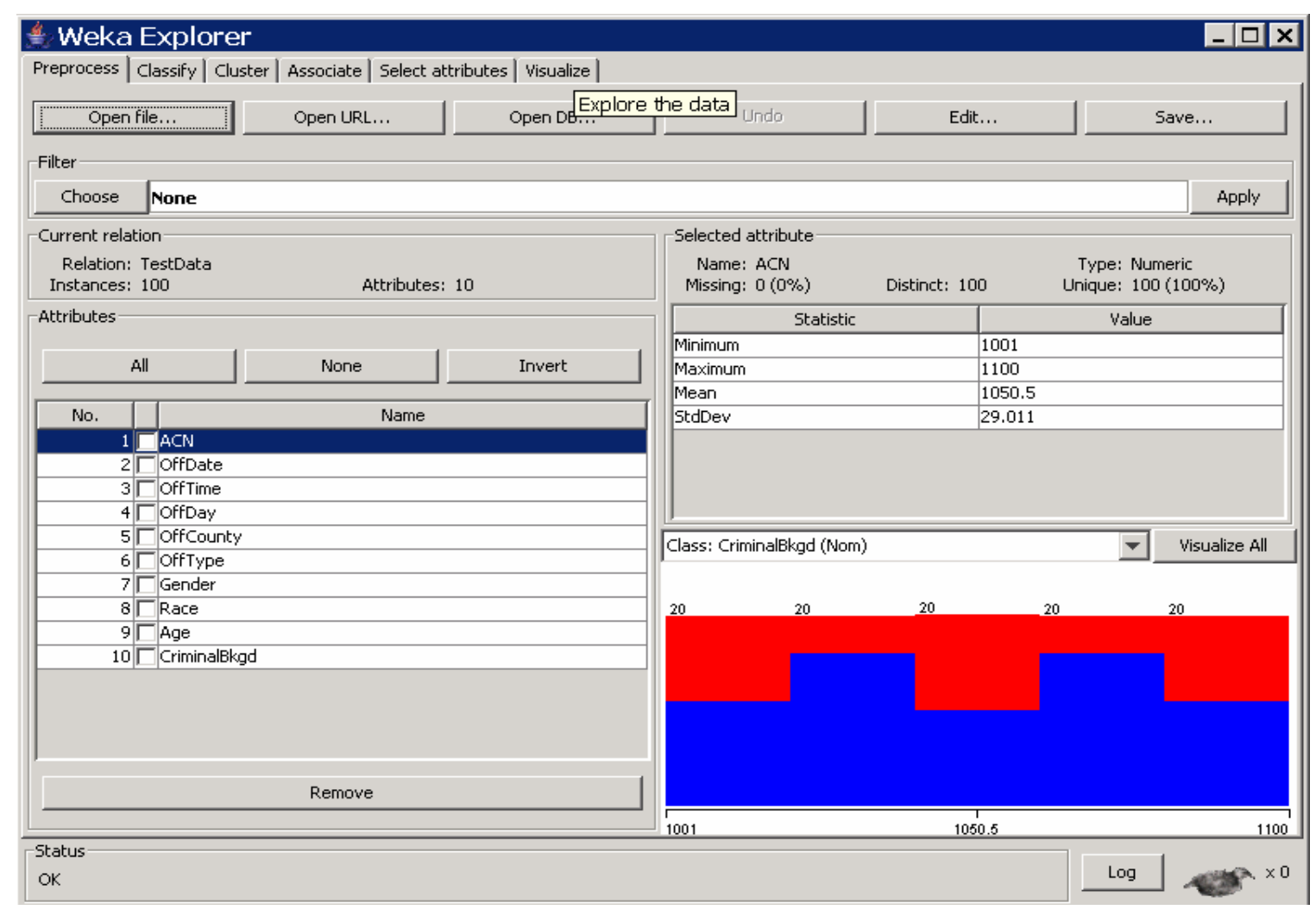

Figure 4.11: WEKA - Explorer Page 
Further, the user can choose the required fields and click on "Visualize" tab at the top of the application. He can view the confusion matrix of the data, as shown in Figure 4.12 .

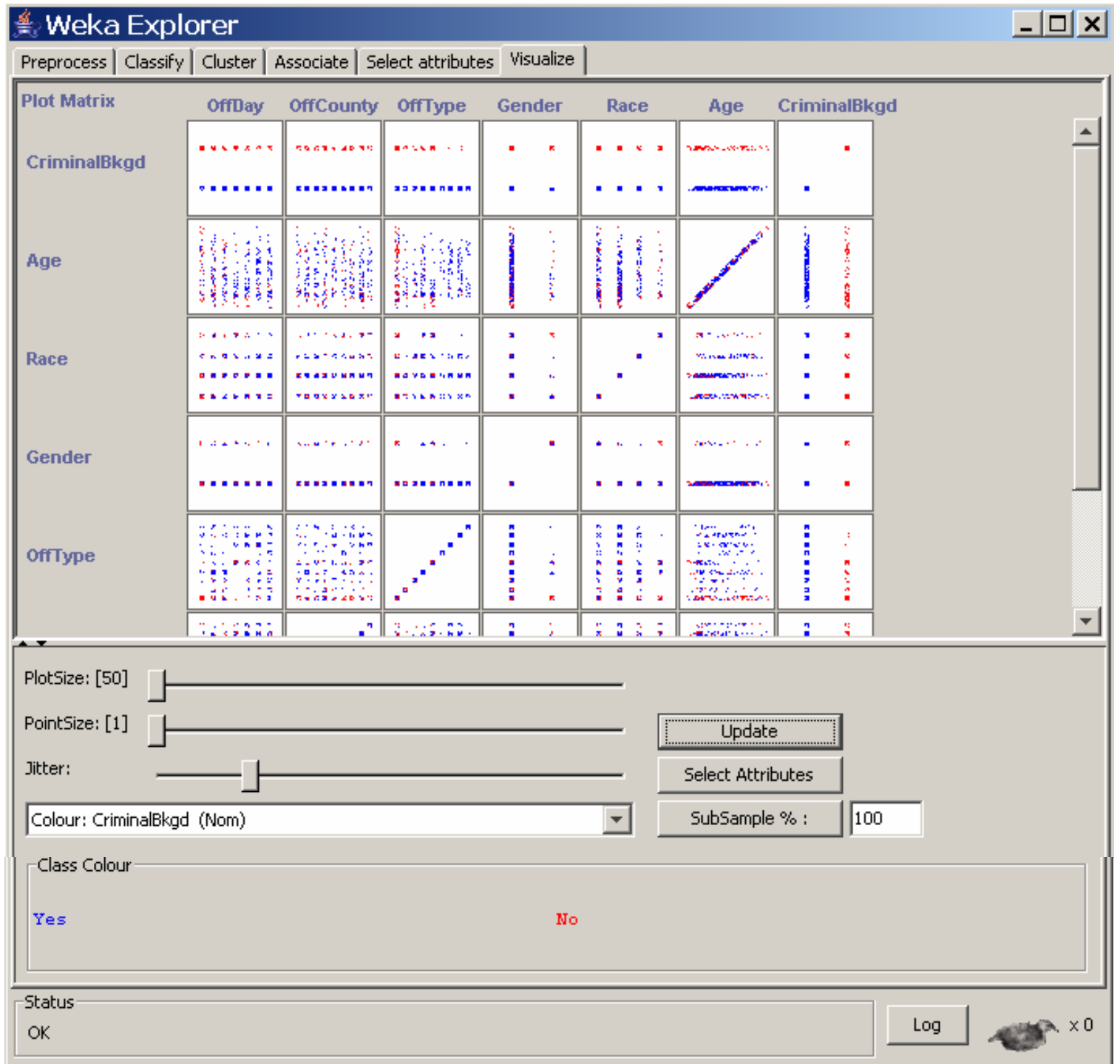

Figure 4.12: WEKA - Visualize (Confusion Matrix) 
By clicking on one of the graphs and by changing the $\mathrm{x}$-axis, $\mathrm{y}$-axis and color options one can view different trends and patterns in the data as in Figure 4.13. The jitter scale on the plot should be at maximum for best visualization.

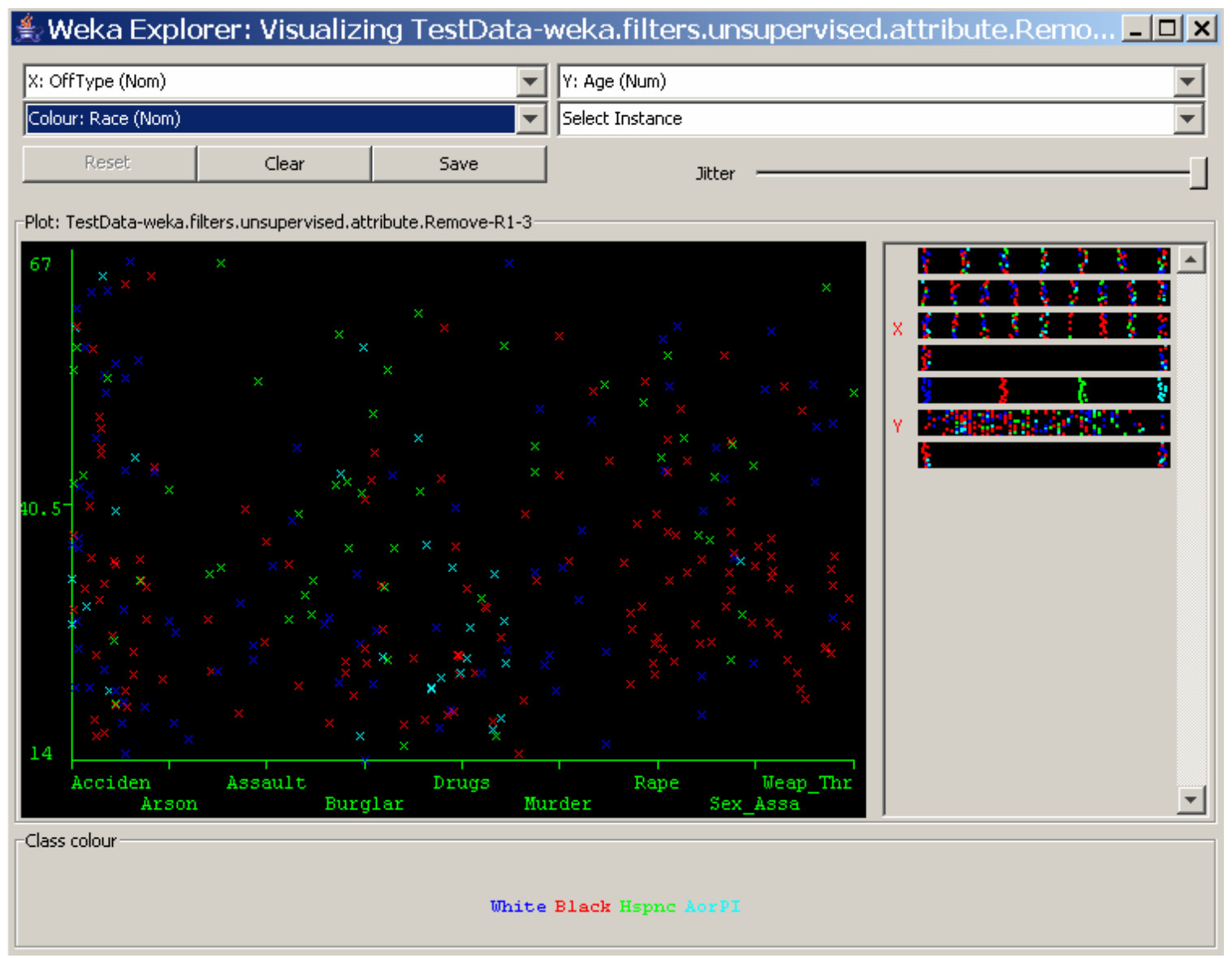

Figure 4.13: WEKA - Plot from confusion matrix 


\section{APPLICATION STUDY}

Data Mining Methodology was briefly described in Section 2.2. This chapter describes how that methodology was carried out for an application study. Similar to Data Mining methodology, the application study was also done in a phased manner.

\subsection{Business Understanding Phase}

The primary objective is to give to the end user (e.g., a crime investigator) a simple tool that will help him or her utilize the crime data to identify criminals and crime patterns. Even with minimal Data Mining knowledge one should be able to use the tool and generate meaningful results. Also, the tool should provide Web functionality so that the user can access it from anywhere and at any time.

Thus, the user will be provided with Web-based basic and advanced search techniques to query for specific inputs. Additionally, he or she will be offered suitable Data Mining techniques to generate vital information (e.g., crime-related leads) from the data. To visualize the data, he or she will use the WEKA-Experimenter.

\subsection{Data Understanding Phase}

The data required for Data Mining were not available due to security reasons, so major data fields used in the crime database were determined from the Web and other sources. However, a need for data (query) table for Querying and Data Mining was identified.

The data consisted of nominal, non-ordinal and/or null values with varied data types such as numeric, datetime, and varchar. It did not have "Dependent - Inependent" relationship nor was it available in any particular sequence. Moreover, the data contained 
13 fields with a maximum of 112 (crime types) possible values for a given field. Such data posed unique constraints concerning the selection of Data Mining techniques.

\subsection{Data Preparation Phase}

To develop the Data Mining Tool, the crime database was created, as described in Chapter 3, and populated. Initially, the "OffDate" and the "OffTime" fields of the tables were populated with the help of random numbers and the "OffDay" field was populated with the help of calendar. From the "Most Wanted" criminal data of West Virginia Police Dept. [21] and Bureau of Justice Statistics database [22], other fields such as "OffType," "Gender," "Race," and "CriminalBkgd" were populated. But these data was distributed in three tables "dtOffense," "dtSuspect_Physical," and "dtSuspect_Variable."

For ease of Data Mining application, the data was put into single data table called "tblQuery." This was done in two stages by selecting data from the database in middle tier and inserting the results back to the query table "tblQuery." The test data that were populated can be seen in Appendix A. Finally, the query table "tblQuery" was used for the Data Mining tool.

\subsection{Modeling Phase}

As described in Chapter 4, the searching algorithms as well as appropriate Data Mining techniques were implemented according to the established objective. This was done in ASP.NET to give Web-based functionality to the tool. But this tool lacked visual depiction of the results. To overcome this issue, the user was given an option to use the data with WEKA software at server end. Another aspect concerning the tool was that the Data Mining techniques used hard coded field descriptions to work with data, as it was necessary to reduce the complexity the algorithm. 


\subsection{Evaluation Phase}

The model was evaluated in two stages. At first, the model was run directly on the given data. The outcomes of all the techniques were directly validated by MS Excel and SQL Query Analyzer by running specific queries. The validation results were judged by actual numeric value of the output of the techniques. This ensured that the values generated were correct and the relation that is expressed is true. The second stage was to test the model against an external source. It was decided to test results of the model against WEKA and then compare the output. This testing was carried out, but the actual numeric values could not be confirmed, as WEKA does not report an outcome in a form similar to ones tool. The relationships represented by WEKA and the tool were found to be same during testing phase. Moreover, the code for dynamic conversion of test data into ARFF was checked by comparing file created by code with the actual physically created file.

\subsection{Deployment Phase}

This is the last stage of the Data Mining Process. Once the database and software was implemented and tested, the tool was put through a pilot run and further deployment. Often, steps (2) to (5) of the methodology are re-run for further refining the Data Mining Tool. For an application study, some patterns were embedded into the test data. In this study a pattern refers to relationship between data fields that have some relevance to crime. These patterns resemble actual patterns in a Data Mining scenario. The patterns that were embedded are:

a. Harrison County had a high rate of accidents.

b. Crime against women occurred mostly on weekends and was committed by older age group.

c. Drugs were consumed more during weekends by young men. 
d. Monongalia County had significant number of burglary and drug cases.

These patterns were placed in a very non-obvious way. A very low frequency of occurrence was maintained, such that the inherent noise in the data may overcome the intended patterns and one could get an altogether different and non-obvious pattern similar to real life scenario. An attempt was made to identify these patterns with the Data Mining Tool.

Figure 5.1 shows the implementation of the Deployment Phase. The Validation of the tool is only done initially during the pilot of the tool. Once implemented the user will select the tools based on the task. For Searching and Querying operation he will use the "Search Engine" and "Expert Search"; while to mine these data for non-obvious crime patterns the "Association Rules" and "Decision Rules" will be used. User may use searching tools to further query these data based on the mining results.

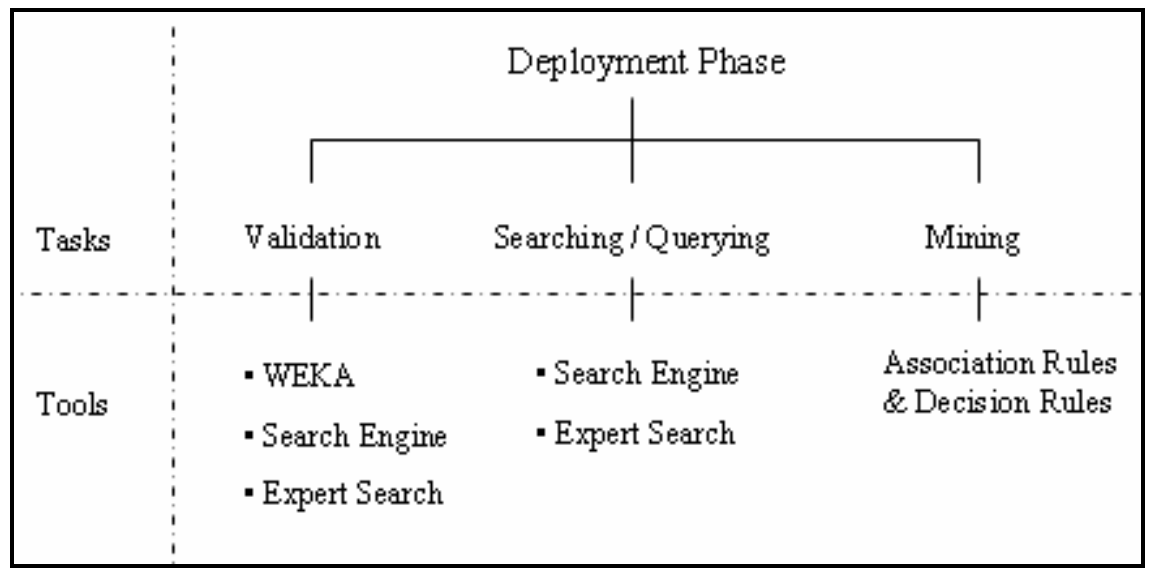

Figure 5.1: Tree for Deployment Phase

\section{Data Mining with Searching Tools}

The outcomes of the Search Engine were unable to identify any patterns in the data. The Expert Search also worked on similar lines, as initially there were no leads available. One faced an overwhelming number of combinations while using the two searching tools. 
When the patterns were specifically queried, even then the Search Engine was unable to clearly determine the conditions that govern them. While the Expert Search with a better interface could find the results, they were isolated or exact outcomes and did not clearly determine if they represent any patterns.

\section{Data Mining with Association Rules}

The Association Rules was used with selection of various combinations of the four fields - "OffDay," "OffType," "OffCounty," and "Race." They were:
a. OffDay - OffType - OffCounty - Race
b. OffDay - OffType - OffCounty
c. OffDay-OffType
d. OffDay - OffCounty

These combinations were randomly chosen. The other two field types, "CrimeBkgd" and "Gender," of the query table "tblQuery" were left out of the study as they had only two Field Values. By selecting them, the outcome would be biased, as these field values will split the data into two and always end up with higher frequency. Also, the numeric fields, such as "Age," "Date," and "Time" of Crime are excluded as they cannot be used for the Association Rules technique in their present form and coding them requires significant knowledge and input that was beyond the scope of the thesis.

The Association Rules technique selected the first three Field Values from each of the above Fields, with a high frequency of occurrence, and checked their combinations to find out associations in the data. The four fields "OffDay," "OffType," "County," and "Race" are selected by choosing each and clicking the right arrow key. When the "run" button is pressed, the outcome of association for the selected fields is displayed in the text box, as show in Figure 5.2. The complete outcome of the above textbox is displayed in Figure 5.3, while the outcomes for different field combinations are shown in Appendix C. 


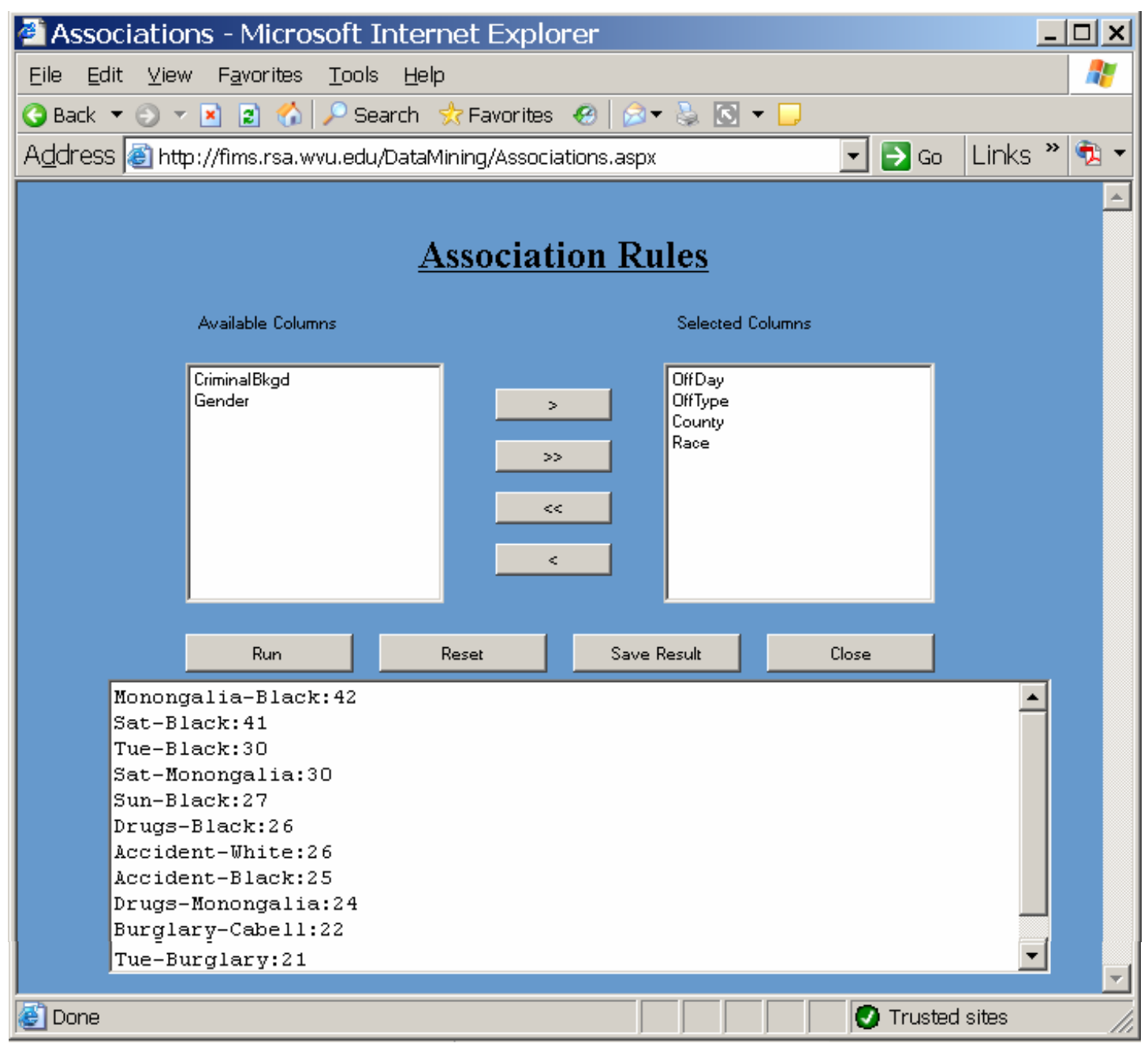

Figure 5.2: Association Rules with selected fields

\begin{tabular}{|ll|}
\hline Monongalia-Black & $: 42$ \\
Sat-Black & $: 41$ \\
Tue-Black & $: 30$ \\
Sat-Monongalia & $: 30$ \\
Sun - Black & $: 27$ \\
Accident - White & $: 26$ \\
Drugs - Black & $: 26$ \\
Accident - Black & $: 25$ \\
Monongalia - Drugs & $: 24$ \\
Cabell-Burglary & $: 22$ \\
Tue-Burglary & $: 21$ \\
& \\
\hline
\end{tabular}

Figure 5.3: Association Rules outcome 
The selective (top four associations) view of the Association Rules for various combinations is shown in Table 5.1.

\begin{tabular}{|c|c|}
\hline \multicolumn{2}{|c|}{ Table 5.1: Tabulated Outcome of Association Rule } \\
\hline Combinations & Selective Outcome \\
\hline \multirow[t]{4}{*}{ "OffDay," "OffType," "County," and "Race" } & Monongalia - Black \\
\hline & Sat - Black \\
\hline & Tue - Black \\
\hline & Sat - Monongalia \\
\hline \multirow[t]{4}{*}{ "OffDay," "OffType," and "County" } & Sat - Monongalia \\
\hline & Drugs - Monongalia \\
\hline & Tue - Burglary \\
\hline & Burglary - Cabell \\
\hline \multirow[t]{4}{*}{ "OffDay" and "OffType" } & Tue - Burglary \\
\hline & Tue - Accident \\
\hline & Sat-Drugs \\
\hline & Sun - Burglary \\
\hline \multirow[t]{4}{*}{ "OffDay" and "County" } & Sat-Monongalia \\
\hline & Tue - Cabell \\
\hline & Tue - Monongalia \\
\hline & Sun - Cabell \\
\hline
\end{tabular}

From the table, it was observed that most of the incidents in the data that have high association occur on Tuesdays and/or Weekends. For the first combination, "OffDay OffType - County - Race," it was seen that the associations mainly included just the Black race. The combination of "OffDay - OffType - County" showed association between Tuesday and Burglary, Saturday and Monongalia, Drugs and Monongalia, and Burglary and Cabell. The combination of "OffDay - OffType" showed associations on similar lines involving Tuesday with Burglary and Accident, Saturday and Drugs and Sunday and Burglary. While in the last combination, "OffDay - County," it was seen that Monongalia County was associated with Tuesday and Saturday, while Cabell was associated with Tuesday and Sunday. 


\section{Data Mining with Decision Rules}

The Decision Rules followed the Association as the Data Mining Tool. The field "OffType" was randomly selected and all the offenses or field values were selected one at a time. This "Field-Field Value" combination was then worked against other fields that were selected for generating the Decision Rules. The Figure 5.4 shows the outcome of the Decision Rules for Field Name = "OffType" and Field Value = "Accident."

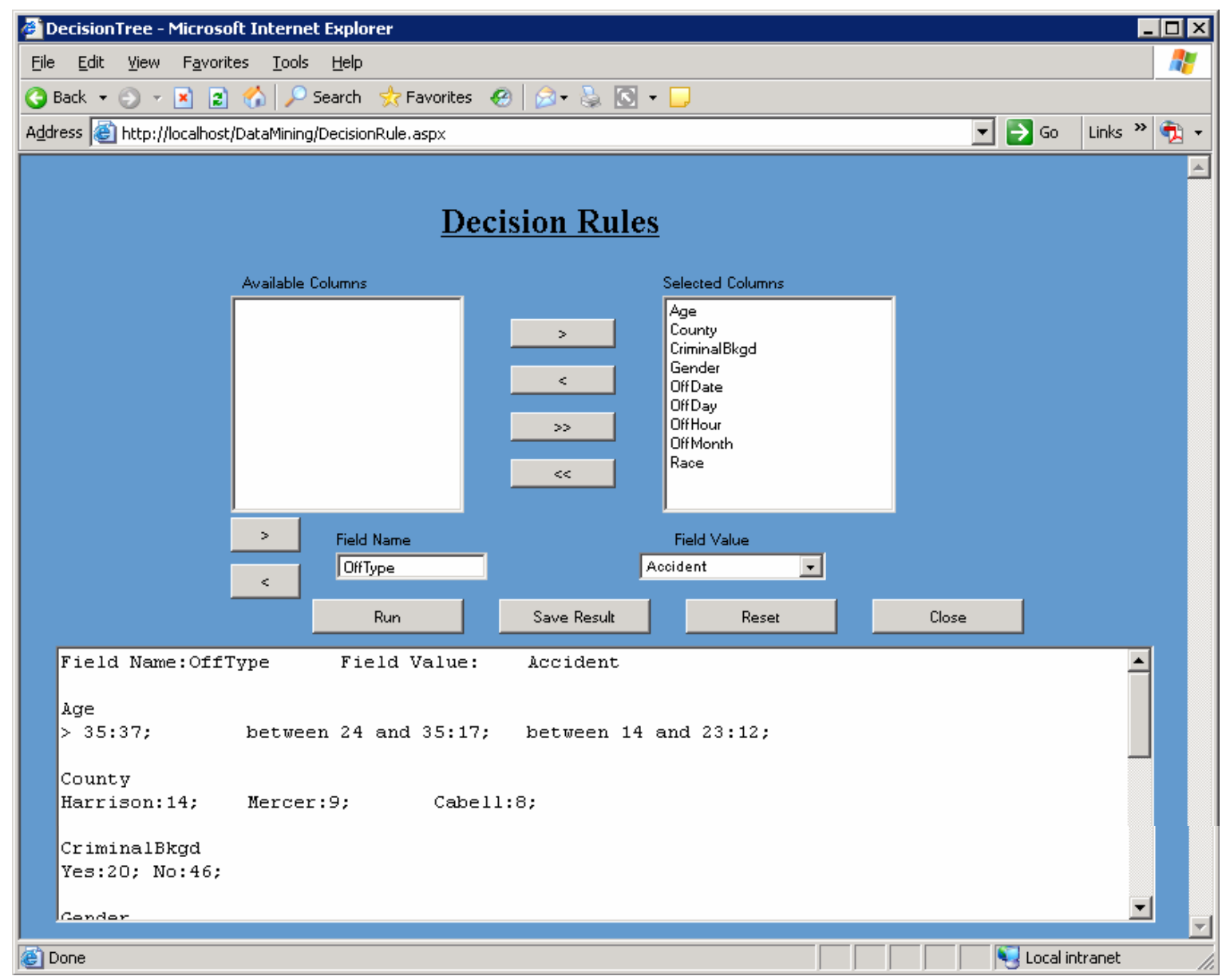

Figure 5.4: Decision Rules for OffType = "Accident"

The complete outcome of the above textbox is displayed in Figure 5.5, while the outcomes for different field combinations are shown in Appendix D. 


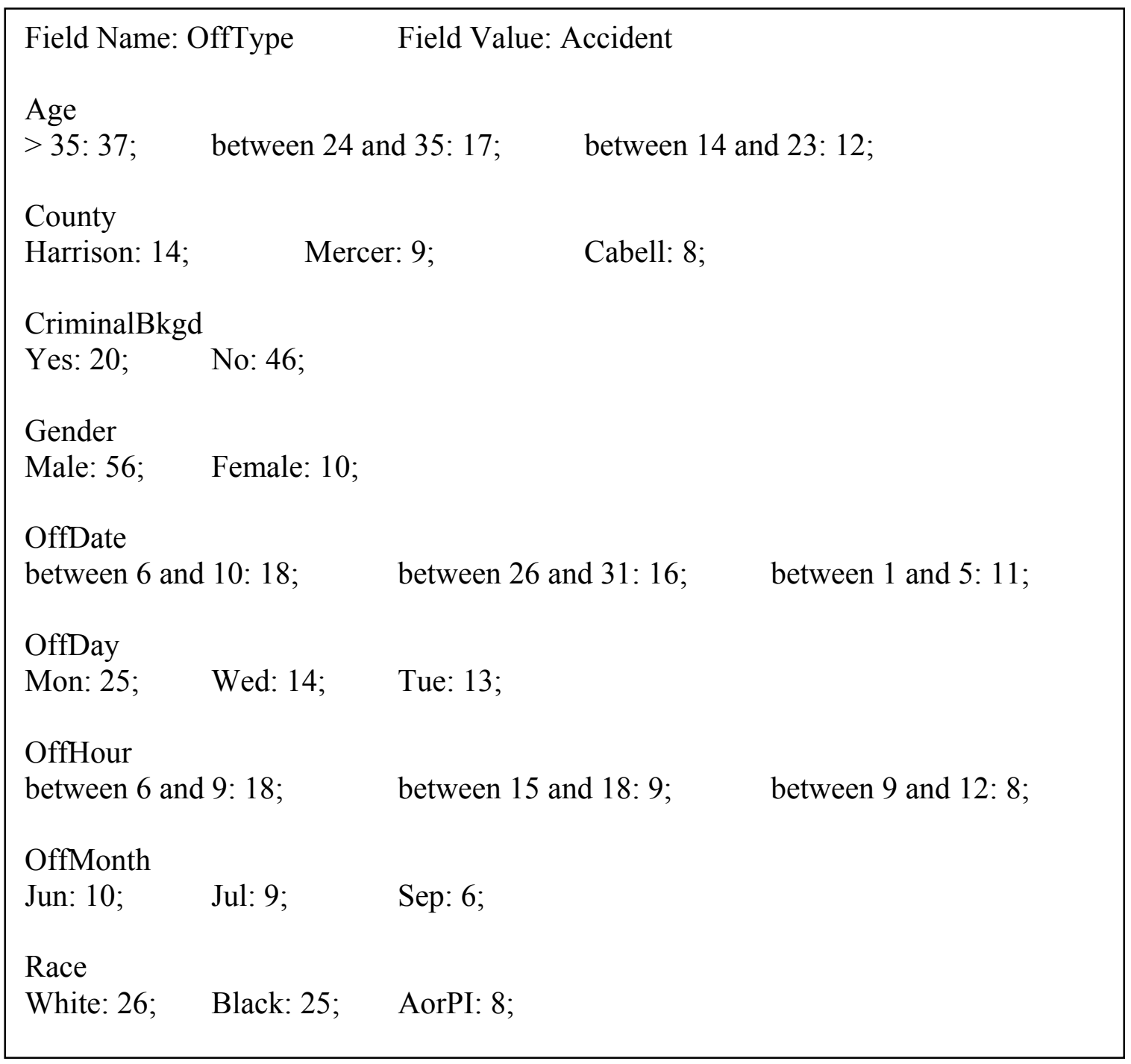

Figure 5.5: Decision Rules outcome

The technique finds the maximum frequency of occurrence of all field values of the selected fields with the Field-Field Value combination from the data table "tblQuery." Then, the top three occurrences for each selected field were listed as outcome of the Decision Rule. The outcomes for each Field Value or Offense Type were shown in Appendix D. The selective view of the outcomes, with significantly high occurrences from the group, is shown in Table 5.2. 
Table 5.2: Tabulated Outcome of Decision Rule

\begin{tabular}{|c|l|}
\hline Offense Types & Selective Outcome \\
\hline Accident & Age $>35$, County - Harrison, Day - Monday, Race - White \& Black \\
\hline Arson & Age between 24 \& 35, County - Harrison, Day - Sunday, Race - Black \\
\hline Assault & Age between $24 \&$ 35, Day - Sunday, Race - Black \\
\hline Burglary & Age $>24$, County - Cabell, Day - Tuesday \\
\hline Drugs & $\begin{array}{l}\text { Age between } 14 \& \text { 23, County - Monongalia, Day - Friday \& Saturday, } \\
\text { Race - Black }\end{array}$ \\
\hline Murder & Age $>35$, County - Marion, Day - Sunday, Race - Black \\
\hline Rape & Age $>35$, County - Monongalia, Day - Saturday, Race, Black \\
\hline Sex_Assault & Age $>35$, County - Monongalia, Day - Saturday, Race - Black \\
\hline Weap_Threat & $\begin{array}{l}\text { Age }>35 \text { and between 24 \& 35, County - Hancock, Day - Tuesday \& } \\
\text { Sunday, Race - Black }\end{array}$ \\
\hline
\end{tabular}

From the Table 5.2, the Decision Rules for each of the Offense types were observed. Most Crimes against women occurred on weekends and the offenders belonged to higher age group (35 to 45). Based on Age groups, namely between $14 \& 23$, between $24 \& 35$ and greater than 35, the offense type changed from Drugs, Arson and Assault to more serious ones such as Murder and Weapons Threat. Based on Race for most of the crime incidents, the Black population had maximum involvement while there are Asian or Pacific Islanders who were involved in Drugs-related offenses. While considering Day of offense, it was seen that Drugs offense and Crime against Women, were reported more, in the later half of the week, on Friday and Saturday respectively. Also, it was seen that on Monday, a greater number of Accidents occurred, while more Burglary incidents were reported on Tuesday. With County of Offense, it was observed that Monongalia County reported a greater number of Drug and Crime against Women incidents. Harrison County lead Accident- and Arson-related cases and finally Burglary, Murder and Weapon Threat were reported in Cabell, Marion, and Hancock counties respectively. 


\section{Interpretation of Data Mining Tools}

In the above sections, the outcomes of the two Data Mining Techniques were gathered in a selective manner. Those outcomes are interpreted in this section. The approach is to first compare the results of both the techniques and then figure out whether the selected Field Values indeed turn out to be a pattern. Moreover, the Decision Rules give us Age related outcomes, so those would not be compared but directly used for interpretation.

The Association Rules, from Table 5.2, showed only the Black and White race for crime. This can be attributed to the Test Data where $77.67 \%$ of the population was represented by these two races. From other combinations the ones with common Field Values were paired. For this the Field with more occurrences was selected as common field, which as per the Association outcome was Day of Offense. These pairs (links) are show below:
a. Tuesday - Burglary and Accident
- Cabell and Monongalia
- Black
b. Saturday - Monongalia
- Black
c. Sunday - Burglary and Accident
- Monongalia

There was also another single pair:

d. Drugs - Monongalia

The pairs identified above were then compared with the outcomes of Table 5.2. The commonalities found by comparison were:
A. Drugs - Monongalia - Saturday - Black
B. Burglary - Cabell - Tuesday 
Moreover, from the Table 5.2, by pairing based on the outcomes, another single pair was found:
C. Age Between $24 \& 35$ - Sunday - Black
- Assault
-Weap_Threat
D. Age $>35-$ Monongalia - Saturday - Black
- Sex_Assault
- Rape

The last four selected cases (from A to D) were then run specifically through the searching tools and their number of occurrence was reported in the Table 5.3.

\begin{tabular}{|c|l|c|}
\hline \multicolumn{3}{|c|}{ Table 5.3: Number of Occurrences of Combinations } \\
\hline S. No. & \multicolumn{1}{|c|}{ Combinations } & $\begin{array}{c}\text { No of } \\
\text { Occurrence }\end{array}$ \\
\hline 1 & Drugs - Monongalia - Saturday - Black & 8 \\
\hline 2 & Burglary - Cabell - Tuesday & 5 \\
\hline 3 & Age Between 24 \& 35 - Sunday - Black - Assault & 5 \\
\hline 4 & Age Between 24 \& 35 - Sunday - Black - Weap_Threat & 2 \\
\hline 5 & Age > 35 - Monongalia - Saturday - Black - Sex_Assault & 4 \\
\hline 6 & Age > 35 - Monongalia - Saturday - Black - Rape & 6 \\
\hline
\end{tabular}

It was observed that for the Drugs offense had the highest number of occurrences followed by Rape, Burglary, and Assault. The Weapons Threat reported just two incidents, so they would be pruned.

The outcome was then compared with the pattern (Page 67) that was planted into the test data of the query table "tblQuery." The Data Mining tool was not able to find the sub-pattern (a). This was selected in Table 5.2 but was not selected for further study as it neither match the relations in Table 5.1 nor formed pair in the same table. Also, the subpatterns (b) and (c) were identified by the Data Mining tool. For pattern (d), the tool could find the relation for the Drugs offense, but for the Burglary offense no relation was identified. Instead, the tool found a new relation shown in Table 5.3 - S. No. 2. These results were validated with the WEKA software. 


\section{Data Mining with WEKA}

The test data from table "tblQuery" were converted into ARFF format with a code specifically developed to dynamically access data from the database and convert them into an ARFF file. Thus, the generated file was input with WEKA software. The data were preprocessed with an unsupervised filter "Discretize -B 10-M -1.0-Rfirst -last" and then "Apriori" and "Tertius" classifiers (Associators) were used. Figure 5.6 shows the outcome for WEKA with Discretize filter and Tertius classifies with 6 attributes.

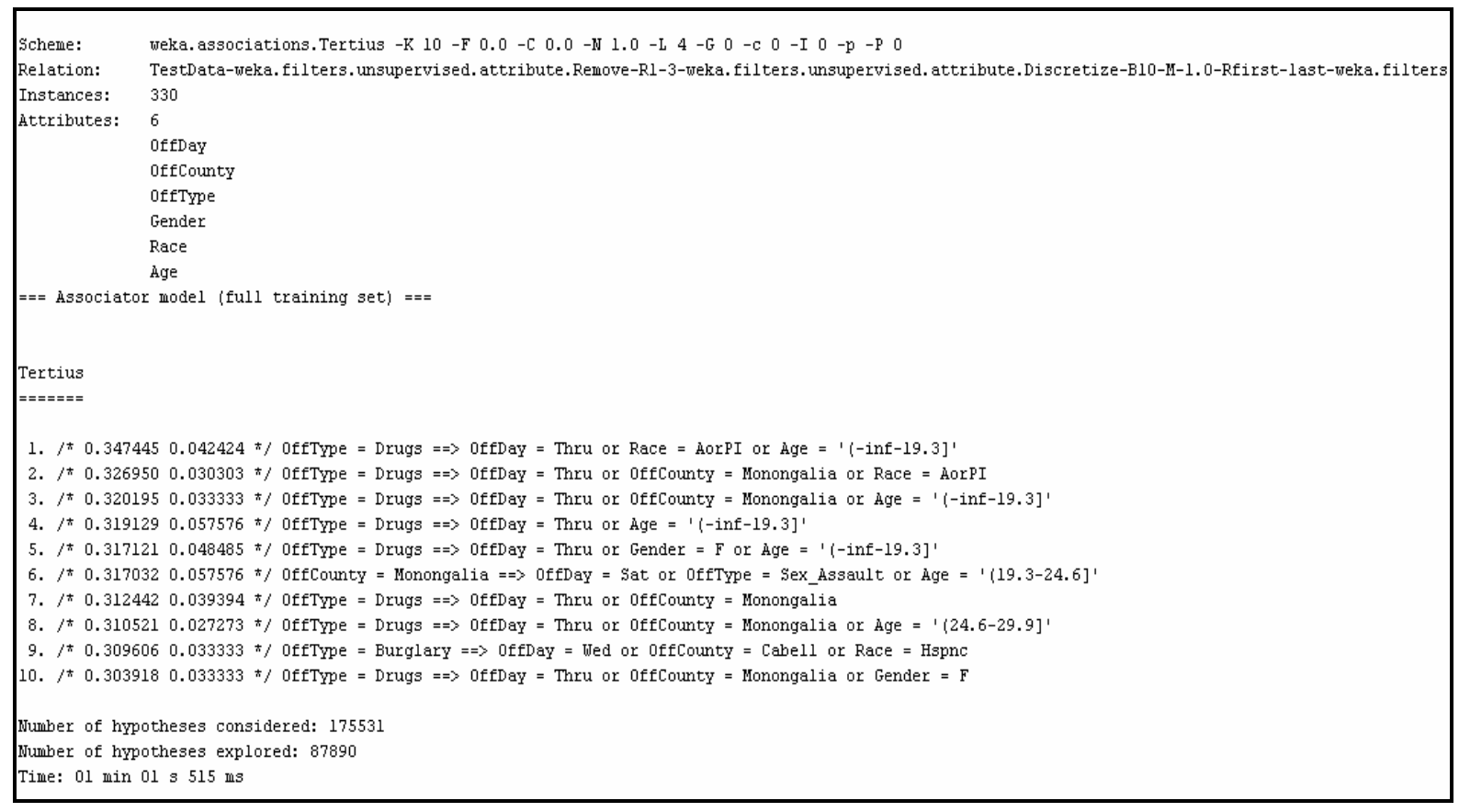

Figure 5.6: Tertius classifier with 6 attributes using Discretize filter

The outcomes for all other combinations of these classifiers and number of attributes are shown in the Appendix E. The selective outcomes are listed by pairing them, as done in prior sections, in the Table 5.4. 


\begin{tabular}{|c|c|c|c|c|}
\hline \multicolumn{5}{|c|}{ Table 5.4: Tabulated outcome of WEKA } \\
\hline S. No & \multicolumn{4}{|c|}{ Apriori } \\
\hline 1 & Saturday & Black & Male & \\
\hline \multirow[t]{2}{*}{2} & Monongalia & Black & Male & \\
\hline & \multicolumn{4}{|c|}{ Tertius } \\
\hline 3 & Accident & Harrison & Monday & \\
\hline 4 & Accident & Harrison & Female & \\
\hline 5 & AorPI & Accident & Harrison & \\
\hline 6 & Drugs & Thru & Monongalia & Age $<19$ \\
\hline 7 & Monongalia & Saturday & Sex_Assault & Age between $24 \& 29$ \\
\hline 8 & Burglary & Tuesday & Cabell & Hspnc \\
\hline 9 & Burglary & Cabell & Hspnc & \\
\hline 10 & Drugs & Thursday & AorPI & \\
\hline
\end{tabular}

The WEKA software identified all the patterns that were planted into the database. Moreover, the newly discovered relation that was identified by the Data Mining tool was also identified by the WEKA software in Table 5.4 - S.No. 8 and 9. From relation (d) of the planted pattern (Page 67), even WEKA did not find any relation between Burglary and Monongalia County. The WEKA outcomes had many more paired relations that included the "CriminalBkgd" and "Gender" fields. These relations were ignored as explained in previous section. In cases of the Drug offense, the Data Mining model identified the Day of offense in the link as "Saturday," while WEKA reported it to be "Thursday." The database was specifically queried for this and it was found that number of occurrence of Drug offense on "Thursday" and "Saturday" was 10 and 8 respectively. This was due to the additional constraint, Race $=$ Black, that was included while using Data Mining tool. The other small variations in the outcome of the Data Mining and WEKA software can be justified as both have different approaches for finding the patterns. The WEKA also found one more relation in the database that is listed in Table 5.4 - S.No.10. When specifically queried it was found that Asian or Pacific Islanders were involved in Drugs offense significantly.

The outcome of WEKA validates the Data Mining tool (stage II) as discussed in the Evaluation Phase (Page 67). Further, one can make use of WEKA to "Visualize" the patterns and other interesting combinations as described in Section 4.10. 


\section{CONCLUSION AND FUTURE WORK}

\subsection{Conclusion}

The objective of this study was to develop a Data Mining tool for the crime investigator. The tool should be able to identify obvious and non-obvious crime patterns in the database that would be helpful in investigations. The tool needed development of a crime database as well as the software to work on the data. Moreover, the software included development and implementation of data searching and mining tools. The tool was developed and implemented using the MS SQL Server and ASP.NET. The basic and advanced search techniques as well as the Association and Decision Rules techniques were implemented successfully. A suitable user interface was created to access them and a navigation page was provided to use different tools preferentially.

For validation, the tool was first checked by actual querying the database with SQL Query Analyzer. The test data were created with a pattern planted deliberately in it. The outcome of the tool for the test data was then compared with the outcome of WEKA software. It was observed that the tool was able to find the non-obvious patterns in the test data. Some other features of the tools are:

a. The Data Mining tool is customized for the application as per the objective; so unlike WEKA, which is a generalized application, it requires no preprocessing of the data.

b. The outcome of the tool showed direct relations in the field values and was easily interpreted even with limited knowledge of the Data Mining tools.

c. Further, the outcome can be immediately analyzed by using specific queries with the searching techniques provided in the tool. This required basic SQL querying knowledge on part of user. 
d. The tool can be used over the Web and, at the same time, ensure the privacy and security of the data.

e. An ARFF file can be generated, which acts as a cross platform, thus enabling other Data Mining software to use the data for analysis.

\subsection{Future Work}

The tool provided satisfactory results and was able to determine crime patterns from the data for further investigation. This satisfies the foremost objective of the tool. However, there are several improvements that can be made. Some of these are listed below:

a. Currently, the tool does not have an ability to visualize the data. This makes it dependent on other applications such as WEKA for the same. Data Visualization could be incorporated in the tool.

b. The Data Mining algorithms were specific to the application. These algorithms can be further generalized so that they can be used in other cases and applications.

c. The query table "tblQuery" was essentially static in terms of fields and field types. An application can be built to achieve dynamic generation of the table based on user choice to make the tool more robust.

d. Further, an option to generate an XML file from the SQL data, similar to an ARFF file could be added. This would provide a general purpose platform for use of other Data Mining techniques. 


\section{REFERENCES}

[1] Daniel T. Larose, "Discovering Knowledge in Data"; Wiley-Interscience, ISBN: 0-471-66657-2.

[2] Margaret H. Dunham, "Data Mining: Introductory and Advanced Topics"; Prentice Hall, ISBN: 0-13-088892-3.

[3] Jason Frand, University of California, Los Angles - Class Notes; http://www.anderson.ucla.edu/faculty/jason.frand/teacher/technologies/palace/data mining.htm. (January 06)

[4] ABC News, "US Plans Massive Data Sweep", $15^{\text {th }}$ February 2006.

[5] Hsinchun Chen, Wingyan Chung, Yi Qin, Michael Chau, Jennifer Jie Xu, Gang Wang, Rong Zheng, Homa Atabakhsh, "Crime Data Mining: An Overview and Case Studies."; Artificial Intelligence Lab, Department of Management Information Systems, University of Arizona. (March 2006)

[6] Chen, H., Chung, W., Xu, J.J., Wang, G., Qin, Y., Chau, M., “Crime data mining: A general framework and some examples"; Volume 37, Issue 4, April 2004 Page(s):50 - 56.

[7] Brown, D.E, "The Regional Crime Analysis Program (ReCAP): a framework for mining data to catch criminals"; IEEE International Conference on Systems, Man, and Cybernetics; Volume 3, 11-14 Oct. 1998 Page(s):2848 - 2853 Vol.3.

[8] Chan, P.K.; Fan, W., Prodromidis A.L.; Stolfo S.J., "Distributed data mining in credit card fraud detection"; Intelligent Systems and Their Applications, IEEE; Volume 14, Issue 6, Nov.-Dec. 1999 Page(s):67 - 74.

[9] U.S. Congress, Office of Technology Assessment, "Information Technologies for Control of Money Laundering"; OTA-ITC-630 (Washington, DC: U.S. Government Printing Office, September 1995).

[10] Anil K. Jain, Robert P.W. Duin, Jianchang Mao, "Statistical Pattern Recognition: A Review"; IEEE Transactions on Pattern Analysis and Machine Intelligence, Vol. 22, No. 1, January 2000.

[11] Anil K. Jain, M. N. Murthy, P. J. Flynn, "Data Clustering: A Review"; ACM Computing Surveys, Vol. 31, No. 3, September 1999.

[12] CGG Aitken, Dept. of Mathematics and Statistics, The University of Edinburg, UK EH9 3JZ; T Connolly, Boimathematics and Statistics Scotland, Scottish Corp Research Institue, UK DD2 5DA; A Gammerman, Dept. of Computer Science, Royal Holloway and Bedford New College, University of London, Uk, TW20 0EX; G Zang, Dept. of Electrical Engineering and Computer Science, LeHigh University, US 18015; D Bailey and R Gordon, Derbyshire Constabulary Headquaters, Uk DE5 3RS; R Oldfield, Police Research Group London, UK SW1H 9AT, "Science \& Justice 1996"; 36(4): Page 245-255. 
[13] David Hand, Heikki Mannila, Padhraic Smyth, "Principles of Data Mining".

[14] Kutner, Nachtsheim, Neterr, "Applied Linear Regression Models"; $4^{\text {th }}$ Edition, McGraw-Hill, ISBN 0-07-301344-7.

[15] Caroline Clabaugh, Dave Myszewski, Jimmy Pang; "Presentation on Neural Networks", cse.stanford.edu/class/sophomore-college/projects-00/neuralnetworks/, CSE Dept. University of Stanford. (Project Year 2000)

[16] Gisele L. Pappa, Alex A. Freitas, "Towards a Genetic Programming Algorithm for Automatically Evolving Rule Induction Algorithms"; University of Kent, www.ke.informatik.tu-darmstadt.de/events/ECML-PKDD-04WS/Proceedings/pappa.pdf. (March 2006)

[17] Corin R. Anderson, Pedro Domingos, Daniel S. Weld, "Relational Markov Models and their Application to Adaptive Web Navigation"; SIGKDD 2002 Edmonton, Alberta, Canada.

[18] Michael J. Hernandez, "Database Design for Mere Mortals"; $2^{\text {nd }}$ Edition, Addison - Wesley, ISBN: 0-201-75284-0.

[19] Laurene Fausett, "Fundamentals of Neural Networks"; Prentice Hall, ISBN: 0-13334186-0.

[20] Ian H. Witten and Eibe Frank (2005), "Data Mining: Practical machine learning tools and techniques"; $2^{\text {nd }}$ Edition, Morgan Kaufmann, San Francisco, 2005.

[21] West Virginia State Police Department; http://www.wvstatepolice.com/wanted/wanted.shtml. (August 2006)

[22] Bureau of Justice Statistics, US; http://www.ojp.usdoj.gov/bjs/welcome.html. (July 2006)

[23] Dr. Kristof Van Laerhoven, Post-Doc, Computer Science, Darmstadt University of Technology, Germany; http://www.comp.lancs.ac.uk/ kristof/research/notes/index.html. (January 2006)

[24] Juha Vesanto, Esa Alhoniemi, "Clustering of the Self-Organizing Map." IEEE Transactiosn on Neural Networks, Vol. 11, No. 3, May 2000.

[25] The Queens University of Belfast UK - Data Mining Notes, http://www.pcc.qub.ac.uk/tec/courses/datamining/stu_notes/dm_book_1.html. (February 2006)

[26] Dr. Kardi Tekonomo, http://people.revoledu.com/kardi/tutorial/kMean/index.html. (February 2006)

[27] Wikipedia.org, http://en.wikipedia.org/wiki/Main_Page. (August 2006) 


\section{APPENDIX A: Test Data from Query Table “tblQuery"}

\begin{tabular}{|c|c|c|c|c|c|c|c|c|c|c|c|c|}
\hline ACN & Year & Mth. & Dt. & Hr. & Min. & Day & County & OffType & Gen. & Race & Age & $\begin{array}{l}\text { Crime } \\
\text { Bkgd }\end{array}$ \\
\hline 1001 & 2004 & 1 & 2 & 12 & 28 & Tue & Harrison & Assault & $\mathrm{M}$ & White & 31 & No \\
\hline 1002 & 2004 & 1 & 3 & 2 & 7 & Sat & Monongalia & Drugs & $\mathrm{M}$ & Black & 21 & No \\
\hline 1003 & 2004 & 1 & 3 & 2 & 22 & Wed & Cabell & Murder & $M$ & Black & 23 & Yes \\
\hline 1004 & 2004 & 1 & 4 & 10 & 55 & Thru & Monongalia & Drugs & $\mathrm{F}$ & AorPI & 20 & No \\
\hline 1005 & 2004 & 1 & 10 & 4 & 22 & Sat & Marion & \begin{tabular}{|l|} 
Burglary \\
\end{tabular} & $\mathrm{M}$ & \begin{tabular}{|l|} 
White \\
\end{tabular} & 24 & Yes \\
\hline 1006 & 2004 & 1 & 10 & 23 & 38 & Sun & Hancock & Murder & $\mathrm{M}$ & White & 36 & Yes \\
\hline 1007 & 2004 & 1 & 13 & 7 & 50 & Tue & Berkley & Accident & $\mathrm{F}$ & AorPI & 52 & No \\
\hline 1008 & 2004 & 1 & 16 & 3 & 9 & Fri & Monongalia & Sex_Assault & $M$ & White & 40 & Yes \\
\hline 1009 & 2004 & 1 & 20 & 7 & 13 & Tue & Mercer & Accident & $\mathrm{M}$ & White & 52 & No \\
\hline 1010 & 2004 & 1 & 25 & 11 & 16 & Sun & Harrison & Arson & $\mathrm{M}$ & Black & 22 & Yes \\
\hline 1011 & 2004 & 1 & 25 & 20 & 34 & Sun & Mercer & Weap_Threat & $\mathrm{M}$ & Black & 27 & Yes \\
\hline 1012 & 2004 & 1 & 27 & 9 & 59 & Tue & Cabell & Assault & $\mathrm{M}$ & Black & 29 & Yes \\
\hline 1013 & 2004 & 1 & 27 & 3 & 29 & Tue & Cabell & Burglary & $\mathrm{M}$ & Black & 48 & Yes \\
\hline 1014 & 2004 & 2 & 1 & 7 & 42 & Sun & Marion & Murder & $\mathrm{M}$ & Black & 43 & Yes \\
\hline 1015 & 2004 & 2 & 2 & 1 & 1 & Mon & Monongalia & Accident & $\mathrm{M}$ & AorPI & 22 & No \\
\hline 1016 & 2004 & 2 & 7 & 22 & 18 & Sat & Monongalia & Sex_Assault & $\mathrm{M}$ & White & 21 & No \\
\hline 1017 & 2004 & 2 & 7 & 5 & 29 & Sat & Monongalia & Rape & $\mathrm{M}$ & Black & 21 & Yes \\
\hline 1018 & 2004 & 2 & 9 & 18 & 5 & Mon & Hancock & Accident & $\mathrm{F}$ & Black & 24 & No \\
\hline 1019 & 2004 & 2 & 10 & 4 & 29 & Tue & Mercer & Burglary & $M$ & Black & 33 & Yes \\
\hline 1020 & 2004 & 2 & 10 & 9 & 49 & Tue & Cabell & Burglary & $\mathrm{M}$ & AorPI & 25 & No \\
\hline 1021 & 2004 & 2 & 11 & 10 & 53 & Wed & Marion & \begin{tabular}{|l|} 
Burglary \\
\end{tabular} & $\mathrm{M}$ & AorPI & 56 & No \\
\hline 1022 & 2004 & 2 & 17 & 13 & 20 & Tue & Monongalia & Burglary & $\mathrm{F}$ & Black & 37 & Yes \\
\hline 1023 & 2004 & 2 & 21 & 3 & 5 & Sat & Monongalia & Rape & $\mathrm{M}$ & White & 46 & Yes \\
\hline 1024 & 2004 & 2 & 23 & 19 & 51 & Mon & Kanawha & Sex_Assault & $\mathrm{M}$ & Black & 38 & Yes \\
\hline 1025 & 2004 & 3 & 1 & 16 & 27 & Mon & Mercer & Accident & $M$ & White & 28 & No \\
\hline 1026 & 2004 & 3 & 13 & 1 & 10 & Sat & Kanawha & Sex_Assault & $M$ & Black & 21 & Yes \\
\hline 1027 & 2004 & 3 & 31 & 21 & 8 & Wed & Cabell & Arson & $\mathrm{M}$ & White & 39 & Yes \\
\hline 1028 & 2004 & 4 & 4 & 0 & 27 & Sun & Hancock & Weap_Threat & $\mathrm{M}$ & Black & 23 & Yes \\
\hline 1029 & 2004 & 4 & 6 & 1 & 57 & Tue & Cabell & Burglary & $\mathrm{M}$ & White & 41 & No \\
\hline 1030 & 2004 & 4 & 9 & 1 & 32 & Fri & Monongalia & Rape & $M$ & Black & 28 & Yes \\
\hline 1031 & 2004 & 4 & 11 & 2 & 39 & Sun & Mercer & \begin{tabular}{|l} 
Burglary \\
\end{tabular} & $\mathrm{M}$ & Hspnc & 44 & Yes \\
\hline 1032 & 2004 & 4 & 17 & 15 & 23 & Sat & Monongalia & Drugs & $M$ & Black & 19 & Yes \\
\hline 1033 & 2004 & 4 & 17 & 23 & 16 & Sat & Cabell & Arson & $\mathrm{M}$ & \begin{tabular}{|l|} 
Black \\
\end{tabular} & 29 & Yes \\
\hline 1034 & 2004 & 4 & 17 & 23 & 26 & Sat & Raleigh & Rape & $\mathrm{M}$ & Black & 43 & Yes \\
\hline 1035 & 2004 & 4 & 20 & 1 & 13 & Tue & Harrison & Arson & $\mathrm{M}$ & Black & 32 & Yes \\
\hline 1036 & 2004 & 4 & 29 & 22 & 20 & Thru & Hancock & Drugs & $M$ & Black & 29 & Yes \\
\hline 1037 & 2004 & 5 & 5 & 15 & 15 & Wed & Monongalia & Burglary & $M$ & Hspnc & 36 & Yes \\
\hline 1038 & 2004 & 5 & 8 & 22 & 52 & Sat & Monongalia & Drugs & $\mathrm{M}$ & Black & 30 & Yes \\
\hline 1039 & 2004 & 5 & 16 & 1 & 10 & Sun & Cabell & Burglary & $\mathrm{M}$ & Black & 21 & Yes \\
\hline 1040 & 2004 & 5 & 18 & 1 & 24 & Tue & Harrison & Arson & $\mathrm{M}$ & Black & 24 & Yes \\
\hline
\end{tabular}




\begin{tabular}{|c|c|c|c|c|c|c|c|c|c|c|c|c|}
\hline 1041 & 2004 & 5 & 19 & 15 & 46 & Wed & Mercer & Assault & $\mathrm{M}$ & Hspnc & 37 & No \\
\hline 1042 & 2004 & 5 & 21 & 1 & 50 & Fri & Monongalia & Rape & $\mathrm{M}$ & Hspnc & 46 & Yes \\
\hline 1043 & 2004 & 5 & 27 & 20 & 46 & Thru & Kanawha & Sex_Assault & $\mathrm{M}$ & Hspnc & 33 & Yes \\
\hline 1044 & 2004 & 5 & 27 & 23 & 14 & Thru & Monongalia & Rape & $\mathrm{M}$ & White & 23 & Yes \\
\hline 1045 & 2004 & 6 & 2 & 7 & 36 & Wed & \begin{tabular}{|l|} 
Kanawha \\
\end{tabular} & Accident & $\mathrm{F}$ & \begin{tabular}{|l} 
White \\
\end{tabular} & 36 & Yes \\
\hline 1046 & 2004 & 6 & 2 & 7 & 53 & Wed & Kanawha & Accident & $F$ & AorPI & 41 & No \\
\hline 1047 & 2004 & 6 & 2 & 7 & 18 & Wed & Cabell & Accident & $\mathrm{M}$ & White & 57 & No \\
\hline 1048 & 2004 & 6 & 2 & 23 & 50 & Wed & Cabell & \begin{tabular}{|l} 
Burglary \\
\end{tabular} & $\mathrm{M}$ & Hspnc & 26 & Yes \\
\hline 1049 & 2004 & 6 & 5 & 15 & 52 & Sat & Hancock & Assault & $\mathrm{M}$ & Hspnc & 37 & Yes \\
\hline 1050 & 2004 & 6 & 8 & 8 & 44 & Tue & Berkley & Weap_Threat & $\mathrm{M}$ & Hspnc & 59 & Yes \\
\hline 1051 & 2004 & 6 & 8 & 9 & 0 & Tue & Cabell & Burglary & $\mathrm{F}$ & Hspnc & 29 & Yes \\
\hline 1052 & 2004 & 6 & 8 & 19 & 3 & Tue & Monongalia & Accident & $\mathrm{M}$ & Black & 29 & No \\
\hline 1053 & 2004 & 6 & 11 & 21 & 38 & Fri & Monongalia & Sex_Assault & $\mathrm{M}$ & Black & 23 & Yes \\
\hline 1054 & 2004 & 6 & 11 & 2 & 31 & Fri & Monongalia & Rape & $\mathrm{M}$ & \begin{tabular}{|l} 
Black \\
\end{tabular} & 23 & Yes \\
\hline 1055 & 2004 & 6 & 12 & 1 & 54 & Sat & Monongalia & Sex_Assault & $\mathrm{M}$ & White & 46 & Yes \\
\hline 1056 & 2004 & 6 & 15 & 8 & 11 & Tue & Monongalia & Accident & $\mathrm{M}$ & AorPI & 24 & Yes \\
\hline 1057 & 2004 & 6 & 16 & 19 & 44 & Wed & Hancock & Assault & $\mathrm{M}$ & Hspnc & 30 & Yes \\
\hline 1058 & 2004 & 6 & 18 & 21 & 34 & Fri & Hancock & Weap_Threat & $\mathrm{M}$ & White & 49 & Yes \\
\hline 1059 & 2004 & 6 & 24 & 23 & 15 & Thru & Monongalia & \begin{tabular}{|l|} 
Drugs \\
\end{tabular} & $\mathrm{M}$ & Hspnc & 21 & Yes \\
\hline 1060 & 2004 & 6 & 24 & 22 & 29 & Thru & Monongalia & Drugs & $M$ & AorPI & 22 & No \\
\hline 1061 & 2004 & 6 & 25 & 23 & 8 & Fri & Monongalia & Sex_Assault & $\mathrm{M}$ & \begin{tabular}{|l} 
White \\
\end{tabular} & 47 & Yes \\
\hline 1062 & 2004 & 6 & 30 & 7 & 15 & Wed & Mercer & Accident & $\mathrm{M}$ & Hspnc & 52 & No \\
\hline 1063 & 2004 & 6 & 30 & 14 & 46 & Wed & Marion & \begin{tabular}{|l} 
Burglary \\
\end{tabular} & $\mathrm{F}$ & Hspnc & 34 & Yes \\
\hline 1064 & 2004 & 7 & 3 & 20 & 51 & Sat & Kanawha & Rape & $\mathrm{M}$ & Black & 39 & Yes \\
\hline 1065 & 2004 & 7 & 4 & 23 & 27 & Sun & Cabell & Burglary & $M$ & Hspnc & 36 & Yes \\
\hline 1066 & 2004 & \begin{tabular}{|l|}
7 \\
\end{tabular} & 5 & 9 & 38 & Mon & Raleigh & Accident & $\mathrm{M}$ & \begin{tabular}{|l} 
White \\
\end{tabular} & 31 & Yes \\
\hline 1067 & 2004 & 7 & 6 & 19 & 38 & Tue & Mercer & Accident & $\mathrm{M}$ & \begin{tabular}{|l} 
White \\
\end{tabular} & 20 & No \\
\hline 1068 & 2004 & \begin{tabular}{|l|}
7 \\
\end{tabular} & 10 & 21 & 16 & Sat & Monongalia & Sex_Assault & $\mathrm{M}$ & Black & 37 & Yes \\
\hline 1069 & 2004 & \begin{tabular}{|l|}
7 \\
\end{tabular} & 11 & 2 & 21 & Sun & Cabell & Burglary & $\mathrm{F}$ & White & 31 & Yes \\
\hline 1070 & 2004 & 7 & 26 & 0 & 46 & Mon & Harrison & Accident & $\mathrm{M}$ & Black & 37 & No \\
\hline 1071 & 2004 & 7 & 31 & 1 & 39 & Sat & \begin{tabular}{|l|} 
Kanawha \\
\end{tabular} & Sex_Assault & $\mathrm{M}$ & Hspnc & 46 & Yes \\
\hline 1072 & 2004 & 8 & 1 & 22 & 50 & Sun & Berkley & Arson & $\mathrm{M}$ & White & 61 & Yes \\
\hline 1073 & 2004 & 8 & 7 & 22 & 42 & Sat & Monongalia & Rape & $\mathrm{M}$ & Hspnc & 37 & Yes \\
\hline 1074 & 2004 & 8 & 8 & 15 & 43 & Sun & Marion & Arson & $\mathrm{M}$ & White & 24 & Yes \\
\hline 1075 & 2004 & 8 & 9 & 23 & 38 & Mon & Marion & Accident & $\mathrm{M}$ & Black & 18 & No \\
\hline 1076 & 2004 & 8 & 11 & 3 & 51 & Wed & Berkley & Burglary & $\mathrm{F}$ & White & 29 & Yes \\
\hline 1077 & 2004 & 8 & 31 & 3 & 11 & Tue & Cabell & Burglary & $\mathrm{M}$ & AorPI & 21 & Yes \\
\hline 1078 & 2004 & 9 & 8 & 7 & 56 & Wed & Monongalia & Accident & $\mathrm{M}$ & White & 19 & No \\
\hline 1079 & 2004 & 9 & 11 & 2 & 19 & Sat & Monongalia & Rape & $\mathrm{M}$ & Black & 38 & Yes \\
\hline 1080 & 2004 & 9 & 14 & 22 & 49 & Tue & Berkley & Drugs & $M$ & Black & 25 & Yes \\
\hline 1081 & 2004 & 9 & 17 & 19 & 39 & Fri & Monongalia & Sex_Assault & $\mathrm{M}$ & \begin{tabular}{|l|} 
Black \\
\end{tabular} & 27 & Yes \\
\hline 1082 & 2004 & 9 & 18 & 23 & 10 & Sat & Monongalia & Accident & $\mathrm{M}$ & White & 67 & Yes \\
\hline 1083 & 2004 & 9 & 21 & 2 & 59 & Tue & Marion & Murder & $\mathrm{F}$ & Black & 34 & Yes \\
\hline 1084 & 2004 & 9 & 21 & 20 & 23 & Tue & Cabell & \begin{tabular}{|l} 
Burglary \\
\end{tabular} & $\mathrm{M}$ & Black & 24 & Yes \\
\hline 1085 & 2004 & 9 & 24 & 19 & 19 & Fri & Kanawha & \begin{tabular}{|l} 
Drugs \\
\end{tabular} & $\mathrm{M}$ & AorPI & 33 & Yes \\
\hline 1086 & 2004 & 9 & 26 & 2 & 48 & Sun & Harrison & \begin{tabular}{|l|} 
Accident \\
\end{tabular} & $\mathrm{M}$ & Black & 15 & Yes \\
\hline 1087 & 2004 & 10 & 3 & 0 & 7 & Sun & Berkley & Accident & $\mathrm{M}$ & White & 49 & No \\
\hline
\end{tabular}




\begin{tabular}{|c|c|c|c|c|c|c|c|c|c|c|c|c|}
\hline 1088 & 2004 & 10 & 3 & 23 & 27 & Sun & Monongalia & Assault & $\mathrm{M}$ & Hspnc & 33 & Yes \\
\hline 1089 & 2004 & 10 & 17 & 4 & 1 & Sun & Cabell & \begin{tabular}{|l} 
Burglary \\
\end{tabular} & $\mathrm{M}$ & White & 44 & No \\
\hline 1090 & 2004 & 10 & 17 & 15 & 49 & Sun & Kanawha & Weap_Threat & $\mathrm{M}$ & Black & 20 & Yes \\
\hline 1091 & 2004 & 10 & 18 & 8 & 36 & Mon & Hancock & Accident & $\mathrm{M}$ & White & 28 & Yes \\
\hline 1092 & 2004 & 10 & 26 & 3 & 46 & Tue & Cabell & \begin{tabular}{|l|} 
Burglary \\
\end{tabular} & $\mathrm{M}$ & Black & 21 & No \\
\hline 1093 & 2004 & 10 & 29 & 2 & 18 & Fri & Marion & Sex_Assault & $\mathrm{M}$ & Black & 27 & Yes \\
\hline 1094 & 2004 & 10 & 30 & 2 & 7 & Sat & Hancock & Drugs & $\mathrm{M}$ & Black & 22 & Yes \\
\hline 1095 & 2004 & 11 & 2 & 21 & 2 & Tue & Berkley & Weap_Threat & $\mathrm{M}$ & White & 54 & Yes \\
\hline 1096 & 2004 & 11 & 3 & 16 & 6 & Wed & Kanawha & Arson & $\mathrm{M}$ & Black & 34 & No \\
\hline 1097 & 2004 & 11 & 15 & 18 & 54 & Tue & Cabell & Burglary & $\mathrm{M}$ & AorPI & 53 & Yes \\
\hline 1098 & 2004 & 11 & 27 & 2 & 9 & Sat & Mercer & Rape & $\mathrm{M}$ & White & 28 & Yes \\
\hline 1099 & 2004 & 11 & 28 & 1 & 30 & Sun & Raleigh & Accident & $\mathrm{M}$ & \begin{tabular}{|l} 
White \\
\end{tabular} & 27 & No \\
\hline 1100 & 2004 & 11 & 30 & 3 & 56 & Tue & Mercer & Burglary & $M$ & White & 24 & No \\
\hline 1101 & 2004 & 12 & 5 & 23 & 56 & Mon & Marion & Murder & $\mathrm{M}$ & Black & 38 & Yes \\
\hline 1102 & 2004 & 12 & 6 & 18 & 56 & Tue & Hancock & Burglary & $\mathrm{M}$ & White & 17 & No \\
\hline 1103 & 2004 & 12 & 23 & 18 & 43 & Thru & Monongalia & Drugs & $\mathrm{M}$ & White & 21 & Yes \\
\hline 1104 & 2004 & 12 & 28 & 9 & 1 & Tue & Marion & Assault & $\mathrm{M}$ & White & 32 & Yes \\
\hline 1105 & 2004 & 12 & 28 & 1 & 46 & Tue & Harrison & Arson & $\mathrm{M}$ & White & 16 & Yes \\
\hline 1106 & 2004 & 12 & 30 & 12 & 6 & Thru & Hancock & Weap_Threat & $\mathrm{M}$ & Black & 28 & Yes \\
\hline 1107 & 2004 & 12 & 30 & 10 & 34 & Thru & Hancock & \begin{tabular}{|l|} 
Drugs \\
\end{tabular} & $\mathrm{M}$ & White & 62 & Yes \\
\hline 1108 & 2004 & 12 & 30 & 2 & 7 & Thru & Marion & \begin{tabular}{|l|} 
Drugs \\
\end{tabular} & $\mathrm{M}$ & Black & 30 & Yes \\
\hline 1109 & 2004 & 12 & 31 & 18 & 19 & Fri & Raleigh & Assault & $\mathrm{M}$ & Hspnc & 22 & No \\
\hline 1110 & 2004 & 12 & 31 & 14 & 43 & Fri & Monongalia & Sex_Assault & $\mathrm{M}$ & Black & 30 & Yes \\
\hline 1111 & 2005 & 1 & 2 & 0 & 32 & Sun & Hancock & Rape & $\mathrm{M}$ & Black & 38 & Yes \\
\hline 1112 & 2005 & 1 & 2 & 14 & 46 & Sun & Harrison & Arson & $\mathrm{M}$ & White & 25 & No \\
\hline 1113 & 2005 & 1 & 4 & 15 & 23 & Tue & \begin{tabular}{|l|} 
Kanawha \\
\end{tabular} & Weap_Threat & $\mathrm{M}$ & Black & 27 & Yes \\
\hline 1114 & 2005 & 1 & 10 & 7 & 51 & Mon & Harrison & Accident & $\mathrm{M}$ & White & 67 & No \\
\hline 1115 & 2005 & 1 & 15 & 16 & 59 & Sat & Cabell & Assault & $\mathrm{M}$ & Black & 36 & Yes \\
\hline 1116 & 2005 & 1 & 16 & 3 & 36 & Sun & Cabell & Burglary & $\mathrm{M}$ & Hspnc & 53 & Yes \\
\hline 1117 & 2005 & 1 & 21 & 1 & 43 & Fri & Monongalia & Rape & $\mathrm{M}$ & Black & 29 & Yes \\
\hline 1118 & 2005 & 1 & 25 & 14 & 58 & Tue & Hancock & Weap_Threat & $\mathrm{M}$ & Hspnc & 49 & Yes \\
\hline 1119 & 2005 & 1 & 25 & 19 & 24 & Tue & Mercer & Sex_Assault & $\mathrm{M}$ & Black & 33 & Yes \\
\hline 1120 & 2005 & 1 & 30 & 2 & 30 & Sun & Monongalia & Arson & $\mathrm{M}$ & \begin{tabular}{|l} 
White \\
\end{tabular} & 23 & Yes \\
\hline 1121 & 2005 & 1 & 31 & 20 & 17 & Mon & Hancock & Accident & $\mathrm{F}$ & Black & 20 & No \\
\hline 1122 & 2005 & 2 & 1 & 4 & 40 & Tue & Berkley & \begin{tabular}{|l|} 
Burglary \\
\end{tabular} & $\mathrm{M}$ & Hspnc & 35 & Yes \\
\hline 1123 & 2005 & 2 & 2 & 18 & 7 & Wed & Monongalia & Sex_Assault & $\mathrm{M}$ & Black & 31 & Yes \\
\hline 1124 & 2005 & 2 & 7 & 17 & 1 & Mon & Harrison & Accident & $\mathrm{M}$ & Black & 47 & Yes \\
\hline 1125 & 2005 & 2 & 7 & 4 & 5 & Mon & Mercer & \begin{tabular}{|l|} 
Burglary \\
\end{tabular} & $\mathrm{M}$ & Black & 32 & Yes \\
\hline 1126 & 2005 & 2 & 9 & 15 & 51 & Wed & Kanawha & Accident & $\mathrm{M}$ & \begin{tabular}{|l} 
White \\
\end{tabular} & 54 & No \\
\hline 1127 & 2005 & 2 & 10 & 18 & 41 & Thru & Hancock & Drugs & $M$ & Black & 44 & Yes \\
\hline 1128 & 2005 & 2 & 11 & 7 & 22 & Fri & Raleigh & Rape & $\mathrm{M}$ & \begin{tabular}{|l|} 
Black \\
\end{tabular} & 28 & Yes \\
\hline 1129 & 2005 & 2 & 12 & 19 & 19 & Sat & Monongalia & \begin{tabular}{|l|} 
Drugs \\
\end{tabular} & $\mathrm{F}$ & Black & 22 & Yes \\
\hline 1130 & 2005 & 2 & 15 & 12 & 33 & Tue & Berkley & Sex_Assault & $\mathrm{M}$ & Black & 27 & No \\
\hline 1131 & 2005 & 2 & 19 & 22 & 22 & Sat & Raleigh & \begin{tabular}{|l} 
Drugs \\
\end{tabular} & $\mathrm{M}$ & AorPI & 24 & Yes \\
\hline 1132 & 2005 & 2 & 26 & 0 & 49 & Sat & Monongalia & Sex_Assault & $\mathrm{M}$ & White & 50 & Yes \\
\hline 1133 & 2005 & 3 & 1 & 22 & 53 & Tue & Marion & Murder & $\mathrm{M}$ & Black & 57 & Yes \\
\hline 1134 & 2005 & 3 & 13 & 22 & 46 & Sun & Harrison & Murder & $M$ & White & 51 & Yes \\
\hline
\end{tabular}




\begin{tabular}{|c|c|c|c|c|c|c|c|c|c|c|c|c|}
\hline 1135 & 2005 & 3 & 13 & 9 & 35 & Sun & Kanawha & Assault & $\mathrm{M}$ & White & 42 & Yes \\
\hline 1136 & 2005 & 3 & 29 & 2 & 52 & Tue & Monongalia & Burglary & $\mathrm{M}$ & Hspnc & 34 & No \\
\hline 1137 & 2005 & 3 & 31 & 23 & 57 & Thru & Kanawha & Rape & $\mathrm{M}$ & White & 52 & Yes \\
\hline 1138 & 2005 & 4 & 8 & 20 & 8 & Fri & Cabell & Drugs & $\mathrm{F}$ & White & 22 & No \\
\hline 1139 & 2005 & 4 & 9 & 0 & 59 & Sat & Monongalia & Sex_Assault & $\mathrm{M}$ & Black & 39 & Yes \\
\hline 1140 & 2005 & 4 & 12 & 12 & 25 & Tue & Raleigh & Burglary & $\mathrm{M}$ & Black & 39 & Yes \\
\hline 1141 & 2005 & 4 & 17 & 0 & 46 & Sun & Harrison & Accident & $\mathrm{M}$ & Black & 19 & Yes \\
\hline 1142 & 2005 & 4 & 18 & 18 & 51 & Mon & Hancock & Weap_Threat & $\mathrm{M}$ & White & 53 & Yes \\
\hline 1143 & 2005 & 4 & 23 & 20 & 25 & Sat & Raleigh & Sex_Assault & $\mathrm{M}$ & Black & 45 & Yes \\
\hline 1144 & 2005 & 4 & 26 & 17 & 14 & Tue & Kanawha & Accident & $M$ & Black & 25 & No \\
\hline 1145 & 2005 & 5 & 5 & 23 & 56 & Thru & Hancock & Drugs & $\mathrm{F}$ & White & 21 & Yes \\
\hline 1146 & 2005 & 5 & 16 & 9 & 30 & Mon & Berkley & Assault & $\mathrm{M}$ & \begin{tabular}{|l} 
Black \\
\end{tabular} & 24 & Yes \\
\hline 1147 & 2005 & 5 & 18 & 8 & 43 & Wed & Cabell & Accident & $M$ & Black & 33 & Yes \\
\hline 1148 & 2005 & 5 & 19 & 23 & 37 & Thru & Kanawha & Rape & $\mathrm{M}$ & Black & 37 & Yes \\
\hline 1149 & 2005 & 5 & 21 & 4 & 22 & Sat & Cabell & Burglary & $\mathrm{M}$ & Black & 22 & Yes \\
\hline 1150 & 2005 & 5 & 21 & 1 & 54 & Sat & Marion & Murder & $\mathrm{M}$ & White & 46 & Yes \\
\hline 1151 & 2005 & 5 & 25 & 18 & 44 & Wed & Mercer & Burglary & $M$ & Black & 24 & Yes \\
\hline 1152 & 2005 & 5 & 27 & 0 & 2 & Fri & Raleigh & Rape & $\mathrm{M}$ & White & 38 & Yes \\
\hline 1153 & 2005 & 5 & 27 & 20 & 19 & Fri & Mercer & \begin{tabular}{|l|} 
Drugs \\
\end{tabular} & $\mathrm{M}$ & AorPI & 21 & No \\
\hline 1154 & 2005 & 6 & 4 & 23 & 32 & Sat & Hancock & Accident & $\mathrm{M}$ & Hspnc & 39 & Yes \\
\hline 1155 & 2005 & 6 & 7 & 7 & 10 & Tue & Marion & Accident & $\mathrm{M}$ & Black & 30 & No \\
\hline 1156 & 2005 & 6 & 7 & 19 & 31 & Tue & Monongalia & Sex_Assault & $\mathrm{M}$ & Black & 41 & Yes \\
\hline 1157 & 2005 & 6 & 8 & 9 & 21 & Wed & Cabell & Accident & $\mathrm{M}$ & Black & 36 & Yes \\
\hline 1158 & 2005 & 6 & 9 & 17 & 38 & Thru & Kanawha & Drugs & $\mathrm{M}$ & White & 23 & Yes \\
\hline 1159 & 2005 & 6 & 11 & 7 & 3 & Sat & Kanawha & Sex_Assault & $\mathrm{M}$ & Black & 39 & Yes \\
\hline 1160 & 2005 & 6 & 11 & 1 & 22 & Sat & Raleigh & Sex_Assault & $\mathrm{M}$ & Hspnc & 44 & Yes \\
\hline 1161 & 2005 & 6 & 15 & 11 & 11 & Wed & Harrison & Burglary & $\mathrm{M}$ & \begin{tabular}{|l} 
Black \\
\end{tabular} & 51 & Yes \\
\hline 1162 & 2005 & 6 & 16 & 19 & 34 & Thru & Harrison & \begin{tabular}{|l|} 
Drugs \\
\end{tabular} & $\mathrm{M}$ & Black & 24 & Yes \\
\hline 1163 & 2005 & 6 & 17 & 23 & 45 & Fri & Berkley & Assault & $\mathrm{M}$ & Black & 37 & Yes \\
\hline 1164 & 2005 & 6 & 21 & 12 & 7 & Tue & Monongalia & Rape & $\mathrm{M}$ & Black & 24 & Yes \\
\hline 1165 & 2005 & 6 & 24 & 22 & 12 & Fri & \begin{tabular}{|l|} 
Kanawha \\
\end{tabular} & Arson & $\mathrm{M}$ & Black & 32 & Yes \\
\hline 1166 & 2005 & 6 & 26 & 8 & 27 & Sun & Raleigh & Sex_Assault & $\mathrm{M}$ & Hspnc & 52 & Yes \\
\hline 1167 & 2005 & 6 & 26 & 15 & 58 & Sun & Mercer & Burglary & $\mathrm{M}$ & Hspnc & 44 & Yes \\
\hline 1168 & 2005 & 7 & 2 & 0 & 53 & Sat & Hancock & Rape & $\mathrm{M}$ & Hspnc & 52 & Yes \\
\hline 1169 & 2005 & 7 & 3 & 11 & 9 & Sun & Hancock & Assault & $\mathrm{M}$ & \begin{tabular}{|l} 
White \\
\end{tabular} & 22 & Yes \\
\hline 1170 & 2005 & 7 & 4 & 17 & 56 & Mon & Cabell & Accident & $\mathrm{M}$ & White & 19 & No \\
\hline 1171 & 2005 & 7 & 5 & 23 & 23 & Tue & Marion & Murder & $\mathrm{M}$ & White & 39 & Yes \\
\hline 1172 & 2005 & 7 & 6 & 2 & 25 & Wed & Harrison & Burglary & $\mathrm{M}$ & Hspnc & 53 & Yes \\
\hline 1173 & 2005 & 7 & 10 & 10 & 38 & Sun & Cabell & Assault & $\mathrm{M}$ & Black & 25 & Yes \\
\hline 1174 & 2005 & 7 & 11 & 8 & 28 & Mon & Raleigh & Accident & $F$ & AorPI & 63 & No \\
\hline 1175 & 2005 & 7 & 24 & 10 & 10 & Sun & Harrison & Assault & $\mathrm{M}$ & \begin{tabular}{|l|} 
Black \\
\end{tabular} & 34 & Yes \\
\hline 1176 & 2005 & 7 & 26 & 17 & 16 & Tue & Berkley & Accident & $\mathrm{M}$ & Black & 33 & No \\
\hline 1177 & 2005 & 7 & 31 & 12 & 0 & Sun & Harrison & Arson & $\mathrm{M}$ & Black & 45 & Yes \\
\hline 1178 & 2005 & 8 & 1 & 1 & 17 & Mon & Monongalia & Drugs & $\mathrm{M}$ & Black & 19 & No \\
\hline 1179 & 2005 & 8 & 7 & 13 & 29 & Sun & Hancock & Weap_Threat & $\mathrm{F}$ & Black & 33 & Yes \\
\hline 1180 & 2005 & 8 & 8 & 0 & 7 & Mon & Kanawha & Sex_Assault & $\mathrm{M}$ & Black & 44 & Yes \\
\hline 1181 & 2005 & 8 & 9 & 15 & 23 & Tue & Berkley & Assault & $\mathrm{M}$ & Black & 20 & No \\
\hline
\end{tabular}




\begin{tabular}{|c|c|c|c|c|c|c|c|c|c|c|c|c|}
\hline 1182 & 2005 & 8 & 11 & 21 & 23 & Thru & Raleigh & Drugs & $\mathrm{M}$ & AorPI & 28 & Yes \\
\hline 1183 & 2005 & 8 & 23 & 11 & 41 & Tue & Cabell & Burglary & $\mathrm{M}$ & White & 41 & Yes \\
\hline 1184 & 2005 & 8 & 24 & 16 & 16 & Wed & Marion & Accident & $\mathrm{M}$ & White & 47 & No \\
\hline 1185 & 2005 & 8 & 27 & 1 & 47 & Sat & Monongalia & Rape & $\mathrm{M}$ & Black & 32 & Yes \\
\hline 1186 & 2005 & 9 & 3 & 0 & 15 & Sat & Monongalia & \begin{tabular}{|l|} 
Drugs \\
\end{tabular} & $\mathrm{M}$ & Black & 16 & Yes \\
\hline 1187 & 2005 & 9 & 4 & 6 & 17 & Sun & Harrison & Sex_Assault & $\mathrm{M}$ & Black & 34 & Yes \\
\hline 1188 & 2005 & 9 & 11 & 19 & 48 & Sun & Berkley & Assault & $\mathrm{M}$ & Black & 29 & Yes \\
\hline 1189 & 2005 & 9 & 14 & 22 & 8 & Wed & Berkley & Sex_Assault & $\mathrm{M}$ & Hspnc & 44 & Yes \\
\hline 1190 & 2005 & 9 & 17 & 14 & 38 & Sat & Mercer & Accident & $\mathrm{F}$ & White & 28 & No \\
\hline 1191 & 2005 & 9 & 23 & 0 & 34 & Fri & Kanawha & Drugs & $F$ & Black & 27 & Yes \\
\hline 1192 & 2005 & 9 & 28 & 4 & 8 & Wed & Mercer & Burglary & $\mathrm{M}$ & Black & 24 & Yes \\
\hline 1193 & 2005 & 9 & 28 & 3 & 30 & Wed & Cabell & Weap_Threat & $\mathrm{M}$ & Black & 50 & Yes \\
\hline 1194 & 2005 & 9 & 30 & 17 & 52 & Fri & Mercer & Arson & $\mathrm{M}$ & Hspnc & 57 & Yes \\
\hline 1195 & 2005 & 10 & 3 & 20 & 54 & Mon & Hancock & Accident & $\mathrm{M}$ & White & 51 & No \\
\hline 1196 & 2005 & 10 & 14 & 0 & 25 & Fri & Monongalia & Rape & $\mathrm{M}$ & Hspnc & 52 & Yes \\
\hline 1197 & 2005 & 10 & 15 & 23 & 54 & Sat & Hancock & Assault & $\mathrm{M}$ & White & 24 & Yes \\
\hline 1198 & 2005 & 10 & 22 & 2 & 16 & Sat & Cabell & Drugs & $\mathrm{M}$ & Black & 20 & Yes \\
\hline 1199 & 2005 & 10 & 22 & 22 & 45 & Sat & Kanawha & Sex_Assault & $\mathrm{M}$ & White & 57 & Yes \\
\hline 1200 & 2005 & 10 & 23 & 0 & 6 & Sun & Marion & Assault & $\mathrm{M}$ & Black & 24 & No \\
\hline 1201 & 2005 & 10 & 27 & 23 & 26 & Thru & Monongalia & Drugs & $\mathrm{M}$ & Hspnc & 21 & Yes \\
\hline 1202 & 2005 & 10 & 27 & 20 & 35 & Thru & Hancock & Drugs & $\mathrm{M}$ & AorPI & 29 & Yes \\
\hline 1203 & 2005 & 10 & 30 & 3 & 28 & Sun & Monongalia & Murder & $\mathrm{M}$ & Black & 41 & Yes \\
\hline 1204 & 2005 & 11 & 3 & 23 & 49 & Thru & Raleigh & Drugs & $\mathrm{M}$ & White & 21 & No \\
\hline 1205 & 2005 & 11 & 27 & 3 & 3 & Sun & Berkley & Rape & $\mathrm{M}$ & Black & 47 & Yes \\
\hline 1206 & 2005 & 11 & 29 & 1 & 55 & Tue & Kanawha & Accident & $\mathrm{M}$ & Black & 60 & Yes \\
\hline 1207 & 2005 & 11 & 30 & 3 & 19 & Wed & Cabell & Burglary & $\mathrm{M}$ & Black & 22 & Yes \\
\hline 1208 & 2005 & 11 & 30 & 15 & 0 & Wed & Hancock & Arson & $\mathrm{M}$ & Black & 41 & Yes \\
\hline 1209 & 2005 & 11 & 30 & 23 & 1 & Wed & Berkley & \begin{tabular}{|l|} 
Drugs \\
\end{tabular} & $\mathrm{M}$ & Black & 28 & Yes \\
\hline 1210 & 2005 & 12 & 3 & 21 & 33 & Sat & Monongalia & Drugs & $\mathrm{M}$ & Black & 23 & Yes \\
\hline 1211 & 2005 & 12 & 17 & 0 & 40 & Sat & Monongalia & Drugs & $\mathrm{F}$ & Black & 15 & No \\
\hline 1212 & 2005 & 12 & 22 & 19 & 27 & Thru & Monongalia & \begin{tabular}{|l|} 
Drugs \\
\end{tabular} & $\mathrm{F}$ & \begin{tabular}{|l|} 
White \\
\end{tabular} & 23 & Yes \\
\hline 1213 & 2005 & 12 & 22 & 14 & 15 & Thru & Mercer & Rape & $M$ & Black & 27 & Yes \\
\hline 1214 & 2005 & 12 & 26 & 6 & 26 & Mon & Berkley & Accident & $\mathrm{M}$ & \begin{tabular}{|l|} 
Black \\
\end{tabular} & 67 & No \\
\hline 1215 & 2005 & 12 & 26 & 7 & 47 & Mon & Harrison & Accident & $\mathrm{M}$ & White & 63 & No \\
\hline 1216 & 2005 & 12 & 30 & 0 & 55 & Fri & Monongalia & \begin{tabular}{|l|} 
Drugs \\
\end{tabular} & $\mathrm{M}$ & AorPI & 23 & No \\
\hline 1217 & 2005 & 12 & 31 & 1 & 29 & Sat & Kanawha & Rape & $\mathrm{M}$ & White & 45 & Yes \\
\hline 1218 & 2005 & 12 & 31 & 22 & 12 & Sat & Berkley & Sex_Assault & $\mathrm{M}$ & Black & 49 & Yes \\
\hline 1219 & 2005 & 12 & 31 & 23 & 53 & Sat & \begin{tabular}{|l|} 
Kanawha \\
\end{tabular} & Rape & $\mathrm{M}$ & Black & 27 & No \\
\hline 1220 & 2006 & 1 & 1 & 14 & 41 & Sun & Mercer & Weap_Threat & $\mathrm{M}$ & Black & 24 & Yes \\
\hline 1221 & 2006 & 1 & 1 & 23 & 26 & Sun & Marion & Burglary & $M$ & AorPI & 50 & Yes \\
\hline 1222 & 2006 & 1 & 3 & 15 & 2 & Tue & Monongalia & \begin{tabular}{|l|} 
Drugs \\
\end{tabular} & $\mathrm{M}$ & Black & 18 & Yes \\
\hline 1223 & 2006 & 1 & 7 & 0 & 19 & Sat & Cabell & Arson & $\mathrm{M}$ & White & 51 & No \\
\hline 1224 & 2006 & 1 & 7 & 21 & 27 & Sat & Monongalia & Rape & $\mathrm{M}$ & Black & 53 & Yes \\
\hline 1225 & 2006 & 1 & 12 & 19 & 50 & Thru & Berkley & Drugs & $\mathrm{M}$ & Black & 26 & Yes \\
\hline 1226 & 2006 & 1 & 14 & 20 & 56 & Sat & Harrison & Assault & $\mathrm{M}$ & White & 33 & Yes \\
\hline 1227 & 2006 & 1 & 17 & 0 & 20 & Tue & Mercer & Weap_Threat & $\mathrm{M}$ & Black & 22 & Yes \\
\hline 1228 & 2006 & 1 & 20 & 3 & 34 & Fri & Hancock & Weap_Threat & $\mathrm{M}$ & White & 56 & Yes \\
\hline
\end{tabular}




\begin{tabular}{|c|c|c|c|c|c|c|c|c|c|c|c|c|}
\hline 1229 & 2006 & 1 & 20 & 3 & 47 & Fri & Monongalia & \begin{tabular}{|l} 
Drugs \\
\end{tabular} & $\mathrm{M}$ & Black & 19 & No \\
\hline 1230 & 2006 & 1 & 30 & 6 & 40 & Mon & Harrison & Accident & $M$ & Hspnc & 19 & No \\
\hline 1231 & 2006 & 1 & 31 & 18 & 14 & Tue & Marion & Burglary & $\mathrm{M}$ & Hspnc & 53 & Yes \\
\hline 1232 & 2006 & 2 & 4 & 0 & 53 & Sat & Monongalia & Rape & $\mathrm{M}$ & Black & 45 & Yes \\
\hline 1233 & 2006 & 2 & 9 & 18 & 38 & Thru & \begin{tabular}{|l|} 
Kanawha \\
\end{tabular} & \begin{tabular}{|l|} 
Drugs \\
\end{tabular} & $\mathrm{M}$ & \begin{tabular}{|l} 
White \\
\end{tabular} & 24 & Yes \\
\hline 1234 & 2006 & 2 & 11 & 23 & 59 & Sat & Raleigh & Rape & $\mathrm{M}$ & Black & 29 & Yes \\
\hline 1235 & 2006 & 2 & 12 & 23 & 8 & Sun & Monongalia & Sex_Assault & $\mathrm{M}$ & AorPI & 36 & Yes \\
\hline 1236 & 2006 & 2 & 16 & 0 & 27 & Thru & Harrison & Drugs & $\mathrm{M}$ & Black & 16 & No \\
\hline 1237 & 2006 & 2 & 23 & 19 & 57 & Thru & Mercer & Accident & $\mathrm{M}$ & Hspnc & 56 & No \\
\hline 1238 & 2006 & 2 & 23 & 21 & 37 & Thru & Marion & Weap_Threat & $\mathrm{M}$ & Black & 27 & Yes \\
\hline 1239 & 2006 & 2 & 28 & 2 & 45 & Tue & Cabell & Burglary & $\mathrm{M}$ & AorPI & 46 & Yes \\
\hline 1240 & 2006 & 3 & 2 & 21 & 42 & Thru & Hancock & Rape & $\mathrm{M}$ & Black & 36 & Yes \\
\hline 1241 & 2006 & 3 & 4 & 22 & 39 & Sat & Monongalia & Rape & $\mathrm{M}$ & Black & 49 & Yes \\
\hline 1242 & 2006 & 3 & 5 & 14 & 17 & Sun & Monongalia & Assault & $\mathrm{M}$ & Black & 33 & No \\
\hline 1243 & 2006 & 3 & 6 & 9 & 19 & Mon & Marion & Accident & $\mathrm{M}$ & AorPI & 39 & No \\
\hline 1244 & 2006 & 3 & 6 & 20 & 9 & Mon & Raleigh & Accident & $\mathrm{M}$ & Black & 49 & No \\
\hline 1245 & 2006 & 3 & 16 & 23 & 4 & Thru & Monongalia & \begin{tabular}{|l|} 
Drugs \\
\end{tabular} & $\mathrm{M}$ & AorPI & 23 & No \\
\hline 1246 & 2006 & 3 & 29 & 14 & 56 & Wed & Hancock & Burglary & $\mathrm{F}$ & White & 22 & Yes \\
\hline 1247 & 2006 & 3 & 30 & 22 & 34 & Thru & Marion & \begin{tabular}{|l|} 
Drugs \\
\end{tabular} & $\mathrm{M}$ & Black & 15 & No \\
\hline 1248 & 2006 & 4 & 1 & 18 & 53 & Sat & Mercer & Sex_Assault & $\mathrm{M}$ & White & 45 & Yes \\
\hline 1249 & 2006 & 4 & 1 & 19 & 23 & Sat & Monongalia & Rape & $\mathrm{M}$ & Black & 38 & Yes \\
\hline 1250 & 2006 & 4 & 2 & 2 & 38 & Sun & Marion & Murder & $\mathrm{M}$ & Hspnc & 49 & Yes \\
\hline 1251 & 2006 & 4 & 2 & 2 & 46 & Sun & Monongalia & \begin{tabular}{|l} 
Burglary \\
\end{tabular} & $\mathrm{M}$ & White & 15 & No \\
\hline 1252 & 2006 & 4 & 15 & 1 & 43 & Sat & Mercer & Rape & $M$ & Hspnc & 44 & Yes \\
\hline 1253 & 2006 & 4 & 18 & 7 & 15 & Tue & Raleigh & Accident & $\mathrm{M}$ & Black & 20 & Yes \\
\hline 1254 & 2006 & 4 & 21 & 1 & 17 & Fri & Marion & \begin{tabular}{|l|} 
Drugs \\
\end{tabular} & $\mathrm{M}$ & Hspnc & 28 & Yes \\
\hline 1255 & 2006 & 4 & 26 & 8 & 59 & Wed & Cabell & Accident & $\mathrm{M}$ & White & 41 & Yes \\
\hline 1256 & 2006 & 5 & 1 & 20 & 16 & Mon & Monongalia & Sex_Assault & $\mathrm{M}$ & Black & 31 & Yes \\
\hline 1257 & 2006 & 5 & 6 & 1 & 52 & Sat & Monongalia & Drugs & $\mathrm{M}$ & Black & 53 & Yes \\
\hline 1258 & 2006 & 5 & 8 & 0 & 4 & Mon & Mercer & Accident & $\mathrm{M}$ & Hspnc & 42 & No \\
\hline 1259 & 2006 & 5 & 8 & 11 & 49 & Mon & Cabell & \begin{tabular}{|l|} 
Burglary \\
\end{tabular} & $\mathrm{M}$ & White & 24 & Yes \\
\hline 1260 & 2006 & 5 & 9 & 16 & 46 & Tue & Harrison & Accident & $\mathrm{F}$ & AorPI & 44 & No \\
\hline 1261 & 2006 & 5 & 12 & 19 & 15 & Fri & Mercer & Arson & $\mathrm{M}$ & Hspnc & 28 & Yes \\
\hline 1262 & 2006 & 5 & 12 & 4 & 24 & Fri & Monongalia & Sex_Assault & $\mathrm{M}$ & White & 27 & Yes \\
\hline 1263 & 2006 & 5 & 14 & 0 & 23 & Sun & Cabell & Weap_Threat & $\mathrm{F}$ & Black & 31 & No \\
\hline 1264 & 2006 & 5 & 14 & 14 & 39 & Sun & Kanawha & Assault & $\mathrm{M}$ & Hspnc & 24 & Yes \\
\hline 1265 & 2006 & 5 & 15 & 15 & 19 & Mon & Marion & Accident & $\mathrm{M}$ & Black & 50 & No \\
\hline 1266 & 2006 & 5 & 15 & 15 & 38 & Fri & Raleigh & Rape & $\mathrm{M}$ & Black & 48 & Yes \\
\hline 1267 & 2006 & 5 & 19 & 22 & 11 & Fri & Berkley & Accident & $\mathrm{M}$ & \begin{tabular}{|l} 
White \\
\end{tabular} & 51 & No \\
\hline 1268 & 2006 & 5 & 23 & 12 & 24 & Tue & Harrison & Arson & $M$ & Black & 23 & No \\
\hline 1269 & 2006 & 5 & 23 & 18 & 5 & Tue & Cabell & \begin{tabular}{|l|} 
Burglary \\
\end{tabular} & $\mathrm{M}$ & White & 45 & Yes \\
\hline 1270 & 2006 & 5 & 26 & 2 & 56 & Fri & Monongalia & \begin{tabular}{|l|} 
Drugs \\
\end{tabular} & $\mathrm{M}$ & White & 23 & Yes \\
\hline 1271 & 2006 & 5 & 27 & 15 & 15 & Sat & Raleigh & Rape & $\mathrm{M}$ & Black & 50 & Yes \\
\hline 1272 & 2006 & 5 & 29 & 22 & 6 & Mon & Marion & Murder & $\mathrm{M}$ & Hspnc & 57 & Yes \\
\hline 1273 & 2006 & 6 & 1 & 19 & 2 & Thru & Monongalia & \begin{tabular}{|l|} 
Drugs \\
\end{tabular} & $\mathrm{M}$ & AorPI & 21 & Yes \\
\hline 1274 & 2006 & 6 & 3 & 19 & 3 & Sat & Monongalia & Rape & $\mathrm{M}$ & Black & 45 & No \\
\hline 1275 & 2006 & 6 & 9 & 0 & 25 & Fri & Berkley & Drugs & $M$ & Black & 14 & No \\
\hline
\end{tabular}




\begin{tabular}{|c|c|c|c|c|c|c|c|c|c|c|c|c|}
\hline 1276 & 2006 & 6 & 12 & 21 & 57 & Mon & Cabell & Rape & $\mathrm{M}$ & Black & 54 & Yes \\
\hline 1277 & 2006 & 6 & 17 & 0 & 45 & Sat & Mercer & Sex_Assault & $M$ & Black & 38 & Yes \\
\hline 1278 & 2006 & 6 & 17 & 1 & 33 & Sat & Harrison & Rape & $\mathrm{M}$ & Black & 37 & Yes \\
\hline 1279 & 2006 & 6 & 23 & 18 & 8 & Fri & Berkley & Assault & $\mathrm{M}$ & Black & 24 & Yes \\
\hline 1280 & 2006 & 6 & 25 & 9 & 44 & Sun & Monongalia & \begin{tabular}{|l|} 
Drugs \\
\end{tabular} & $\mathrm{M}$ & AorPI & 22 & Yes \\
\hline 1281 & 2006 & 6 & 28 & 9 & 36 & Wed & Raleigh & Accident & $\mathrm{M}$ & Hspnc & 57 & No \\
\hline 1282 & 2006 & 6 & 28 & 20 & 14 & Wed & Kanawha & Assault & $\mathrm{M}$ & Hspnc & 51 & Yes \\
\hline 1283 & 2006 & 7 & 1 & 18 & 14 & Sat & Monongalia & Burglary & $\mathrm{M}$ & Hspnc & 62 & Yes \\
\hline 1284 & 2006 & 7 & 2 & 10 & 42 & Sun & Hancock & Weap_Threat & $\mathrm{M}$ & White & 51 & Yes \\
\hline 1285 & 2006 & 7 & 5 & 10 & 27 & Wed & Monongalia & Accident & $F$ & AorPI & 24 & No \\
\hline 1286 & 2006 & 7 & 5 & 19 & 27 & Wed & Mercer & Sex_Assault & $\mathrm{M}$ & White & 26 & Yes \\
\hline 1287 & 2006 & 7 & 8 & 0 & 39 & Sat & Berkley & Rape & $\mathrm{M}$ & Black & 39 & Yes \\
\hline 1288 & 2006 & 7 & 11 & 14 & 23 & Tue & Hancock & Accident & $\mathrm{F}$ & Hspnc & 59 & Yes \\
\hline 1289 & 2005 & 7 & 16 & 23 & 35 & Sat & Monongalia & Sex_Assault & $\mathrm{M}$ & Black & 36 & No \\
\hline 1290 & 2006 & 7 & 24 & 0 & 3 & Mon & Harrison & Accident & $\mathrm{M}$ & Black & 53 & No \\
\hline 1291 & 2006 & 7 & 30 & 20 & 56 & Sun & Mercer & Weap_Threat & $\mathrm{M}$ & Black & 25 & Yes \\
\hline 1292 & 2006 & 8 & 2 & 1 & 56 & Wed & Cabell & Burglary & $\mathrm{M}$ & Hspnc & 34 & Yes \\
\hline 1293 & 2006 & 8 & 6 & 21 & 6 & Sun & Harrison & Accident & $\mathrm{M}$ & Black & 29 & No \\
\hline 1294 & 2006 & 8 & 6 & 0 & 33 & Sun & Berkley & Accident & $\mathrm{M}$ & White & 24 & Yes \\
\hline 1295 & 2006 & 8 & 10 & 23 & 5 & Thru & Marion & Drugs & $\mathrm{M}$ & Black & 33 & Yes \\
\hline 1296 & 2006 & 8 & 11 & 21 & 7 & Fri & Monongalia & Rape & $\mathrm{M}$ & \begin{tabular}{|l|} 
White \\
\end{tabular} & 56 & Yes \\
\hline 1297 & 2006 & 8 & 25 & 22 & 23 & Fri & Cabell & Sex_Assault & $\mathrm{M}$ & Hspnc & 27 & Yes \\
\hline 1298 & 2006 & 8 & 26 & 9 & 56 & Sat & Monongalia & Rape & $\mathrm{M}$ & Black & 41 & No \\
\hline 1299 & 2006 & 8 & 28 & 19 & 52 & Mon & Mercer & Accident & $M$ & White & 46 & No \\
\hline 1300 & 2006 & 9 & 3 & 1 & 19 & Sun & Harrison & Burglary & $\mathrm{M}$ & Hspnc & 22 & Yes \\
\hline 1301 & 2006 & 9 & 3 & 22 & 15 & Sun & Marion & Murder & $\mathrm{M}$ & Black & 39 & Yes \\
\hline 1302 & 2006 & 9 & 6 & 11 & 33 & Wed & Harrison & Accident & $\mathrm{M}$ & White & 19 & Yes \\
\hline 1303 & 2006 & 9 & 8 & 10 & 40 & Fri & Hancock & Weap_Threat & $\mathrm{F}$ & \begin{tabular}{|l|} 
White \\
\end{tabular} & 33 & Yes \\
\hline 1304 & 2006 & 9 & 23 & 10 & 52 & Sat & Monongalia & Sex_Assault & $\mathrm{M}$ & Black & 43 & Yes \\
\hline 1305 & 2006 & 9 & 24 & 0 & 5 & Sun & Monongalia & Arson & $\mathrm{M}$ & White & 19 & No \\
\hline 1306 & 2006 & 9 & 25 & 9 & 49 & Mon & Mercer & Accident & $\mathrm{M}$ & Black & 45 & No \\
\hline 1307 & 2006 & 9 & 29 & 2 & 0 & Fri & Hancock & Drugs & $M$ & Black & 14 & No \\
\hline 1308 & 2006 & 10 & 5 & 23 & 23 & Thru & Monongalia & Sex_Assault & $\mathrm{M}$ & \begin{tabular}{|l|} 
Black \\
\end{tabular} & 33 & Yes \\
\hline 1309 & 2006 & 10 & 15 & 22 & 54 & Sun & Cabell & Accident & $\mathrm{M}$ & Black & 44 & Yes \\
\hline 1310 & 2006 & 10 & 17 & 2 & 38 & Tue & Mercer & Burglary & $\mathrm{M}$ & Black & 20 & Yes \\
\hline 1311 & 2006 & 10 & 21 & 0 & 10 & Sat & Raleigh & Rape & $\mathrm{M}$ & Black & 42 & Yes \\
\hline 1312 & 2006 & 10 & 23 & 1 & 48 & Mon & Cabell & Accident & $\mathrm{M}$ & White & 51 & No \\
\hline 1313 & 2006 & 10 & 24 & 13 & 6 & Tue & Harrison & Accident & $\mathrm{M}$ & Black & 62 & Yes \\
\hline 1314 & 2006 & 10 & 30 & 13 & 17 & Mon & Cabell & Burglary & $\mathrm{M}$ & \begin{tabular}{|l|} 
White \\
\end{tabular} & 31 & Yes \\
\hline 1315 & 2006 & 11 & 2 & 18 & 23 & Thru & Monongalia & Drugs & $M$ & AorPI & 21 & No \\
\hline 1316 & 2006 & 11 & 6 & 19 & 34 & Mon & \begin{tabular}{|l|} 
Kanawha \\
\end{tabular} & Sex_Assault & $\mathrm{M}$ & Hspnc & 52 & Yes \\
\hline 1317 & 2006 & 11 & 21 & 21 & 54 & Tue & Hancock & Weap_Threat & $\mathrm{M}$ & Black & 30 & Yes \\
\hline 1318 & 2006 & 11 & 21 & 15 & 16 & Tue & Marion & Burglary & $\mathrm{M}$ & AorPI & 22 & Yes \\
\hline 1319 & 2006 & 11 & 23 & 0 & 59 & Fri & Raleigh & Rape & $\mathrm{M}$ & Black & 50 & Yes \\
\hline 1320 & 2006 & 11 & 30 & 21 & 35 & Thru & Monongalia & Drugs & $\mathrm{M}$ & AorPI & 24 & Yes \\
\hline 1321 & 2006 & 12 & 6 & 13 & 27 & Wed & Harrison & Accident & $\mathrm{M}$ & Black & 15 & No \\
\hline 1322 & 2006 & 12 & 23 & 19 & 40 & Sat & Hancock & Drugs & $\mathrm{M}$ & Hspnc & 53 & Yes \\
\hline
\end{tabular}




\begin{tabular}{|l|l|l|l|l|l|l|l|l|l|l|l|l|}
\hline 1323 & 2006 & 12 & 23 & 19 & 10 & Sat & Monongalia & Sex_Assault & M & Black & 45 & Yes \\
\hline 1324 & 2006 & 12 & 25 & 9 & 12 & Mon & Berkley & Accident & M & Black & 25 & No \\
\hline 1325 & 2006 & 12 & 25 & 11 & 18 & Mon & Monongalia & Weap_Threat & M & Black & 29 & Yes \\
\hline 1326 & 2006 & 12 & 30 & 11 & 56 & Sat & Monongalia & Rape & M & Black & 43 & No \\
\hline 1327 & 2006 & 12 & 30 & 22 & 45 & Sat & Cabell & Accident & M & White & 24 & No \\
\hline 1328 & 2006 & 12 & 31 & 8 & 54 & Sun & Mercer & Sex_Assault & M & Black & 33 & Yes \\
\hline 1329 & 2006 & 12 & 31 & 0 & 22 & Sun & Harrison & Accident & M & White & 56 & Yes \\
\hline 1330 & 2006 & 12 & 31 & 0 & 53 & Sun & Raleigh & Rape & M & Black & 37 & Yes \\
\hline
\end{tabular}




\section{APPENDIX B: Requirements Document}

This is a customized and brief form of a requirements document; the original documents are much more extensive and cover other modules such as Database Requirement, Navigation Requirement, etc. Ones document encapsulates the all the aspects of the model into one single document. This helps in clear understanding of various functions and constrains. Finally, the document is an outline to what the model is all about.

\section{Objective}

The objective of the model is to allow the end user to navigate through all the data searching and mining technique, use them with the data stored in the pre-selected data table and store the results of his / her choice in order to refer back to it at the end.

\section{Scope}

a. Allow the user to select the data mining and search technique of his choice.

b. Provide a data source where the user is able to execute the selected algorithm without any concern of the data, algorithms or techniques.

c. Provide ability of storing the results for further reference.

\section{End-users}

This model is intended for use by detectives of different crime investigation agencies such as State Police Dept. and FBI.

\section{Assumptions}

The user should have basic knowledge of Searching / Querying techniques and ability of interpreting the results of Data Mining algorithms. 


\section{Constraints}

The tool works only with predefined data table. Web functionality cannot be provided to all the features in the model.

\section{Model Requirements}

a. The tool should have an appropriate navigational structure.

b. The tool should have a database capable of addressing issues as per the objective.

c. The different algorithms used in the tool should generate correct results.

d. The obtained results should serve the objective.

\section{Model Functionality}

The tool design would be such that the end user must have basic data querying and interpretation knowledge. Initially, the Data Mining methods would assist to identify relationship between different variables of the Query Table and find out any non-obvious crime patterns in it. The searching algorithms would then be used by putting in specific queries that based on the patterns would find specific details about the pattern.

\section{Testing Considerations}

a. Does the tool help the end user meet the functional requirements?

b. Is the user interface consistent and user friendly?

c. Is the tool database robust so as to meet different or specific needs of the end user?

d. Are the results provided by the tool correct and serve purpose of the end user? 


\section{APPENDIX C: Association Rules Output}

Association Rule output with columns “OffDay", "OffType”, "County” and "Race”.

$$
\begin{array}{ll}
\text { Monongalia-Black } & : 42 \\
\text { Sat-Black } & : 41 \\
\text { Tue-Black } & : 30 \\
\text { Sat-Monongalia } & : 30 \\
\text { Sun-Black } & : 27 \\
\text { Accident-White } & : 26 \\
\text { Drugs - Black } & : 26 \\
\text { Accident-Black } & : 25 \\
\text { Monongalia-Drugs } & : 24 \\
\text { Cabell-Burglary } & : 22 \\
\text { Tue-Burglary } & : 21
\end{array}
$$

Association Rule output with columns "OffDay", "OffType” and "County".

$$
\begin{array}{ll}
\text { Sat-Monongalia } & : 30 \\
\text { Monongalia-Drugs } & : 24 \\
\text { Cabell-Burglary } & : 22 \\
\text { Tue-Burglary } & : 21 \\
\text { Tue-Accident } & : 13 \\
\text { Tue-Cabell } & : 12 \\
\text { Sat-Drugs } & : 12 \\
\text { Sun-Burglary } & : 10 \\
\text { Sun-Cabell } & : 8 \\
\text { Sun-Monongalia } & : 8 \\
\text { Cabell-Accident } & : 8
\end{array}
$$


Association Rule output with columns "OffDay" and "OffType".

\begin{tabular}{|ll|}
\hline Tue - Burglary & $: 21$ \\
Tue-Accident & $: 13$ \\
Sat - Drugs & $: 12$ \\
Sun - Burglary & $: 10$ \\
Sun - Accident & $: 8$ \\
Sat - Accident & $: 4$ \\
Sat - Burglary & $: 3$ \\
Tue - Drugs & $: 2$ \\
Sun - Drugs & $: 1$ \\
\hline
\end{tabular}

Association Rule output with columns "OffDay" and "County".

$\begin{array}{|ll|}\text { Sat-Monongalia } & : 30 \\ \text { Tue-Cabell } & : 12 \\ \text { Sun-Monongalia } & : 8 \\ \text { Sun-Cabell } & : 8 \\ \text { Tue-Monongalia } & : 7 \\ \text { Sat-Cabell } & : 6 \\ \text { Sat-Hancock } & : 6 \\ \text { Sun-Hancock } & : 6 \\ \text { Tue-Hancock } & : 4 \\ & \\ \end{array}$




\section{APPENDIX D: Decision Rule Output}

Decision Rule Output with Field as "OffType" and Field Value as "Accident".

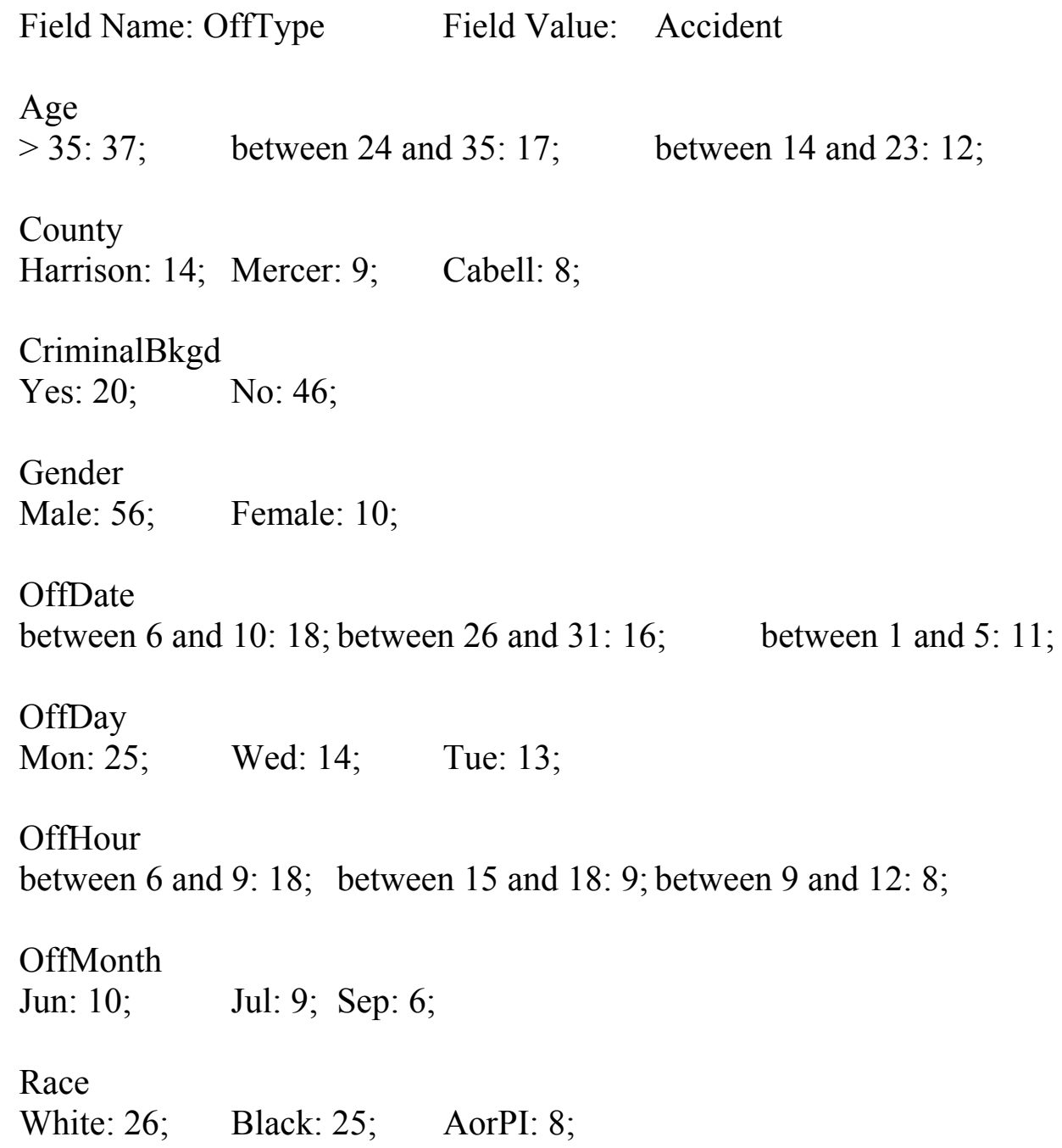


Decision Rule Output with Field as "OffType" and Field Value as "Arson".

\begin{tabular}{|c|c|}
\hline Field Name: OffType & Field Value: Arson \\
\hline between 24 and 35: 8; & between 14 and 23: 5; \\
\hline $\begin{array}{l}\text { County } \\
\text { Harrison: 7; Cabell: 3; }\end{array}$ & Kanawha: 2; \\
\hline CriminalBkgd & \\
\hline \multicolumn{2}{|l|}{ Male: 19; } \\
\hline $\begin{array}{l}\text { OffDate } \\
\text { between } 26 \text { and 31: 6; }\end{array}$ & between 21 and 25: 4; \\
\hline OffDay & Fri:3; \\
\hline $\begin{array}{l}\text { OffHour } \\
\text { between } 15 \text { and 18: 4; }\end{array}$ & between 21 and 24: 4; \\
\hline \multicolumn{2}{|l|}{ OffMonth } \\
\hline $\begin{array}{l}\text { Race } \\
\text { Black: 9; }\end{array}$ & Hspnc: 2; \\
\hline
\end{tabular}


Decision Rule Output with Field as "OffType" and Field Value as "Assault".

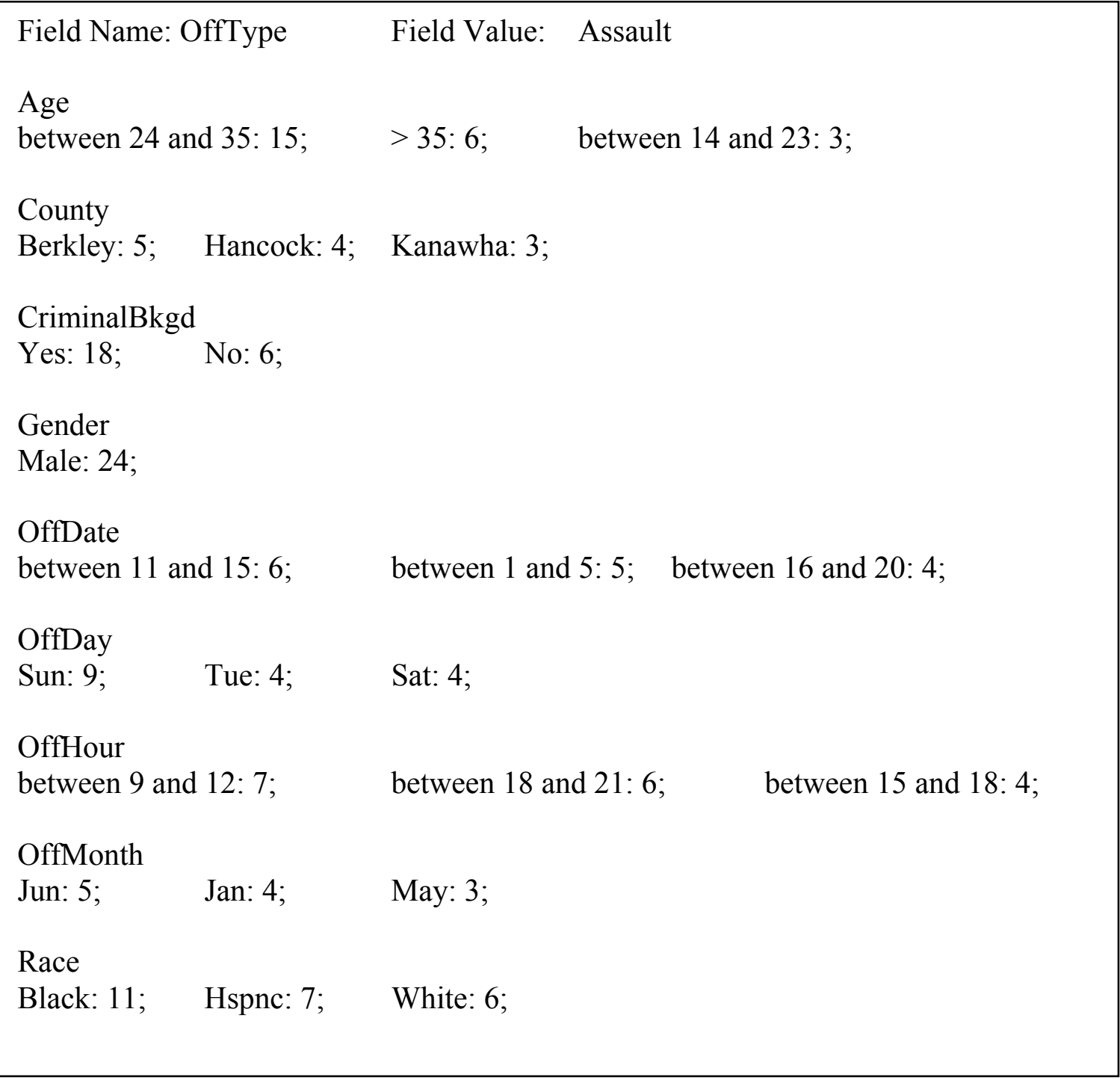


Decision Rule Output with Field as "OffType" and Field Value as "Burglary".

\begin{tabular}{|c|c|c|c|}
\hline \multicolumn{2}{|c|}{ Field Name: OffType } & \multicolumn{2}{|l|}{ Field Value: } \\
\hline $\begin{array}{l}\text { Age } \\
>35: 20\end{array}$ & \multicolumn{3}{|c|}{ between 24 and 35 : 18; } \\
\hline $\begin{array}{l}\text { County } \\
\text { Cabell: 22; }\end{array}$ & Mercer: 8; & \multicolumn{2}{|l|}{ Marion: 6; } \\
\hline $\begin{array}{l}\text { CriminalBk } \\
\text { Yes: } 40\end{array}$ & No: 9; & & \\
\hline $\begin{array}{l}\text { Gender } \\
\text { Male: 43; }\end{array}$ & Female: 6; & & \\
\hline $\begin{array}{l}\text { OffDate } \\
\text { between } 26\end{array}$ & d 31: 13; & between 1 and 5: 9; & en 6 and 10: 7 \\
\hline $\begin{array}{l}\text { OffDay } \\
\text { Tue: } 21 ;\end{array}$ & Wed: 12 & Sun: 10 & \\
\hline $\begin{array}{l}\text { OffHour } \\
\text { between } 3 \text { a }\end{array}$ & $6: 14$ & between 12 and 15: 7; & between 18 and 21: 6; \\
\hline $\begin{array}{l}\text { OffMonth } \\
\text { Feb: } 7\end{array}$ & May: 6; & Jan: 5; & \\
\hline $\begin{array}{l}\text { Race } \\
\text { Hspnc: 15; }\end{array}$ & Black: 13; & White: 13; & \\
\hline
\end{tabular}


Decision Rule Output with Field as "OffType" and Field Value as "Drugs".

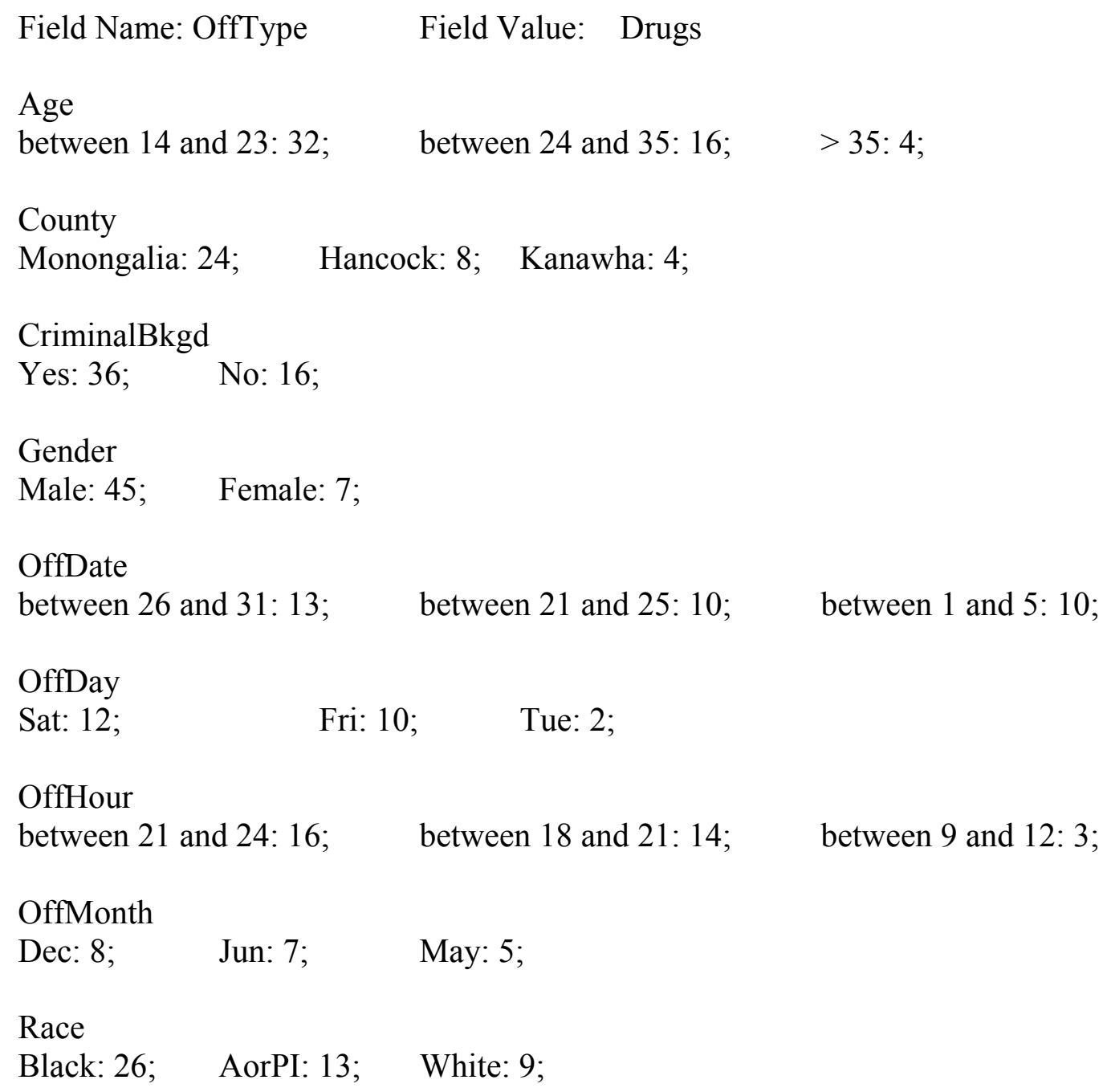


Decision Rule Output with Field as "OffType" and Field Value as "Murder".

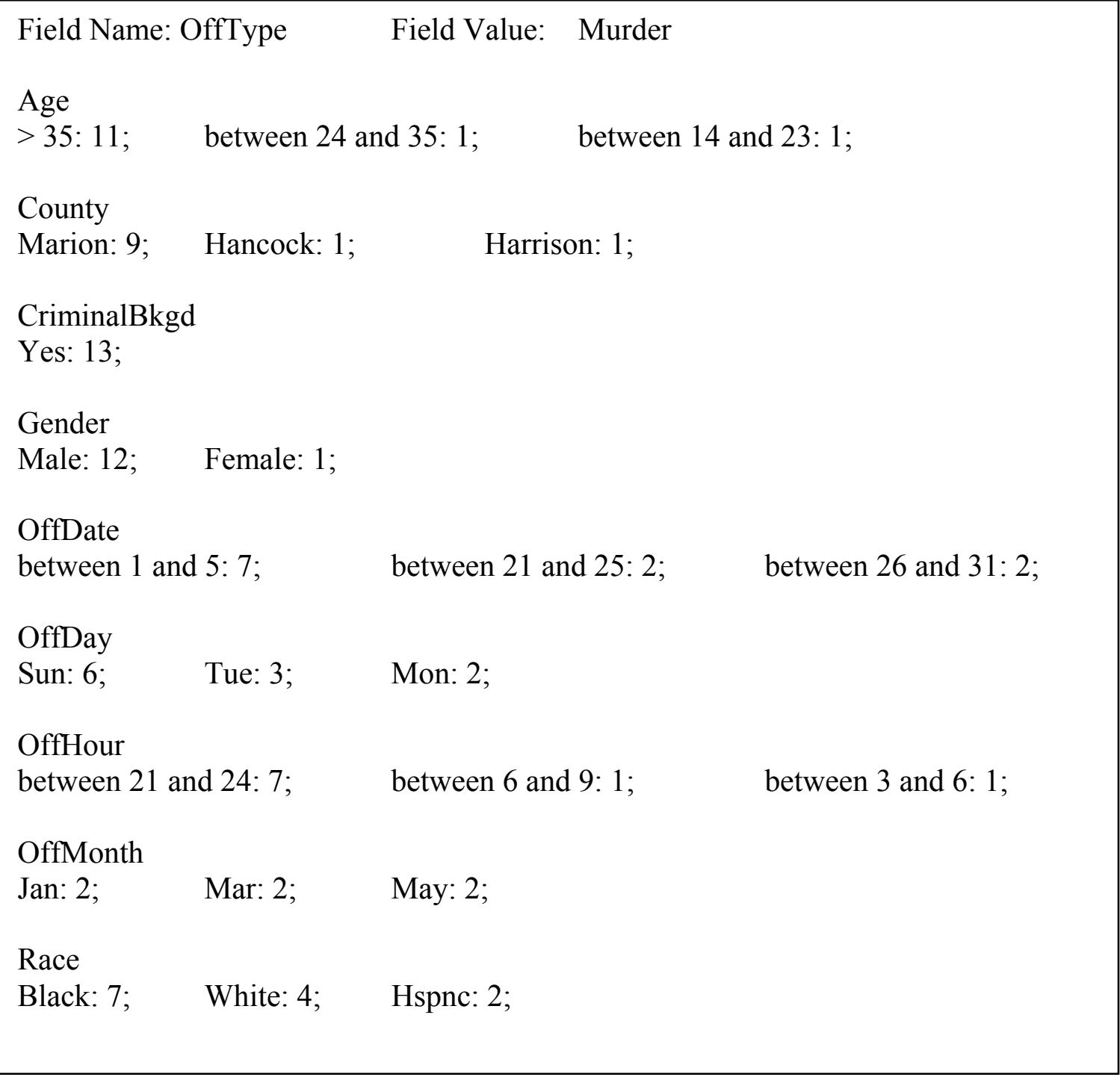


Decision Rule Output with Field as "OffType" and Field Value as "Rape".

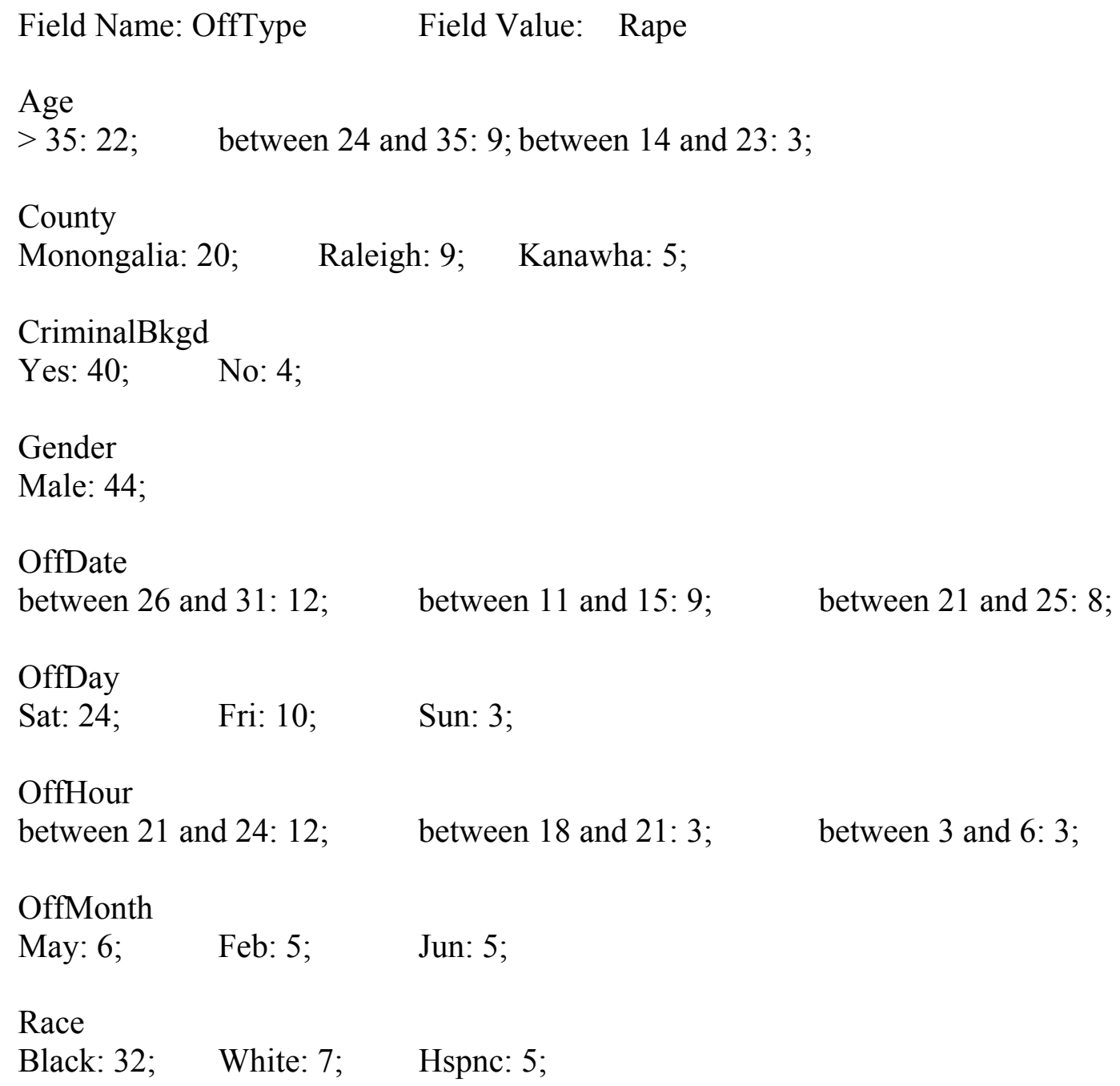


Decision Rule Output with Field as "OffType" and Field Value as "Sex_Assault".

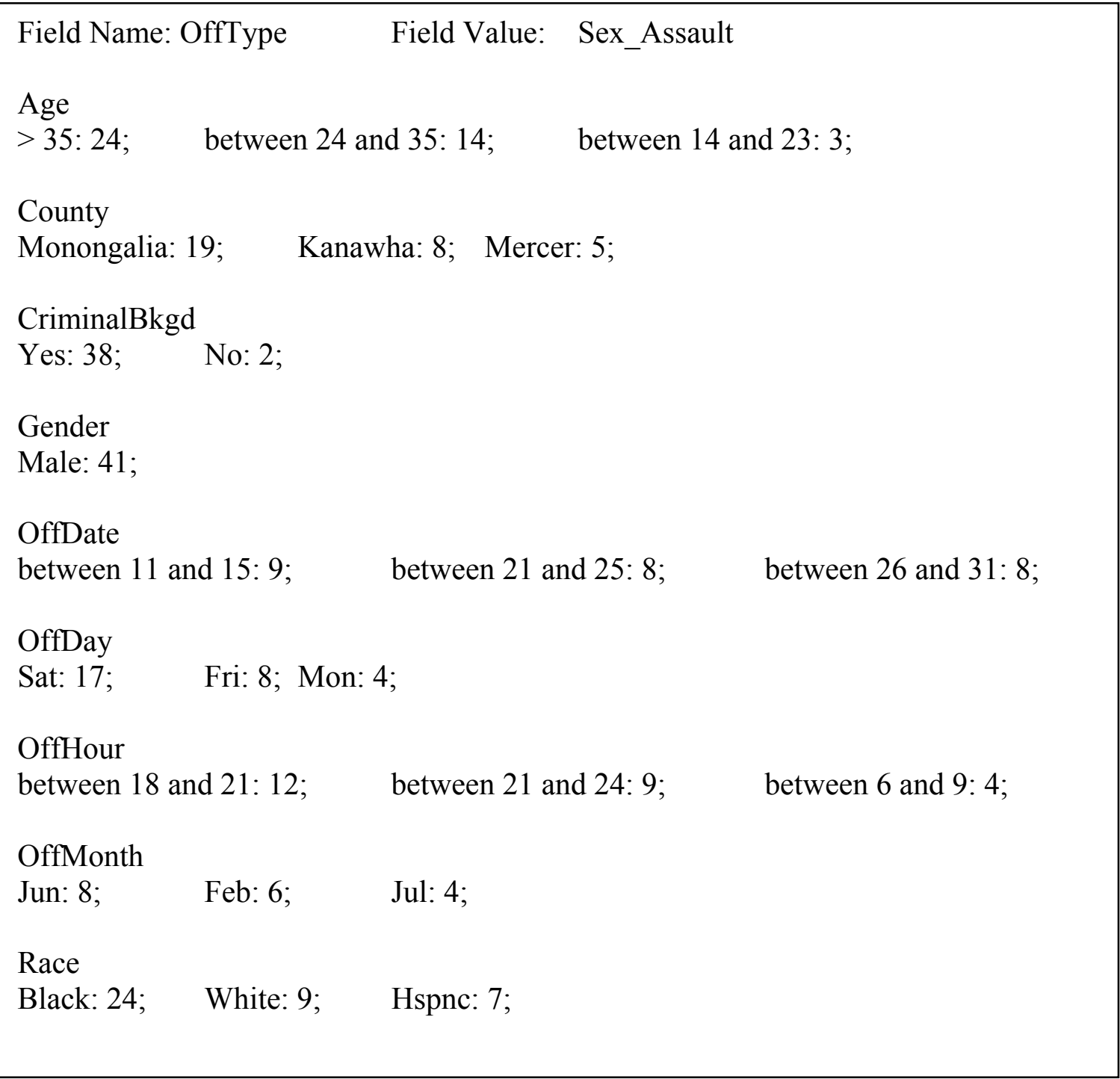


Decision Rule Output with Field as "OffType" and Field Value as "Weap_Threat".

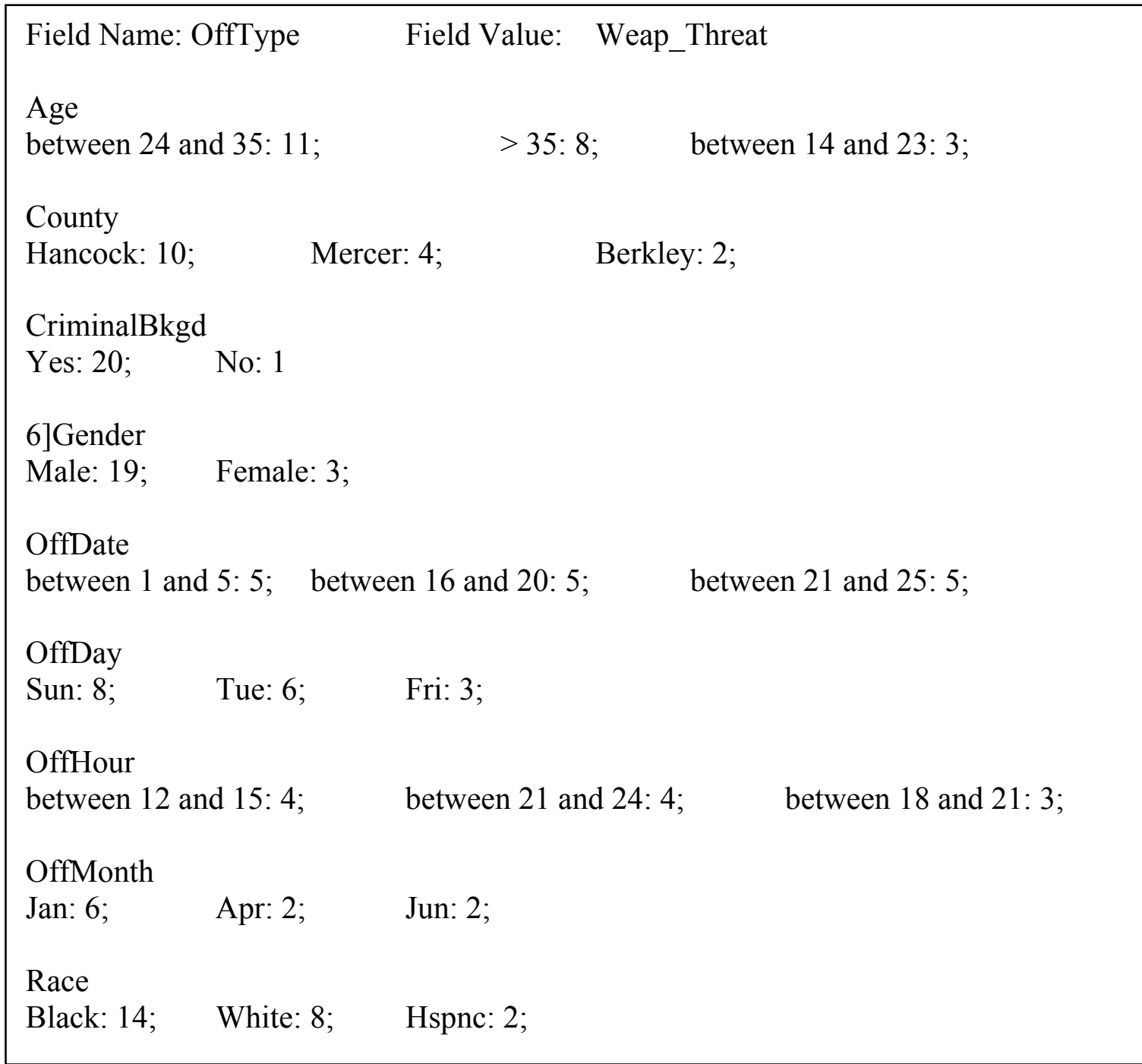




\section{APPENDIX E: WEKA Output}

Apriori Output with 6 attributes.

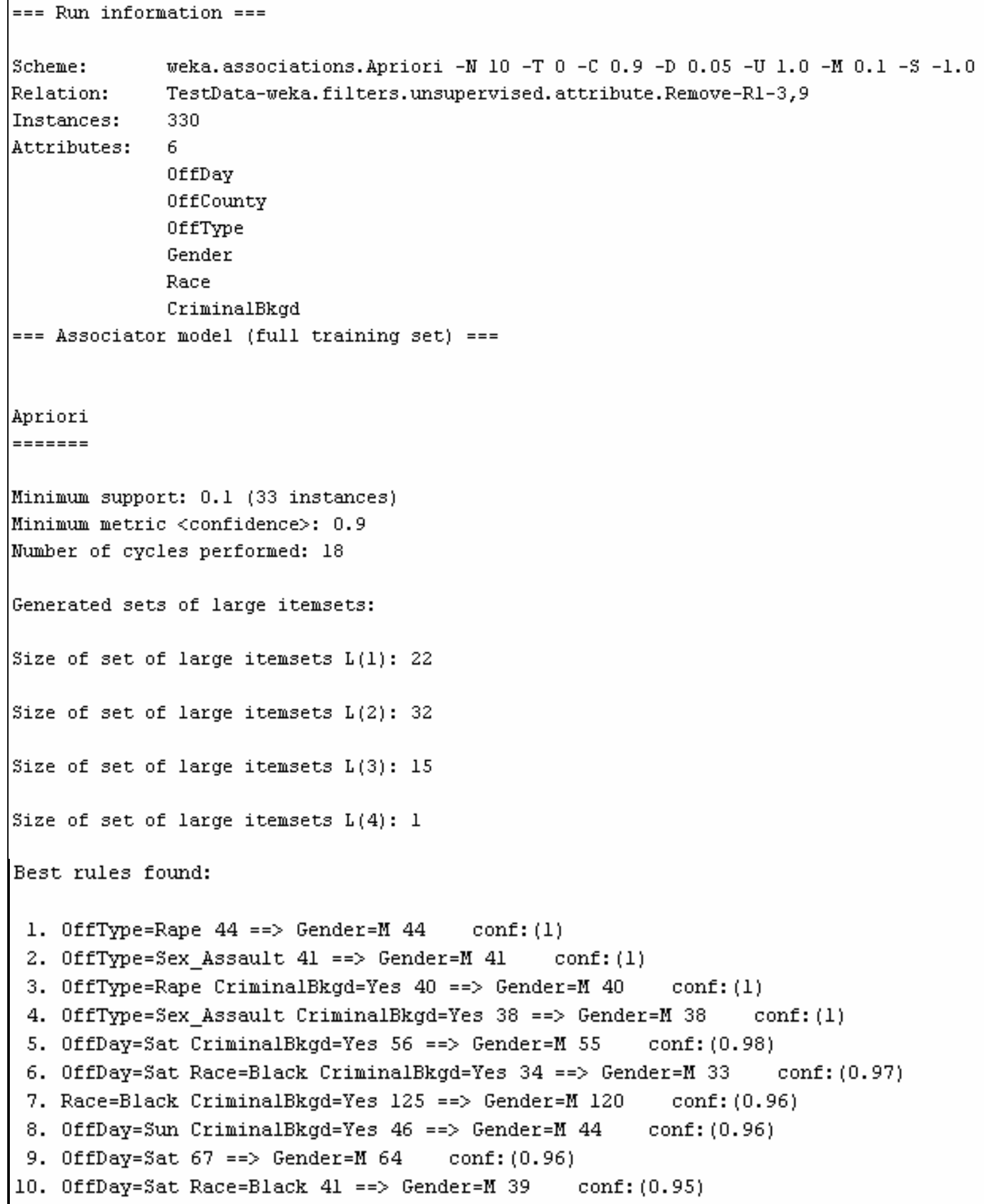




\section{Apriori Output with 5 attributes.}

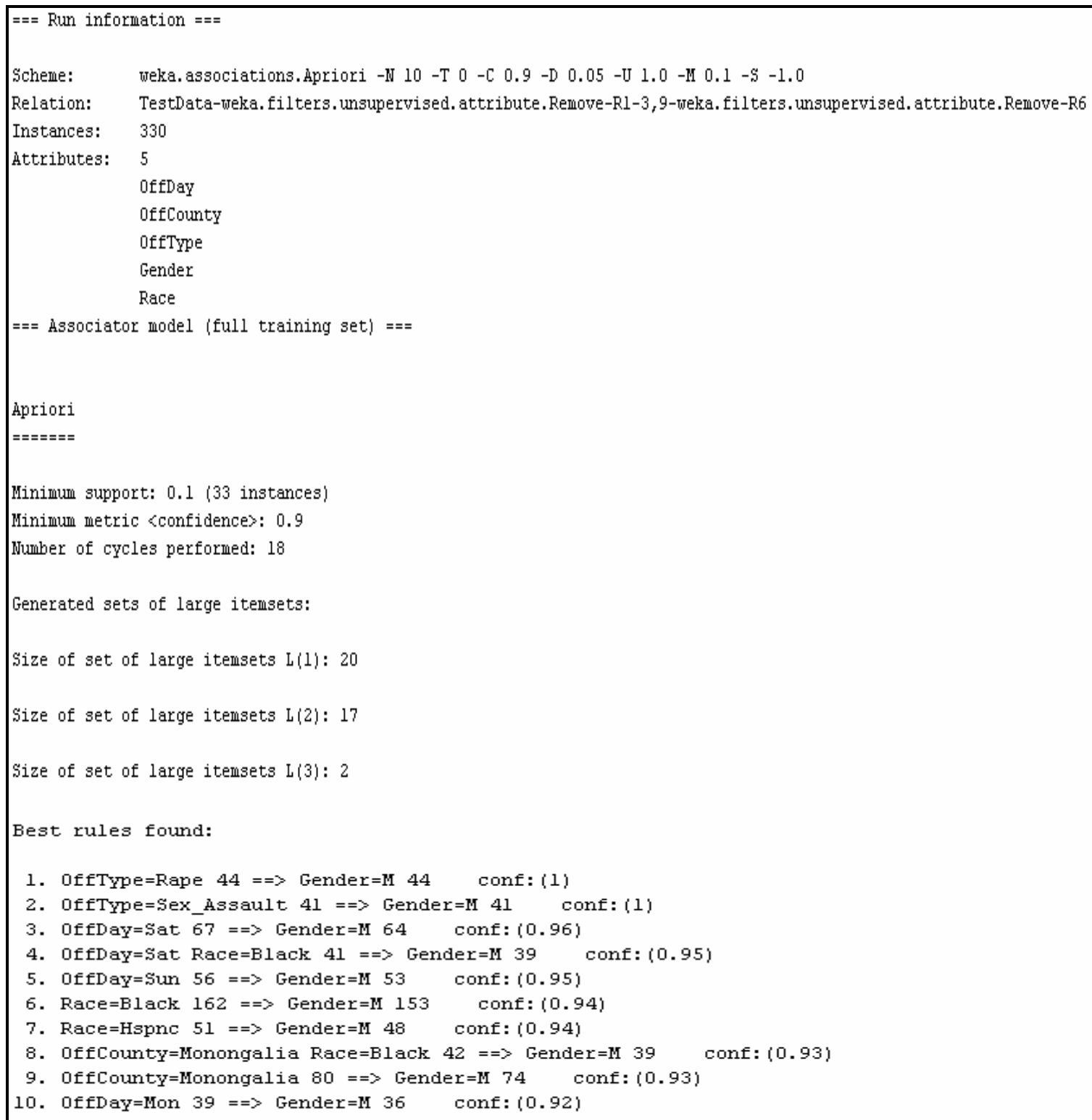




\section{Tertius Output with 6 attributes.}

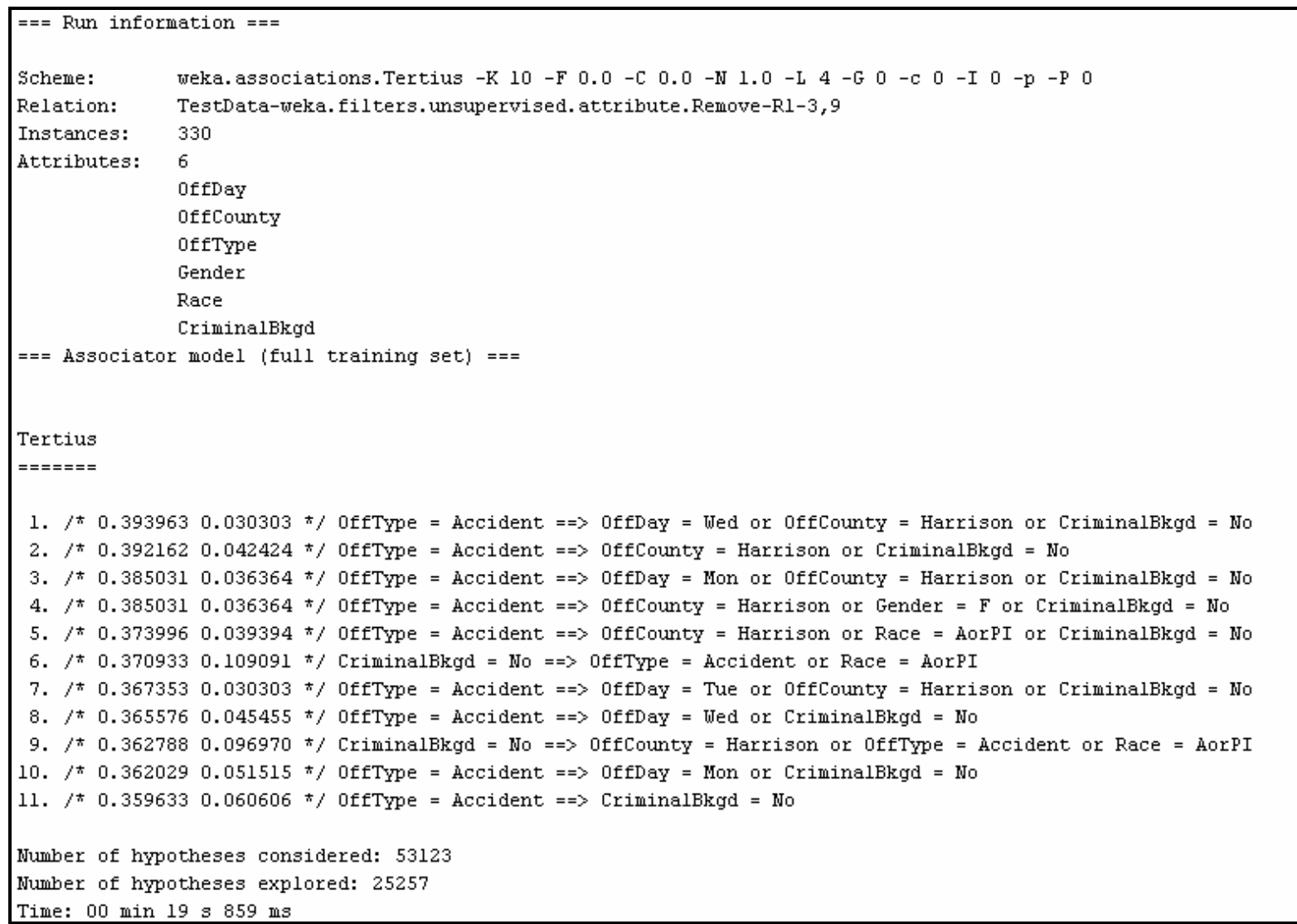




\section{Tertius Output with 6 attributes with filter.}

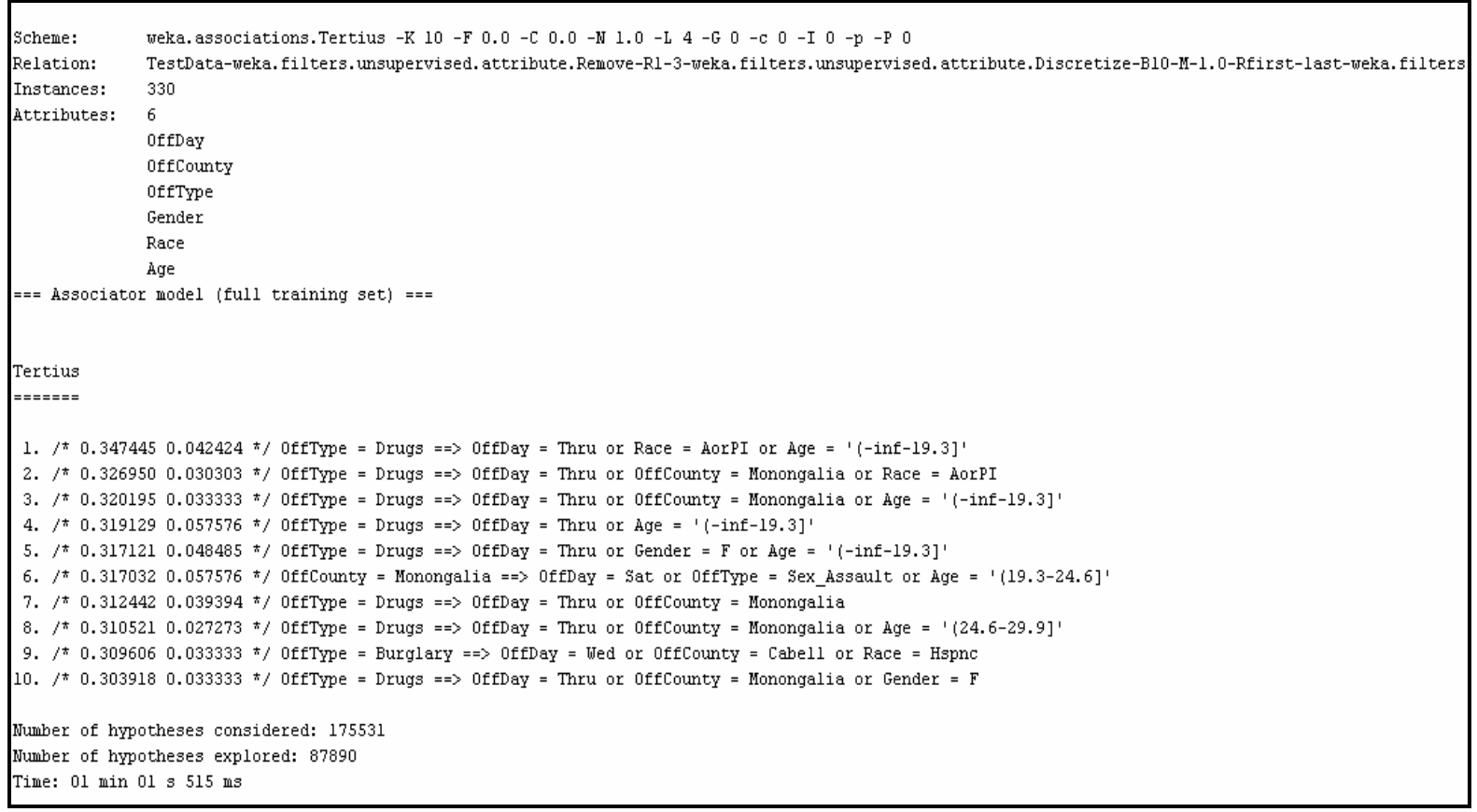




\section{Tertius Output with 5 attributes.}

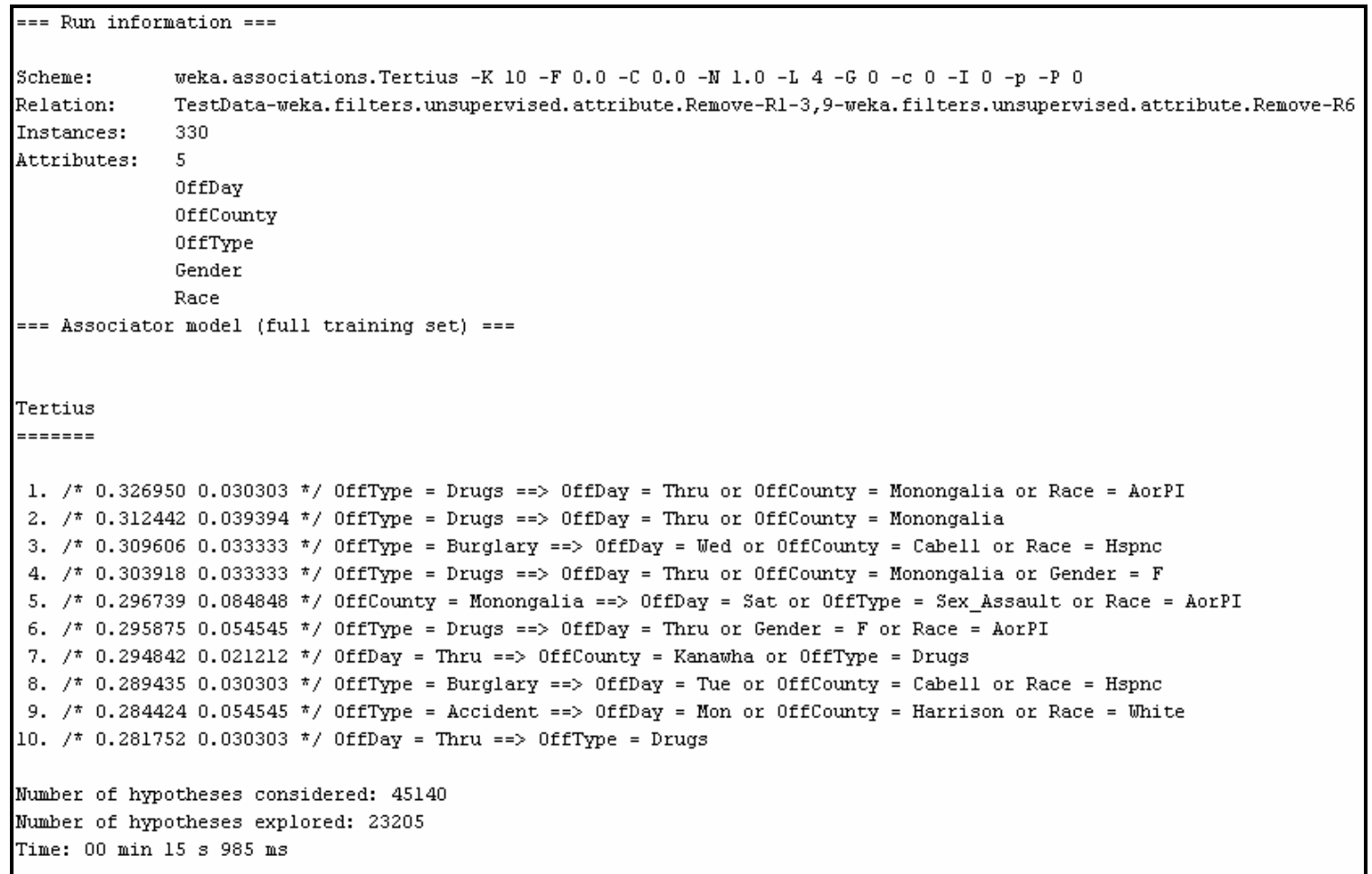




\section{Tertius Output with 4 atributes.}

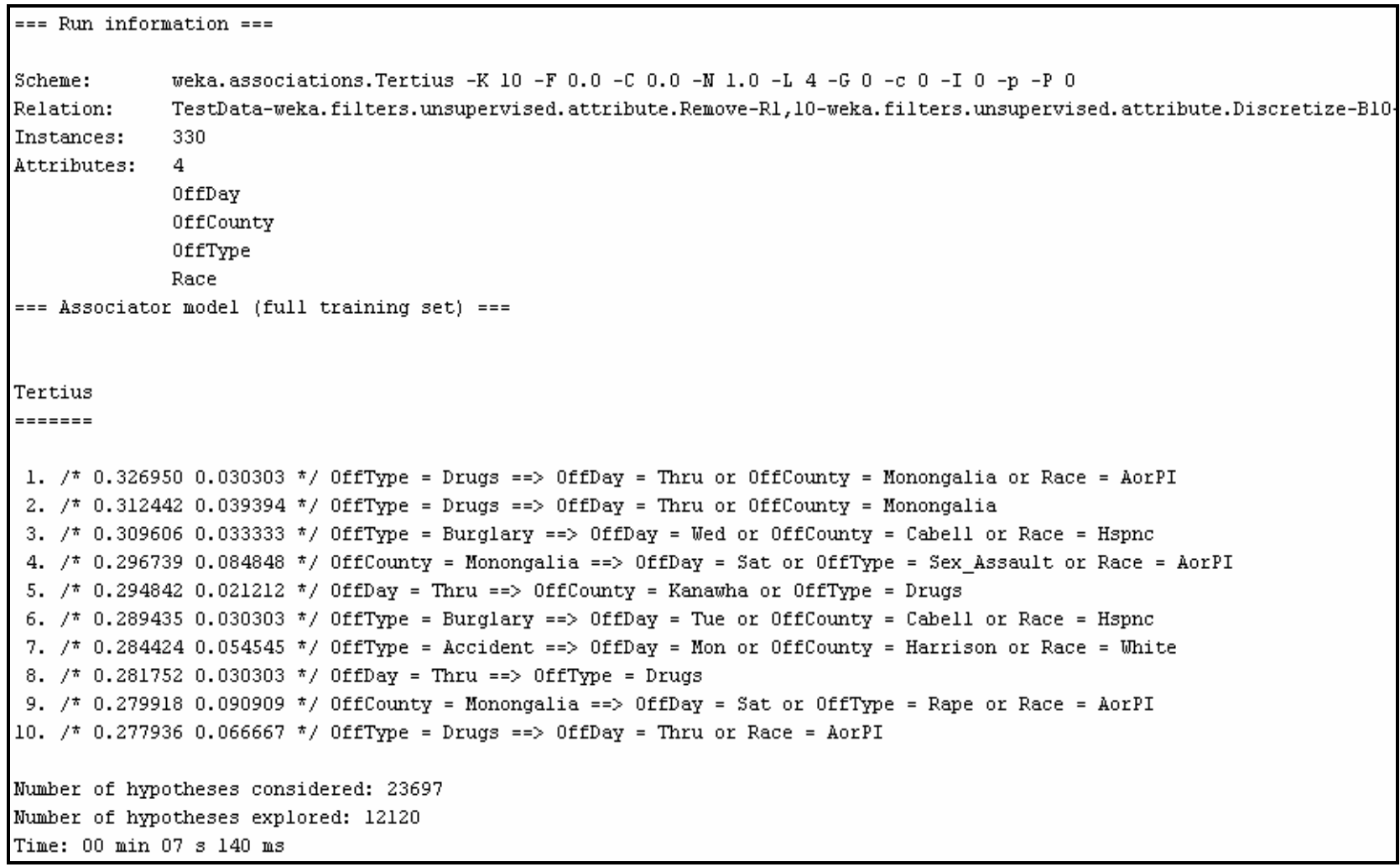

